\title{
EFICIÊNCIA ECONÔMICA DA PEQUENA PRODUÇÃO FAMILIAR AGRÍCOLA NO RECÔNCAVO DO ESTADO DA BAHIA: UMA ANÁLISE NÃO-PARAMÉTRICA DE FRONTEIRAS DE PRODUÇÃO MULTI-PRODUTO
}

\section{CARLOS AUGUSTO PEREIRA FILHO}

Engenheiro Agrônomo

Orientador: Prof. Dr. JOAQUIM BENTO DE SOUZA FERREIRA FILHO

\begin{abstract}
Tese apresentada à Escola Superior de Agricultura "Luiz de Queiroz", Universidade de São Paulo, para obtenção do título de Doutor em Ciências, Área de Concentração: Economia Aplicada.
\end{abstract}

PIRACICABA

Estado de São Paulo - Brasil

Novembro - 2000 


\section{ERRATA}

Paginas vii a x: As tabelas 1 a 25 estão localizadas, respectivamente, nas páginas 22, 23, 24, 25, 26, 27 , $68,70,73,76,76,77,78,80,82,84,86,88,90,91,93,96,98$ e 100.

\begin{tabular}{|c|c|c|c|}
\hline Página & Posição: & Onde se lê: & Leia-se: \\
\hline 45 & $\$ 1$, linha 3 & ...aos dados que podem... & ...aos dados que pode... \\
\hline 81 & $\S 1$, linha 1 & ...é da ordem de $57,6 \% \ldots$ & ...é da ordem de $47,6 \% \ldots$ \\
\hline 94 & Tabela 22 , coluna 5 , penúltima linha & 1881,39 & 1880,95 \\
\hline 97 & $\S 1$, linha 3 & ...(escolaridade média...)... & ...(idade média...)... \\
\hline
\end{tabular}


Dados Internacionais de Catalogação na Publicação (CIP) DIVISÃO DE BIBLIOTECA E DOCUMENTAÇĀO - Campus "Luiz de Queiroz"/USP

\section{Pereira Filho, Carlos Augusto}

Eficiência econômica da pequena produção familiar agrícola no Recôncavo do Estado da Bahia: uma análise não-paramétrica de fronteiras de produção multi-produto / Carlos Augusto Pereira Filho. - - Piracicaba, 2000.

$$
122 \mathrm{p} \text {. }
$$

Tese (doutorado) - - Escola Superior de Agricultura Luiz de Queiroz, 2000.

Bibliografia.

1. Agricultura familiar 2. Eficiência econômica 3. Estatística não-paramétrica 4. Produtor rural 5. Propriedade rural I. Título

CDD 331.763 
Aos meus pais, Carlos e Maria, pela régua e pelo compasso.

A Aurora, Bruno, Tais, Catula, Thanira, Jacilene e Breno, pelo apoio e incentivo. 


\section{A GRADECIMENTOS}

Ao Prof. Joaquim Bento de Souza Ferreira Filho, pela cordialidade, dedicação e eficiência na orientação do doutorado, que em muito contribuíram para que minhas limitações fossem superadas.

Aos professores Carlos José Caetano Bacha, Evaristo Marzabal Neves, e Ricardo Shirota pelas inúmeras sugestões que deram à pesquisa.

Ao professores e funcionários do Departamento de Economia, Administração e Sociologia da ESALQ/USP que, direta ou indiretamente, colaboraram com a realização deste trabalho.

Aos colegas do curso, pelo estímulo e apoio.

À Universidade Federal da Bahia que me possibilitou a participação no curso.

A Tereza Cristina Pippa Rochelle pela colaboração na revisão do texto final. 
A Manoel Pedro Louça e Edna Louça que, pela acolhida, amizade e companheirismo, ajudaram, a mim e à minha família, a superar a saudade da Bahia.

Aos colegas da Escola de Agronomia da Universidade Federal da Bahia, pós-graduandos na ESALQ/USP, que compartilharam comigo das dúvidas, incertezas e esperanças durante a realização do curso. 


\section{SUMÁ R IO}

Página

LISTA DE TABELAS ................................... vii

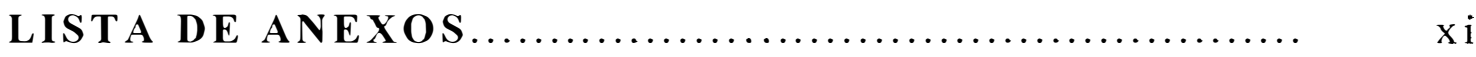

RES UMO

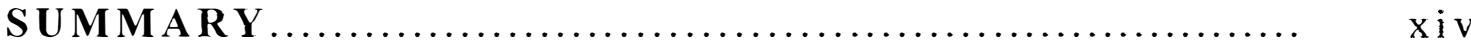

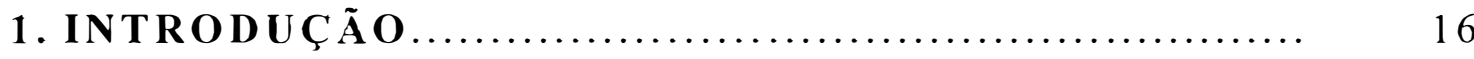

1.1. Características dos pequenos produtores do Recôncavo Baiano.............................................. 22

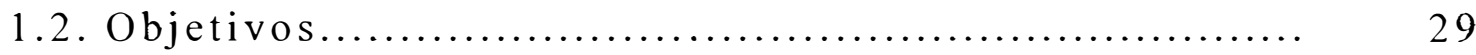

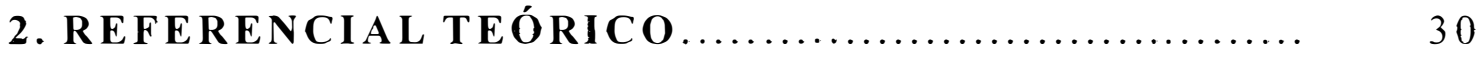

2.1. Os conceitos de eficiência técnica e alocativa.......... 31

2.2 Eficiência técnica e retornos à escala ................... 33

2.3 O conceito de racionalização dos dados................... 35

2.1.3.1 P-racionalização dos dados......................... 36 


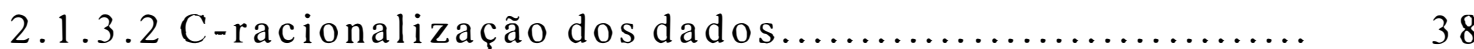

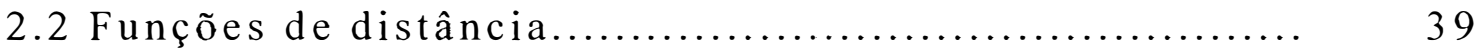

2.3 As abordagens na análise de eficiência................... 44

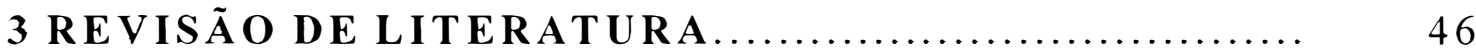

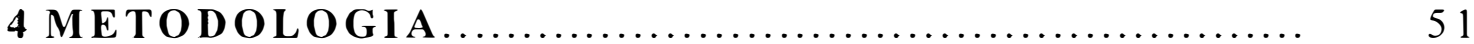

4.1 Teste da hipótese de minimização de custos.............. 52

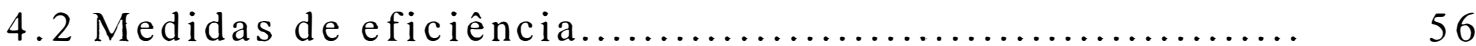

4.3 Estimativa dos índices de eficiência.................. 57

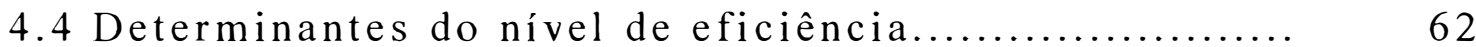

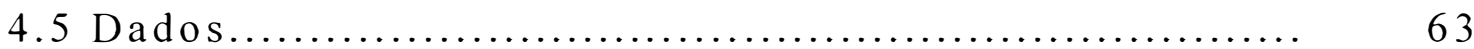

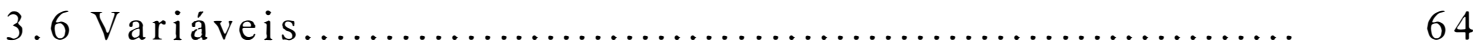

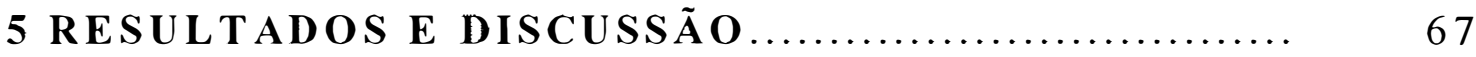

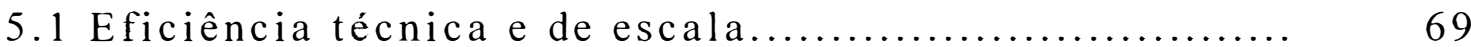

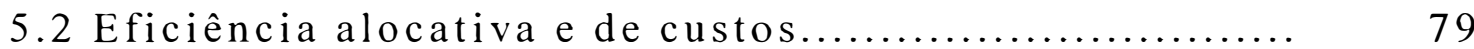

5.3 Fatores determinantes da eficiência da pequena

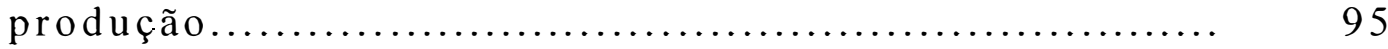

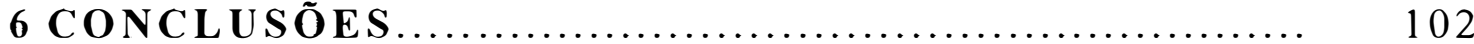

7 REFER E NCIAS B I BLIOGRÁFICAS .................... 105

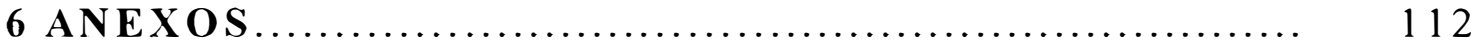




\section{LISTA DE TABELAS}

Página

01. Número e área dos estabelecimentos agrícolas menores que 10 hectares, por município, 1995/96...............

02. Valor da produção agrícola dos estabelecimentos com menos de 10 hectares e participação percentual sobre

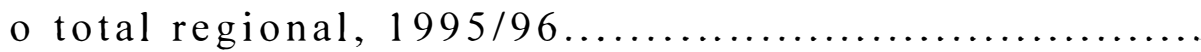

03. Utilização das terras nos estabelecimento com área

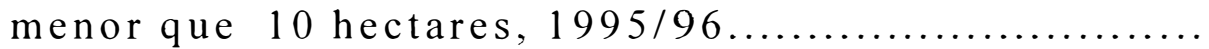

04. Participação dos pequenos produtores na produção das principais culturas da região, $1995 / 96 \ldots \ldots \ldots . . . . . . . .$.

05. Pessoal ocupado nos estabelecimentos com menos de 10 hectares e participação percentual sobre o total

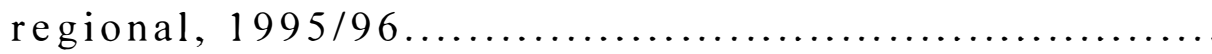


06. Composição das despesas dos estabelecimentos com menos de 10 hectares e participação percentual sobre as despesas agrícolas regional, 1995/96.................

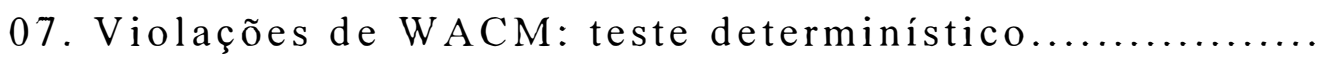

08. Índices de eficiência técnica $\left(\theta_{i}\right)$ sob retornos constantes, variáveis e não crescentes à escala para as observações da amostra..................................

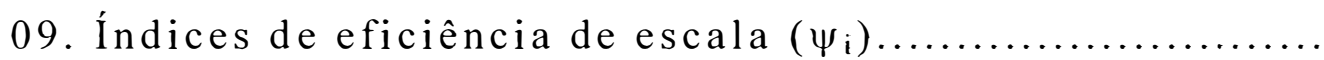

10. Valores de $\lambda$ para as propriedades tecnicamente ineficientes, sob retornos constantes à escala............

11. Valores de $\lambda$ para as propriedades tecnicamente ineficientes, sob retornos variáveis à escala.............

12. Acréscimo no produto das propriedades ineficientes levando em conta suas unidades de

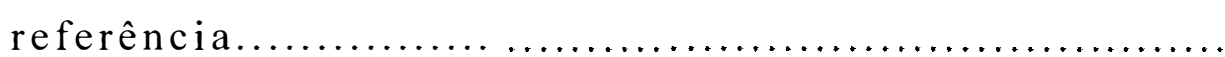

13. Redução no uso de fatores das propriedades ineficientes levando em conta as suas unidades de

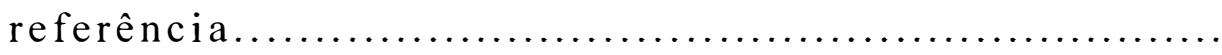

14. Custo mínimo e índices de eficiência técnica, de escala, alocativa e agregada sob retornos constantes à escala 
15. Grau de eficiência alocativa das propriedades da amostra, segundo o critério de Ray e Bhadra

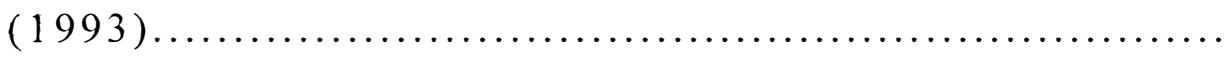

16. Classificação das propriedades amostradas de acordo com os índices de eficiência técnica e alocativa ..............................................

17. Unidades de referência e valores de $\lambda$ resultantes da minimização de custos sob retornos constantes à escala.

18. Decomposição da ineficiência econômica nos efeitos técnico, de escala e alocativo (em reais).................

19. Receitas e custos observados e otimizados pela minimização de custos sob retornos constantes à escala

20. Participação percentual dos fatores e dos produtos para a redução dos custos e aumento das receitas, respectivamente........................................

21. Lucro observado e otimizado pela minimização de custos sob retornos constantes à escala

22. Renda observada e otimizada pela minimização de custos sob retornos constantes à escala

23. Estimativa dos parâmetros do modelo logito para eficiência técnica... 
24. Estimativa dos parâmetros do modelo logito para eficiência de escala.......................................

25. Estimativa dos parâmetros do modelo logito para

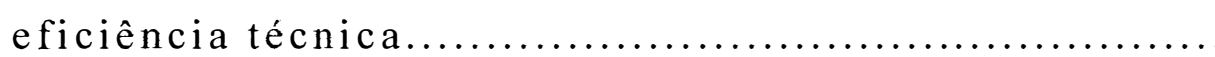




\section{LISTA DE ANEXOS}

A. Quantidades dos produtos por observação da amostra....

B. Quantidade dos fatores utilizados na produção, por

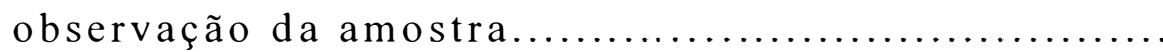

C. Preços dos produtos por observação da amostra

D. Preços dos fatores utilizados na produção, por observação da amostra....

E. Redução no uso dos fatores para cada observação da amostra resultante da minimização de custos.............

F. Incremento nos produtos de cada observação da amostra resultantes da minimização de custos......................

G. Fatores determinantes dos níveis de eficiência............. 


\title{
EFICIENCIA ECONÔMICA DA PEQUENA PRODUÇÃO \\ FAMILIAR AGRÍCOLA NO RECÔNCAVO DO ESTADO DA \\ BAHIA: UMA ANÁlISE NÃO-PARAMÉTRICA DE \\ FRONTEIRAS DE PRODUÇÃO MULTI-PRODUTO
}

Autor: CARLOS AUGUSTO PEREIRA FILHO

Orientador: Prof. Dr. Joaquim Bento de Souza Ferreira Filho

\author{
RESUMO
}

Neste trabalho analisa-se a eficiência da pequena produção familiar agrícola na região Recôncavo do Estado da Bahia através de uma amostra de 44 produtores. Utilizou-se uma abordagem nãoparamétrica, num contexto de minimização de custos sob retornos constantes à escala, para derivar medidas de eficiência técnica, de escala, alocativa e econômica. Foram analisados os efeitos de fatores específicos das firmas sobre a eficiência utilizando um modelo logito. Os resultados obtidos indicam que a maior fonte de ineficiência na pequena produção familiar agrícola da região Recôncavo do Estado da Bahia refere-se à ineficiência alocativa, ou seja, as relações de preço dos fatores não têm sido observadas. A mão-de-obra familiar evidencia-se como a principal fonte de ineficiência econômica, sob o pressuposto que sua remuneração fosse equivalente ao salário médio da região onde se situa cada firma. Observou-se que se as firmas ineficientes minimizassem seus custos, haveria aumento na renda familiar. A análise dos fatores 
determinantes dos índices de eficiência mostra que os níveis de eficiência técnica e de escala estão inversamente relacionados com o tamanho da exploração e a idade média da mão-de-obra familiar e positivamente relacionados com o grau de inserção dos produtores no mercado de produtos. A variável idade média da mão-de-obra familiar apresenta uma relação inversa com a eficiência alocativa enquanto a variável fonte de informação (rádio) mostrou-se positivamente relacionada com esta medida. 


\title{
ECONOMIC EFFICIENCY OF THE SMALL AGRICULTURAL FAMILY \\ PRODUCTION IN THE RECÔNCAVO OF THE STATE OF BAHIA: A NONPARAMETRIC ANALYSIS OF MULTI-OUTPUT PRODUCTION
}

\section{FRONTIERS}

\author{
Author: CARLOS AUGUSTO PEREIRA FILHO
}

Adviser: Prof. Dr. Joaquim Bento of Souza Ferreira Filho

\section{S U M M A R Y}

In this study the efficiency of the small agricultural family production is analyzed in the Reconcavo region in the State of Bahia using a sample of 44 producers. A nonparametric approach was used, in a context of costs minimizing under constant returns to scale, in order to derive technical, scale, allocative and economic efficiency measures. The effects of specific factors of the firms on its efficiency were analyzed using a logit model. The results indicate that the largest source of inefficiency in the small agricultural family production in the Reconcavo region in the State of Bahia refers to the allocative inefficiency, i.e., the input prices relationship has not been observed. It became evident that the family labor is the main source of economic inefficiency, under the presumption that its remuneration is equivalent to the mean wage of the area where each firm is located. It was observed that if the inefficient firms minimized its costs, family income would increase. The analysis of the factors which determine the 
efficiency indexes shows that the levels of technical and scale efficiency are inversely related to the size of the cultivated area and to the mean age of the family labor and positively related to the degree to which the producers are inserted in the market of products. The mean age of the family labor variable presents an inverse relationship to the allocative efficiency while the source of information variable (radio) showed positively related to this measure. 


\section{INTRODUÇÃ O}

O enfoque central deste trabalho é sobre a estrutura da produção familiar em pequenas propriedades agrícolas da região Recôncavo do estado da Bahia. Mais precisamente, procura-se investigar a eficiência da pequena produção familiar, do ponto de vista técnico e alocativo, e quais os fatores que a determinam.

Embora não se possa estabelecer uma definição precisa de "pequenos produtores", reconhece-se que pelo menos duas características se sobressaem e são comuns a estes: o pequeno tamanho em termos de dotação de recursos e o baixo nível de renda.

Do ponto de vista econômico, a característica mais significante dos pequenos produtores é a pequena base de recursos sobre a qual eles operam. Detêm, em geral, a posse de uma pequena área de terra; possuem um nível extremamente baixo de capital humano em termos de educação, conhecimento e saúde; padecem de uma dívida crônica e têm pouco ou quase nenhum acesso a créditos e insumos institucionais (assistência técnica, pesquisa, serviços de educação e saúde, etc). Concomitantemente, se defrontam com mercados e preços instáveis, recebem suporte inadequado de 
serviços de extensão, têm uma parcela diminuta de controle e operação das instituições rurais, e não dispõem de poder sócioeconômico para ter acesso a serviços públicos e outros que são disponíveis para outros membros com maior poder na sociedade (Dillon \& Hardaker, 1980).

No Brasil, é nas pequenas propriedades que se concentra a pobreza rural, decorrente da baixa produtividade dos fatores utilizados que determina um nível de renda insatisfatório (Dias, 1979).

O processo de desenvolvimento econômico brasileiro, notadamente na fase substitutiva de importações, privilegiou o setor secundário da economia. Medidas de política agrícola foram orientadas às propriedades médias e grandes, mais bem adaptadas à tecnologia existente, e capazes de responder, mais rapidamente, à expansão da produção e demanda de produtos industriais. A baixa produtividade dos fatores de produção empregados nas pequenas propriedades somente foi considerada um problema na década de setenta, quando o prosseguimento do desenvolvimento passou a exigir melhoria no nível de renda de amplos setores da sociedade, bem como maior produção de alimentos como forma de reduzir a inflação. Programas especiais foram direcionados ao pequeno produtor, objetivando aumento da produtividade dos recursos empregados na expansão da produção e nível de renda. Tais programas, porém, apresentaram resultados modestos, sendo tal insucesso atribuído à ausência de tecnologias adaptadas aos recursos naturais e ao ambiente econômico desses agricultores (Zagatto, 1991). 
Schultz (1964), em sua hipótese "pobre mas eficiente" argumenta que os agricultores tradicionais, levando um longo período de tempo para aprender seus processos de produção, identificariam seus respectivos conjuntos ótimos de insumos e produtos, sugerindo então que políticas de desenvolvimento agrícola deveriam adotar uma abordagem expansionista com respeito às fronteiras de produção dos pequenos produtores como o meio de menor custo efetivo para aumentar o bem-estar dos produtores de baixa renda.

Esta visão ajudou a orientar a "Revolução Verde" e os programas de pesquisa em andamento na geração de tecnologias de produção agrícola nos países em desenvolvimento. Um número incontável de estudos tem rejeitado a hipótese de Schultz, encontrando uma difusão de ineficiência técnica entre pequenos produtores e, conseqüentemente, recomendando que os formuladores de políticas realoquem os recursos escassos para reparar os obstáculos aparentes à eficiência técnica através da implementação de serviço de extensão, educação do produtor, reforma agrária, etc. (Sherlund et al, 1998).

No Brasil, as políticas econômicas implementadas nas últimas 5 décadas, além de discriminar o setor agrícola como um todo, mantiveram, à margem, o grande contingente de pequenos produtores rurais que, em termos gerais, respondiam pela oferta de alimentos à crescente população urbana.

O crescimento da produção agrícola brasileira, até o início da década de 60 , se dava pela expansão da área cultivada e pelo aumento da mão-de-obra empregada no processo produtivo (Alves \& Pastore, 1977). Até meados da década de 40, a economia 
brasileira se caracterizava como primária-exportadora, sendo a agricultura o setor dinâmico, com geração de divisas através da exportação de produtos primários, baseada no sistema de vantagem comparativa (Zagatto, 1991). A partir do término da Segunda Guerra Mundial, ocorre uma mudança de enfoque na política econômica, buscando-se um crescimento econômico autosustentado, menos dependente do comércio internacional. Tal política priorizava a industrialização via substituição de importações. Neste contexto, a agricultura passava a ocupar um papel secundário na estratégia de desenvolvimento, sendo penalizada pelas restrições às exportações do setor via sobrevalorização cambial e pela proteção à industrial nacional de fatores modernos de produção que tornavam os preços internos superiores àqueles praticados no mercado externo (Pastore, 1979).

Segundo Homem de Melo (1979), as medidas atenuantes então adotadas (subsídios à importação de máquinas agrícolas e insumos modernos, e políticas especiais para produtos exportáveis como café, cacau e açúcar) beneficiaram tanto as propriedades que usavam mais intensamente esses fatores quanto aquelas propriedades de maior tamanho, capazes de obter economias de escala geradas pela maior utilização desses recursos produtivos. Contudo, crises sucessivas ocorreram no abastecimento interno que, em decorrência da política de "preços baixos", desestimulavam a produção de alimentos (Alves \& Pastore, 1980).

Tais problemas levaram à adoção, a partir de meados da década de 60, do modelo de modernização que pretendia, segundo Alves \& Pastore (1980), aumentar a produção no curto prazo, via aumento da produtividade através de mudanças tecnológicas que intensificassem o uso de insumos e fatores 
modernos de produção (fertilizantes, defensivos, sementes melhoradas, tratores, implementos, etc). Tais tecnologias tinham como princípio o desenvolvimento e a introdução de variedades de alta produtividade, porém exigentes em termos de solo, topografia e utilização de insumos modernos, condições essas geralmente inexistentes nas pequenas propriedades que, assim, permaneceram marginalizadas e até mesmo prejudicadas em decorrência da competição com as médias e grandes propriedades que se mostravam mais adaptadas à adoção das novas tecnologias.

Segundo Barros (1998), este modelo, baseado principalmente no fornecimento de créditos e na garantia de preços mínimos, começou a mostrar sinais de esgotamento no final da década de oitenta, com a drástica redução de gastos orçamentários destinados aos programas de suporte à agricultura.

Com o processo de globalização da economia mundial iniciada no início da década de 90 e a formação de blocos econômicos regionais um novo panorama se desenha para a economia brasileira não só do ponto de vista da ação governamental (pela revisão de seus mecanismos de atuação) mas, também, pelo novo cenário com o qual se defronta o setor privado que, com o processo de abertura aos mercados internacionais, se vê exposto a um intenso processo de concorrência o qual, fundamentalmente, requer ganhos de eficiência no processo produtivo como forma de reduzir a fragilidade em relação aos novos competidores.

Neste contexto, a identificação do grau de eficiência das empresas e dos ganhos potenciais de produtividade pelo uso mais eficiente da tecnologia disponível torna-se fundamental para o 
desenvolvimento de políticas públicas e de ações do setor privado para a integração competitiva das empresas ao mercado.

Embora a competitividade de uma firma ou de um setor econômico dependa de um conjunto de fatores macroeconômicos e microeconômicos, a análise da eficiência, focalizada nos fatores microeconômicos, é de grande relevância na explicação da competitividade das firmas, mormente quando se considera que firmas mais eficientes serão, provavelmente, mais competitivas.

As análises sobre eficiência relativa das empresas fornecem indicações quanto aos recursos que estão sendo sub utilizados e sobre os produtos que podem ser expandidos através da melhoria da eficiência econômica do setor agrícola, constituindo-se num importante insight para a identificação da magnitude do ajuste necessário pelo qual o setor agrícola deve passar, na formulação de estratégias de política agrícola e na orientação de serviços de pesquisa, assistência técnica e serviços privados relacionados à agricultura.

Dada a importância que têm os pequenos produtores agrícolas no abastecimento alimentar e também como consumidores de bens produzidos pelo setor industrial, a ênfase na análise da eficiência deste segmento do setor agrícola brasileiro justifica-se tanto do ponto de vista econômico quanto do ponto de vista social, pela identificação dos fatores que restringem a incorporação destes produtores ao mercado e que determinam os baixos níveis de renda e bem-estar social.

O foco do presente estudo é sobre a pequena propriedade agrícola familiar de 8 municípios do Recôncavo Baiano 
que compõem a área definida como a Região Fumageira de Mata Fina (Ramos, 1972).

\subsection{Características dos pequenos produtores da Região Fumageira de Mata Fina}

Nesta região, predominam os pequenos estabelecimentos agrícolas com área menor do que 10 hectares. De acordo com o IBGE (1998) estes representavam, em 1995/96, 89\% do total dos estabelecimentos e ocupavam $28 \%$ da área agrícola total da região (Tabela 01).

Tabela 01: Número e área dos estabelecimentos agrícolas menores que 10 hectares, por município, 1995/96.

\begin{tabular}{lrrrr}
\hline \multirow{2}{*}{ Municípios } & \multicolumn{2}{c}{$\mathrm{N}^{\mathrm{o}}$ de estabelecimentos } & \multicolumn{2}{c}{ Área } \\
\cline { 2 - 5 } & Quantidade & \% da região & Hectares & \% da região \\
\hline Cabaceiras do Paraguaçu & 2260 & 93,00 & 3890 & 26,96 \\
Conceição do Almeida & 1804 & 85,13 & 3596 & 15,79 \\
Cruz das Almas & 1128 & 87,44 & 2902 & 39,25 \\
D. Macedo Costa & 463 & 81,37 & 1207 & 14,08 \\
Governador Mangabeira & 1330 & 94,26 & 2849 & 53,31 \\
Muritiba & 1332 & 92,31 & 2712 & 38,44 \\
São Felipe & 2135 & 86,44 & 5225 & 32,18 \\
Sapeaçu & 1096 & 88,67 & 2965 & 34,03 \\
TOTAIS & 11548 & 89,05 & 25346 & 28,00 \\
\hline
\end{tabular}

Fonte dos dados: IBGE (1998). Cálculos: autor 
Apesar da parcela diminuta da área agrícola utilizada, estes pequenos produtores respondem por, aproximadamente, $61 \%$ do valor da produção regional, $74 \%$ do valor da produção vegetal e $31 \%$ do valor da produção animal (Tabela $02)$.

Tabela 02: Valor da produção agrícola dos estabelecimentos com menos de 10 hectares e participação percentual sobre o total regional, $1995 / 96$.

\begin{tabular}{lcccccc}
\hline \multirow{2}{*}{ Município } & \multicolumn{2}{c}{ Valor da produção (mil reais) } & \multicolumn{3}{c}{$\%$ do total regional } \\
\cline { 2 - 7 } & Total & Animal & Vegetal & Total & Animal & Vegetal \\
\hline Cabaceiras do Paraguaçu & 2001 & 249 & 1752 & 70,36 & 32,25 & 84,56 \\
Conceição do Almeida & 1720 & 326 & 1394 & 35,49 & 12,66 & 61,41 \\
Cruz das Almas & 2550 & 644 & 1906 & 70,23 & 49,73 & 81,59 \\
D. Macedo Costa & 334 & 94 & 240 & 33,23 & 19,18 & 46,60 \\
Governador Mangabeira & 1667 & 171 & 1496 & 84,36 & 68,13 & 86,72 \\
Muritiba & 3459 & 573 & 2886 & 69,29 & 51,21 & 74,52 \\
São Felipe & 3984 & 306 & 3678 & 63,64 & 30,69 & 69,88 \\
Sapeaçu & 1271 & 110 & 1161 & 57,25 & 19,78 & 69,77 \\
\hline TOTAIS & 16986 & 2473 & 14513 & 61,16 & 30,70 & 73,60 \\
\hline Fonte
\end{tabular}

Fonte dos dados: IBGE (1998). Cálculos: autor

Os dados apresentados na tabela 03 indicam não haver possibilidade de expandir a produção pelo aumento da área cultivada já que as terras produtivas não utilizadas representam em torno de $3,7 \%$ da área total dos estabelecimentos. Na mesma tabela, observa-se que a principal atividade produtiva é o cultivo de 
lavouras temporárias seguindo de lavouras permanentes, com 40,8\% e $21,4 \%$ da área dos estabelecimentos, respectivamente.

Tabela 03: Utilização das terras nos estabelecimentos com área menor que 10 hectares, 1995/96.

\begin{tabular}{lrrrr}
\hline Municípios & $\begin{array}{r}\text { Área total } \\
\text { (hectares) }\end{array}$ & $\begin{array}{r}\text { Lavoura } \\
\text { permanente } \\
(\%)\end{array}$ & $\begin{array}{r}\text { Lavoura } \\
\text { temporária não utilizadas } \\
(\%)\end{array}$ & $\begin{array}{r}\text { Terras } \\
\text { produtivas }\end{array}$ \\
\hline Cabaceiras do Paraguaçu & 3890 & 9,3 & 56,2 & 3,0 \\
Conceição do Almeida & 3596 & 14,5 & 39,4 & 3,1 \\
Cruz das Almas & 2902 & 32,6 & 30,4 & 5,1 \\
D. Macedo Costa & 1207 & 10,1 & 18,1 & 2,7 \\
Governador Mangabeira & 2849 & 19,1 & 56,5 & 4,6 \\
Muritiba & 2712 & 33,1 & 41,0 & 4,3 \\
São Felipe & 5225 & 11,8 & 41,8 & 3,9 \\
Sapeaçu & 2965 & 48,0 & 24,7 & 2,4 \\
\hline TOTAIS & 25346 & 21,4 & 40,8 & 3,7 \\
\hline Fonte dos ados: IBGE (1998) & Cálculos: autor & &
\end{tabular}

Na tabela 04 são mostrados os dados referentes à área colhida, quantidade produzida e valor da produção das principais culturas regionais exploradas pelos pequenos produtores, bem como a participação percentual destes produtores na produção regional. Como pode ser observado, é o estrato de produtores com menos de 10 hectares que responde por mais de $80 \%$ dos principais produtos da agricultura regional. Os percentuais de área colhida e quantidade produzida evidenciam ainda que não há diferença de 
produtividade entre estes produtores e aqueles situados em estratos de área mais altos.

Tabela 04: Participação dos pequenos produtores na produção das principais culturas da região, $1995 / 96$.

\begin{tabular}{lrrrrrr}
\hline \multirow{2}{*}{ Produtos } & \multicolumn{2}{c}{ Área colhida } & \multicolumn{2}{c}{ Produção } & \multicolumn{2}{c}{ Valor } \\
\cline { 2 - 7 } & hectares & $\begin{array}{r}\% \text { da } \\
\text { região }\end{array}$ & $\begin{array}{c}\text { Quantidad } \\
\mathrm{e}^{(*)}\end{array}$ & $\begin{array}{r}\% \text { da } \\
\text { região }\end{array}$ & mil reais & $\begin{array}{r}\% \text { da } \\
\text { região }\end{array}$ \\
\hline Amendoim em casca & 744 & 83,8 & 670 & 81,5 & 275 & 82,1 \\
Feijão em grãos & 815 & 86,9 & 265 & 86,9 & 145 & 86,8 \\
Fumo em folha & 2577 & 89,9 & 1937 & 89,2 & 2956 & 88,7 \\
Inhame & 166 & 72,8 & 870 & 74,4 & 457 & 75,4 \\
Laranja & 4125 & 63,1 & 163496 & 63,5 & 2905 & 59,6 \\
Limão & 444 & 61,2 & 25968 & 85,9 & 744 & 82,2 \\
Raiz de mandioca & 6441 & 81,8 & 33982 & 79,3 & 4516 & 79,6 \\
\hline (*) Laranja e limão em mil frutos, demais produtos em toneladas. & \\
Fonte dos dados: IB GE (1998). Cálculos : autor & & &
\end{tabular}

Pode-se afirmar que a produção agrícola deste grupo de agricultores é orientada para o mercado. Com base nos dados do Censo Agropecuário 95/96, as parcelas da produção vendidas foram da ordem de 93,3\% para amendoim, 99,8\% para fumo em folha, 93\% para inhame, $98,3 \%$ para laranja e $99,6 \%$ para limão. As quantidades comercializadas de feijão e mandioca foram da ordem de $44,9 \%$ e $53,9 \%$, respectivamente, indicando que uma parcela destes produtos é destinada à subsistência da família.

Além da expressiva participação dos pequenos produtores no que se refere à produção agrícola regional, 
evidencia-se também a sua importância no que se refere à utilização dos fatores de produção.

$\mathrm{Na}$ tabela 05 são apresentados os dados sobre pessoal ocupado neste segmento, o que representa, em termos percentuais, em relação à região e a sua composição por categorias. Observa-se que, do total de pessoas empregadas na agricultura regional, $87 \%$ localiza-se nos estabelecimentos com menos de 10 hectares. Os dados mostram ainda que $95 \%$ das pessoas ocupadas neste estrato referem-se à mão-de-obra familiar (responsável e membros não remunerados da família, conforme definição do IBGE) indicando que a pequena produção agrícola da região em estudo é tipicamente do tipo familiar.

Tabela 05: Pessoal ocupado nos estabelecimentos com menos de 10 hectares e participação percentual sobre o total regional, $1995 / 96$.

\begin{tabular}{lrrrrr}
\hline Município & $\mathrm{N}^{\circ}$ pessoas $\% \mathrm{~S} /$ região & \multicolumn{3}{c}{ Distribuição por categoria (em \%) } \\
\cline { 4 - 6 } & & & Familiar & Permanente & Temporária \\
\hline Cabaceiras do Paraguaçu & 7475 & 90,03 & 94,45 & 0,54 & 4,09 \\
Conceição do Almeida & 5315 & 84,08 & 97,23 & 1,58 & 0,88 \\
Cruz das Almas & 4148 & 86,51 & 93,11 & 1,62 & 4,82 \\
D. Mac edo Costa & 1047 & 79,50 & 96,18 & 2,48 & 1,15 \\
Governador Mangabeira & 5041 & 93,33 & 96,07 & 0,69 & 3,02 \\
Muritiba & 4608 & 90,82 & 94,66 & 1,02 & 4,30 \\
São Felipe & 6939 & 82,48 & 96,37 & 0,49 & 2,93 \\
Sapeaçu & 3435 & 85,55 & 91,82 & 1,75 & 5,82 \\
\hline TOTAIS & 38008 & 87,10 & 95,09 & 1,03 & 3,47 \\
\hline
\end{tabular}

Fonte dos dados: 1BGE (1998). Cálculos: autor 
A tabela 06 mostra as despesas efetuadas no período agosto/95 a julho/96 e o comparativo com as despesas totais na agricultura regional. Os maiores grupos de despesas referem-se a adubos e corretivos $(26,7 \%)$ e salários pagos a empregados contratados $(23,25)$. Em relação à agricultura regional, os pequenos produtores respondem por mais de $50 \%$ das despesas com adubos e corretivos, sementes e mudas, agrotóxicos e aluguel de máquinas e equipamentos. Os dados evidenciam ainda que estes produtores não têm acesso ao crédito agrícola dado que a parcela das despesas com juros e serviços bancários é irrisória.

Tabela 06: Composição das despesas dos estabelecimentos com menos de 10 hectares e participação percentual sobre as despesas agrícolas da região, 1995/96.

\begin{tabular}{lrcc}
\hline Tipo de despesa & $\begin{array}{c}\text { Valor } \\
\text { (mil reais) }\end{array}$ & \% sobre o total & $\begin{array}{c}\text { \% em relação à } \\
\text { região }\end{array}$ \\
\hline Salário (em dinheiro ou produto) & 984 & 23,2 & 31,90 \\
Adubos e corretivos & 1134 & 26,7 & 76,01 \\
Sementes e mudas & 93 & 2,2 & 64,58 \\
Agrotóxicos & 213 & 5,0 & 65,54 \\
Aluguel de máq. e equipamentos & 149 & 3,5 & 55,60 \\
Juros e de spesas bancárias & 5 & 0,1 & 9,80 \\
Outras despesas & 1670 & 39,3 & 19,0 \\
\hline DESPESAS TOTAIS & 4248 & 100,0 & 48,21 \\
\hline
\end{tabular}

Fonte dos dados: IBGE (1998). Cálculos: autor

Pelo exposto, pode-se afirmar que na Região Fumageira de Mata, situada no Reconcavo Baiano, predomina a 
pequena produção agrícola, tipicamente familiar, orientada para o mercado. Considerando-se as características das culturas e da tecnologia empregadas, os sistemas de produção adotados pelos pequenos produtores são, em sua maioria, intensivos na utilização de mão-de-obra.

Visto que, em geral, estes produtores não dispõem de terra agricultável para expandir a área cultivada, é de se esperar que, para aumentar a produção e a rentabilidade, será preciso obter ganhos de produtividade, via adoção de novas tecnologias e/ou melhoria da eficiência técnica e alocativa.

Pressupondo que o grau de adoção da tecnologia disponível não seja uniforme para o conjunto das unidades de produção, o que refletirá em níveis diferenciados de eficiência, os produtores identificados como ineficientes poderão aumentar a produtividade total dos fatores buscando o benchmarking nas empresas que se encontrem na fronteira de produção e que possam lhes servir de referência.

A eficiência (ou ineficiência) pode estar relacionada a fatores de ordem economica, ambiental, social, etc. Espera-se que o grau de eficiência da pequena produção esteja diretamente relacionado às aptidões dos produtores rurais (escolaridade, experiência e acesso a informações técnicas) e ao grau de inserção no mercado de produtos; e inversamente relacionado ao tamanho do das explorações. As propriedades mais orientadas para o mercado, por estarem submetidas a um processo de concorrência, devem apresentar níveis de eficiência mais elevados em relação àquelas orientadas para a subsistência. 
Considerando-se estes aspectos e hipóteses, justifica-se a análise da eficiencia dos produtores objetos deste estudo, a identificação das fontes de ineficiência e dos fatores a elas relacionados.

\subsection{Objetivos}

O objetivo geral deste estudo é analisar a eficiência técnica, de escala e alocativa de pequenos produtores agrícolas da região Recôncavo do Estado da Bahia e identificar / analisar os fatores que a determinam.

Especificamente, pretende-se:

a) estimar os níveis de eficiência técnica, alocativa e agregada de cada propriedade de uma amostra;

b) identificar os processos produtivos mais eficientes e que representam melhores oportunidades e alternativas para as propriedades ineficientes;

c) testar a influência da aptidão dos produtores, do tamanho da exploração e do grau de participação no mercado de produtos sobre os níveis de eficiência. 


\section{REFERENCIAL TEÓRICO}

Nas últimas duas décadas, tem sido crescente o interesse dos economistas pelos estudos visando analisar as eficiências técnica, de escala e alocativa das atividades produtivas, muitas das quais enfocando o setor agrícola.

A análise tradicional da eficiência é geralmente baseada em índices parciais de produtividade dos fatores os quais relacionam o produto final de uma firma aos recursos utilizados para produzi-los. A principal limitação ao uso dos índices parciais de produtividade na análise da eficiência está no fato de que, para uma firma como um todo, variações nos índices de eficiência não podem ser interpretadas como variações na eficiência de um recurso particular, mas como mudanças no uso de todos os fatores por unidade do produto.

As aplicações econômicas de modelos de avaliação da eficiência global da produção são fundamentadas nos trabalhos de Debreu (1951), Koopmans (1951) e Farrell (1957). Estes autores utilizaram os conceitos de isoquantas e funções de produção de fronteira para definir medidas de eficiência técnica relativa como a 
distância em que cada firma (unidade de observação) se situa em relação à fronteira de produção construída a partir de dados observados de combinações insumo-produto.

\subsection{Os conceitos de eficiência técnica e alocativa}

O conceito de eficiência abordado no presente trabalho engloba as seguintes definições: a) eficiência técnica refere-se à obtenção do máximo produto potencial para uma dada quantidade de insumos, levando em conta as relações físicas de produção; b) eficiência de escala - implica a firma estar operando sob retornos constantes à escala; c) eficiência alocativa - refere-se à alocação dos recursos produtivos levando em conta os preços dos fatores de modo que o valor do produto marginal de cada insumo deve ser igual ao seu preço e, d) eficiência econômica - ou eficiência total, que inclui eficiência técnica, de escala e alocativa.

A figura 1 auxilia no entendimento dos conceitos de eficiência técnica estabelecidos por Debreu, Koopmans e Farrell.

Definindo $x_{1}$ e $x_{2}$ como os insumos empregados na produção, a isoquanta de fronteira é representada pelo segmento FF' que, em termos relativos, pode ser caracterizada como uma isoquanta unitária, ou seja, $f\left(x_{1}, x_{2}\right)=1$. De acordo com o conceito de Debreu e Farrell, são consideradas eficientes as observações A, B, C e D, localizadas a longo da isoquanta de fronteira, já que não seria possivel qualquer redução equiproporcional no uso dos insumos sem que haja redução no nível da produção; a empresa 


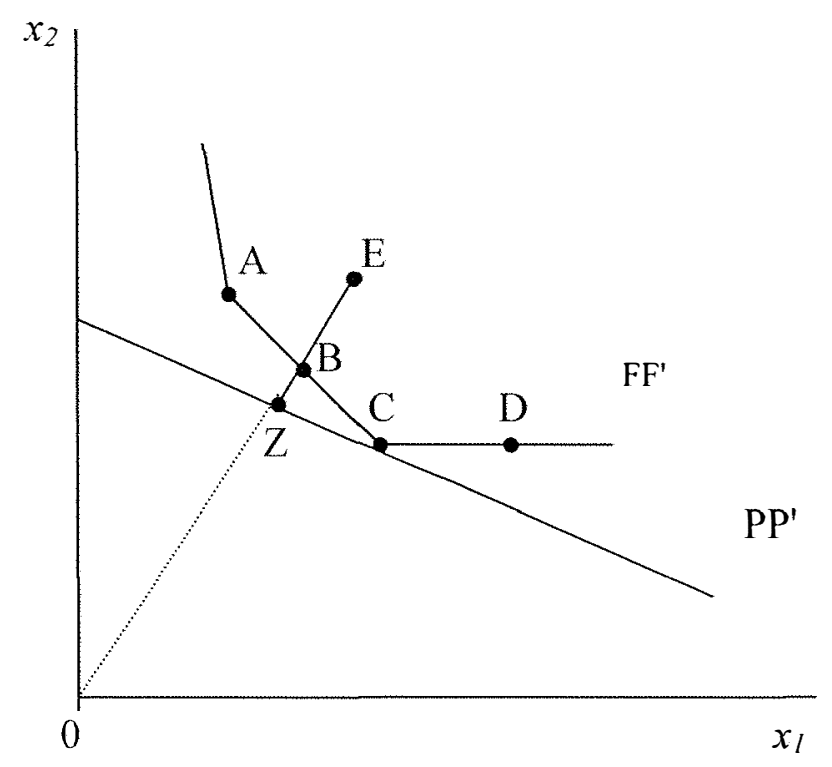

Figura 01: Conceito de efíciência técnica e alocativa

localizada no ponto E é considerada ineficiente pois uma redução radial dos insumos $x_{1}$ e $x_{2}$ até o ponto B seria possível sem alterar o nível do produto. No conceito de Koopmans, a observação D também é ineficiente já que o mesmo produto poderia ser obtido reduzindo o insumo $x_{l}$ até o nível utilizado em $C$. A eficiência técnica de uma firma operando no ponto E utilizando $\left(x_{I E}, x_{2 E}\right)$ de insumos é dada pela relação OB/OE, ou seja, a razão dos insumos necessários para produzir $Y^{E}$ (produto ótimo) em relação aos insumos realmente utilizados para obter a mesma produção. Conseqüentemente, a ineficiência técnica da empresa operando em E é dada por 1-(OB/OE) que representa a redução possível no nível dos insumos, mantendo o mesmo nível do produto. Ainda na Figura 1 , a linha $\mathrm{PP}^{\prime}$ expressa a relação de preços entre os insumos $x_{1}$ e $x_{2}$. $O$ ponto $C$, na isoquanta da fronteira de produção e portanto tecnicamente eficiente, é também eficiente do ponto de vista alocativo já que neste ponto a reta $\mathrm{PP}^{\prime}$ tangencia a isoquanta FF'. O ponto $B$, embora tecnicamente eficiente, é ineficiente do ponto de 
vista alocativo já que o seu custo é superior a $Z=C$ que é o ponto de máxima eficiência alocativa. Logo, a razão OZ/OB mede a eficiencia alocativa e OZ/OE mede a eficiência total (eficiencia econômica).

\subsection{Eficiência técnica e retornos à escala}

Färe et al.(1994) propuseram a construção de uma tecnologia de referência para a medição de eficiência técnica sob várias pressuposições de retorno à escala. Este modelo é ilustrado na Figura 02 pela fronteira de produção para o caso de um produto $(y)$, um insumo $(x)$ e 4 firmas $(A, B, C$ e D).

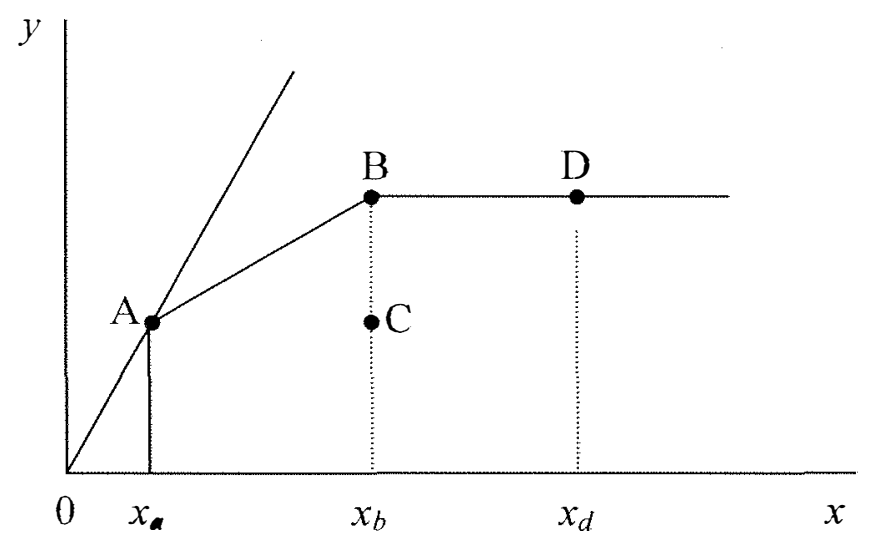

Figura 02: Tecnologia de referência e retornos à escala

Sob retornos constantes à escala, a tecnologia é limitada pelo raio $0 \mathrm{~A}$. Sob retornos não crescentes, a combinação convexa da produção de $y$ entre firmas não pode ser maior que a mais alta quantidade de $y$ produzida por uma única firma, levando a 
uma fronteira de produção dada por $0 \mathrm{ABD}$. Sob retornos variáveis, o uso de insumo de uma firma $j$ não pode ser menor do que a menor quantidade de insumo usada por qualquer outra firma. Isto conduz à possibilidade de retornos crescentes à escala e causa a fronteira ficar não mais próxima ao eixo do $y$ além do ponto $\mathrm{A}\left(x_{a} \mathrm{ABD}\right)$. Sob retornos variáveis à escala, as funções de distância para insumo e produto para a firma no ponto $C$ são dadas, respectivamente, pelas relações $\mathrm{O} x_{b} / 0 \mathrm{x}_{\mathrm{a}}$ e $x_{b} \mathrm{C} / x_{b} \mathrm{~B}$.

$\mathrm{Na}$ ausência de retornos constantes à escala pode ocorrer que uma firma seja eficiente em relação ao uso de insumos e ineficiente em relação ao nível de produto, ou vice-versa. Isto pode ser observado na Figura 02: a firma representada pelo ponto D é eficiente em relação ao produto mas ineficiente em relação ao uso de insumos já que $B$ é mais insumo-eficiente. Pelo mesmo raciocínio pode-se verificar que a firma $C$ é insumo-eficiente e produto-ineficiente em relação a $B$. Para medir a eficiencia nestes casos, Gilligan (1998) sugere a introdução de uma função de transformação, definida como a diferença entre a função de distância do produto e a função de distancia do insumo. Por definição, a função de transformação terá valor igual a zero para as firmas eficientes e valores menores que zero para as firmas ineficientes $(F T \leq 0)$. No exemplo ilustrado na figura 02 as funções de transformação para as firmas B, C e D seriam, respectivamente,

$$
\begin{aligned}
& F T_{B}=\left(x_{b} \mathrm{~B} / x_{b} \mathrm{~B}\right)-\left(0 x_{b} / 0 x_{b}\right)=I-I=0, \\
& F T_{C}=\left(x_{b} \mathrm{C} / x_{b} \mathrm{~B}\right)-\left(0 x_{b} / 0 x_{a}\right)<0 \mathrm{e}, \\
& F T_{D}=x_{d} \mathrm{D} / x_{d} \mathrm{D}-\left(0 x_{d} / 0 x_{b}\right)=I-\left(0 x_{d} / 0 x_{b}\right)<0 .
\end{aligned}
$$


O passo inicial para a análise da eficiência da produção consiste em se obter uma representação da tecnologia empregada pelos agentes produtivos, ou seja, buscar uma função de produção para o conjunto das observações que caracterize um comportamento racional em termos de maximização do lucro ou de minimização de custos.

\subsection{O conceito de racionalização dos dados}

O conceito de racionalização em termos de maximização do lucro (p-racionalização) e de minimização de custos (c-racionalização) é discutido abaixo, com base nos trabalhos de Varian (1984) e Alves (1995).

Seja $x=\left(x_{1}, x_{2}, \ldots, x_{m}\right)$ um vetor de insumos de dimensão $(m \times l)$ usado na produção de um vetor $(n x l)$ de produtos $y$ $=\left(y_{1}, y_{2}, \ldots, y_{n}\right)$. A tecnologia subjacente é caracterizada pelo conjunto de possibilidades de produção $T$, onde $(x, y) \in T \subseteq R^{m+n}$ ou, equivalentemente, pelo conjunto de requerimento de insumos associado representado por $V(y, T)=\left\{x:(x, y) \in T, y \in R^{m}\right\}$. Assume-se que o conjunto $T$ tem as seguintes propriedades:

A 1. O conjunto $T$ é não vazio e existe um $x \geq 0$ e $y \geq 0$ tal que $(x, y) \in T$.

A2. Se $x \in V(y, T)$ e $y \geq y^{\prime}$ então $x \in V\left(y^{\prime}, T\right), \quad \forall y$, $y^{\prime} \in R^{m}$.

A3. Se $x \in V(y, T)$ e $x^{\prime} \geq x$, então $x^{\prime} \in V(y, T), \forall y \in R^{m}$. 
A4. O conjunto $T$ é fechado.

A pressuposição A1 estabelece que é possível produzir qualquer produto positivo a partir de qualquer insumo positivo. As pressuposições A2 (encadeamento) e A3 (monotonicidade) são conhecidas como "disponibilidade forte" de produtos e insumos, respectivamente. A pressuposição A2 estabelece que, se $x$ (insumos) produz $y$ (produtos), então $x$ produzirá qualquer quantidade menor ou igual a $y$. De acordo com A3, se uma combinação de insumos produz $y$, então qualquer outra combinação que contenha cada um dos insumos em quantidade maior ou igual a esta também produzirá $y$. O Pressuposto A4 implica na existencia de isoquantas na fronteira do conjunto de possibilidades de produção.

\subsubsection{P-racionalização dos dados:}

Sejam

$I=\{1,2, \ldots, n\}$ as n observações de $(y, x)$ em um dado setor; $\left(y_{i}, x_{i}\right) \in T=$ vetores das quantidades de produtos e insumos para cada observação $i \in I ;\left(p_{i}, w_{i}\right)=$ vetores dos preços de produtos e insumos de para cada observação $i \in I ; y_{i}, x_{i} \geq 0, p_{i}$, $w_{i}>0$.

Sob a hipótese de maximização de lucro tem-se que

$$
\operatorname{Max}_{y}, x\left[p_{i} y_{i}-w_{i}{ }^{\prime} x_{i}:\left(y_{i}, x_{i}\right) \in T\right] \text { para todo } i \in I
$$


As funções de oferta de produtos e de demanda por insumos de cada observação $i \in I$ derivadas do problema de maximização do lucro dado por (1) são:

$$
\begin{aligned}
& y_{i}{ }^{*}=y_{i}\left(p_{i}, w_{i}\right) \text { oferta de produto } \\
& x_{i}{ }^{*}=x_{i}\left(p_{i}, w_{i}\right) \text { demanda de insumos }
\end{aligned}
$$

Dado o problema (1), a condição necessária e suficiente para maximização do lucro é dada pelo seguinte conjunto de inequações (Varian, 1984):

$$
\begin{aligned}
& Z=\left(p_{i}{ }^{\prime} y_{i}{ }^{*}-w_{i}{ }^{\prime} x_{i}{ }^{*}\right)-\left(p_{i}{ }^{\prime} y_{j}{ }^{*}-w_{i} x_{j}{ }^{*}\right) \geq 0, \\
& \text { para todo } i, j \in I, \quad i \neq j .
\end{aligned}
$$

ou seja, todas as observações das $n$ firmas devem satisfazer a condição dada por (2) para todo $i \in I$ e todo $j \in I$.Em outras palavras, a condição (2) diz que cada firma $i$ do conjunto de observações maximiza o lucro quando os custos e receitas são calculados com base em seus preços $p_{i}$ e $w_{i}$. Assim, o lucro obtido pela firma $i$, feita a sua escolha $\left(y_{i}, x_{i}\right)$, é maior ou igual ao lucro que poderia obter com uma outra escolha qualquer $\left(y_{j}, x_{j}\right)$. A expressão (2) é conhecida como axioma fraco da maximização do lucro - WAPM (Varian, 1984).Quando um conjunto de produção $T$ é consistente com WAPM, diz-se que ele p-racionaliza os dados (p de "profit") e a função de produção é contínua, monotônica e quase-côncava. Quando a condição não ocorre para uma observação diz-se que esta viola WAPM. A ligação entre o comportamento observado e a teoria da produção pode ser estabelecida a partir do Teorema 4 de Varian:

Teorema 4 (Varian, 1984): as seguintes condições são equivalentes: (1) Existe uma função de produção que p- 
racinaliza os dados. (2) $y^{j} \leq y^{i}+\left(w^{i} / p^{i}\right)\left(x^{j}-x^{i}\right)$ para todo $i$ e j. (3) Existe uma função de produção contínua, côncava, monotônica que p-racionaliza os dados.

\subsubsection{C-racionalização:}

Seja $V(y)$ o conjunto das combinações de insumos $x$ que produz pelo menos $y$.

Sob a hipótese de minimização de custos tem-se que

$$
\operatorname{Min}_{x}\left[w_{i} x_{i}: x_{i} \in T\right] \text { para todo } i \in I
$$

A condição necessária e suficiente para minimização de custos é dada pelo seguinte conjunto de inequações (Varian, $1984)$ :

$$
C=w_{i} x_{i}-w_{i} x_{j} \leq 0 \text {, para todo } i, j \in I, \quad i \neq j
$$

ou seja, todas as observações das $n$ firmas devem satisfazer a condição acima para todo $i \in I$ e todo $j \in I$. Em outras palavras, o custo da $i$-ésima firma, dada sua escolha de $x_{i}$, é menor ou igual ao custo de qualquer combinação $x_{j}$ que viesse a escolher para produzir $y_{i}$, dados os preços observados por $i$. Esta condição é conhecida como axioma fraco da minimização de custos (W ACM). Para que esta condição ocorra é preciso que o conjunto de produção $V\left(y_{i}\right)$ seja fechado, não vazio e os preços de insumos positivos. Quando um conjunto de produção $V(y)$ é consistente com WACM diz-se que ele c-racionaliza as observações. A ligação entre o 
comportamento observado e a teoria da produção é estabelecida por Varian (1984) através do seguinte teorema:

As seguintes condições são equivalentes: (1) existe uma família encadeada de conjuntos de produção, $V(y), q u e$ cracionaliza as observações; (2) se $y_{j} \geq y_{i}$ então $w_{i} x_{j} \geq w_{i} x_{i}$; (3) existe uma familia não trivial de conjuntos de produção que são convexos, fechados e satisfazem as pressuposições $\boldsymbol{A}_{1} \mathrm{e} \boldsymbol{A}_{2}$.

\subsection{Funções de distância}

Em geral, os trabalhos visando analisar a eficiência da produção tomam como base as funções de distância de Shephard (1970) que permitem uma representação flexível e conveniente da tecnologia de produção. Mais recentemente, Chavas e Cox (1999) formularam um modelo generalizado de funções de distância que inclui, entre outros casos particulares, as funções de distância de Shephard.

As funções de distância de Shephard (1970) são definidas sob os pressupostos $\mathbf{A}_{1}$ a $\mathbf{A}_{4}$ apresentados acima. As funções orientadas para insumos e produtos são, respectivamente,

$$
\begin{aligned}
& D_{T}(x, y)=\sup _{\theta}\{\theta:(y, x / \theta) \in T\} \mathrm{e} \\
& F_{T}(x, y)=\inf _{\theta}\{\theta:(y / \theta, x) \in T\} .
\end{aligned}
$$

Da expressão (5) tem-se que a função de distância orientada para insumos é a suprema redução proporcional de todos 
os insumos que ainda possibilitaria a produção de $y$. A expressão (6) define a função de distância orientada para produtos como a ínfima expansão proporcional de todos os produtos que possam ser produzidos com o vetor original de insumos.

De (5), pode-se gerar o conjunto de requerimento de insumos,

$$
\left.I R_{T}(y)=\left\{x: D_{T}(y, x)\right) \geq 1\right),
$$

e a isoquanta de fronteira do conjunto de produção

$$
I S_{T}(y)=\left\{x: D_{T}(y, x)=1\right\} .
$$

Do mesmo modo tem-se que, de (6), a função de produção é dada por

$$
P C_{T}(x)=\left\{y: F_{T}(y, x) \leq 1\right\}
$$

e a fronteira de produção correspondente é

$$
F C_{T}(x)=\{y:(y, x)=1\} \text {. }
$$

Tem-se então que a função de distância orientada para insumos mede a redução proporcional (ou radial) em todos os insumos que levaria uma firma à isoquanta de fronteira, ou seja, àquela que representa a "melhor alternativa" dentre as firmas objeto de comparação. A função de distância orientada para produtos define as alternativas de substituição entre produtos dados os insumos $x$. Verifica-se, ainda, que a relação $1 / F_{T}(y, x)$ mede a recombinação proporcional de todos os produtos que levaria a firma à fronteira de produção $F C_{T}(x)$ e deve ser interpretada como o aumento proporcional na receita que poderia ser obtido ao se mover para a fronteira. Pode-se ainda observar que as funções de distância 
representadas por (5) e (6) propiciam uma completa caracterização da tecnologia subjacente.

Sob a condição de retornos constantes à escala temse que $(y / k, x) \subset T$ implica $(y, k x) \subset T$ para qualquer $k>0$. Isto implica na existência de uma relação entre as funções representadas por (5) e (6) tal que $D_{T}(y, x)=I / F_{T}(y, x)$, ou seja, as funções são recíprocas sob retornos constantes à escala. Contudo, sob retornos variáveis à escala tem-se que, em geral $D T(y, x) \neq 1 / F T(y, x)$ o que remete ao problema de determinar qual das duas funções escolher para a obtenção das medidas de eficiência.

Além disso, as funções de distância de Shephard estão estabelecidas sobre a pressuposição de que todos os vetores de produto (insumo) podem ser obtidos a partir do redimensionamento de qualquer vetor não-zero de insumo (produto). Este pressuposto é conhecido na literatura como hipótese da alcançabilidade (attainability assumption). Chavas e Cox (1999) mostram que, em algumas situações, este pressuposto não é satisfeito, especialmente se alguns insumos ou produtos são não essenciais. Considere-se, por exemplo, uma fronteira de produção gerada com tecnologia de retornos variáveis à escala ilustrada na figura 03. Dado que o conjunto de possibilidades de produção é limitado pela fronteira ABCDE, o ponto $F$ viola a hipótese de alcançabilidade, significando que as funções de distância de insumo e produto de Shephard avaliadas neste ponto terão valores infinitos. Contudo,observa-se que é possível mover-se do ponto F em direção à fronteira redimensionando simultaneamente insumo e produto. 


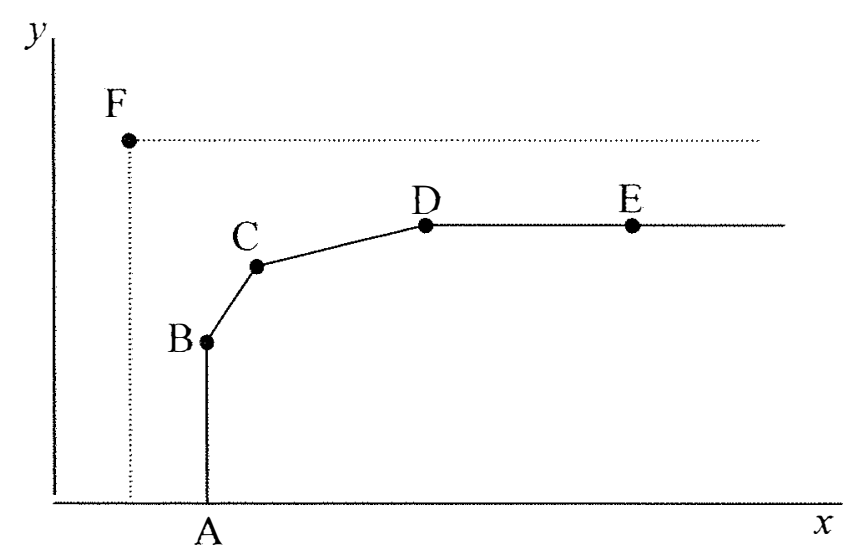

Figura 03: Front eira de produção com tecnologia de retornos variáveis à escala

Considerando este aspecto, Chavas \& Cox (1999) propõem uma generalização da função de distância de Shephard pela incorporação do seguinte pressuposto adicional:

A5. $A=\left\{\alpha: 0 \leq \alpha \leq 1 ; \exists \theta>0\right.$ tal que $\left.\left(\theta^{l-\alpha} x\right) \in V\left(\theta^{-\alpha} y, T\right)\right\}$,
para $x \geq 0, y \geq 0 ;$
O conjunto $A$ é não-vazio.
Dada a pressuposição $\mathbf{A 5}$, a função de distância generalizada proposta por Chavas \& Cox é definida como:

$$
\begin{aligned}
& D(x, y, T, \alpha)=\operatorname{Min}_{\theta}\left\{\theta:\left(\theta^{1-\alpha} x\right) \in V\left(\theta^{-\alpha} y, T\right), \theta>\bullet\right. \\
& \text { para } x \geq 0, y \geq 0 \text { e } \alpha \in A .
\end{aligned}
$$

Chavas \& Cox (1999) demonstram que a função de distância generalizada dada por $D(x, y, T, \alpha)$ inclui, como casos especiais muitas das medidas de eficiência encontradas na 
literatura. Mais especialmente, inclui as funções de distância de Shephard orientadas para insumo e para produto com $\alpha=0$ e $\alpha=1$, respectivamente.

As propriedades da função $D(x, y, \quad T, \alpha)$ são apresentadas nas seguintes proposições:

Proposição 1: Para $x \geq 0, y \geq 0$ e $\alpha \in A$, a função $D(x, y$, $T, \alpha)$ satisfaz $D(x, y, T, \alpha) \leq l$ se e somente se $x \in V(y, T)$;

Proposição 2: Para $x \geq 0, \quad y \geq 0$ e $\quad \alpha \in A$, a função $D(x, y, T, \alpha)$ é:

2a. quase homogênea de grau $(\alpha-1), \alpha$ e 1 em $x$ e $y$;

2b. não crescente em $x$;

2c. semi-contínua inferior em $x$ e $y$;

$2 \mathrm{~d}$. independente de $\alpha$ sob retornos constantes à escala, decrescente (crescente) em $\alpha$ sob retornos crescentes (decrescentes) à escala para $x \in V(y, T)$.

Da proposição 1 tem-se que $D(x, y, T, \alpha)=1$ é a função de transformação representando a fronteira tecnológica para qualquer $\alpha, 0 \leq \alpha \leq 1$. De acordo com a proposição $2 \mathrm{~d}$, a escolha do valor de $\alpha$ quando a tecnologia apresenta retornos constantes à escala é arbitrária já que $D(x, y, T, \alpha)$ independe do valor de $\alpha$. Já sob retornos variáveis à escala a escolha do valor de $\alpha$ deve ser feita de modo a permitir redimensionar insumos e produtos na direção que seja a mais próxima da tecnologia de fronteira. 
Conforme Chavas \& $\operatorname{Cox}(1999)$, isto sugere escolher $\alpha$ do seguinte $\bmod 0$ :

$$
\alpha \in A^{*}=\operatorname{argmin}_{\alpha}\{|D(x, y, T, \alpha)-1|: \alpha \in A\}
$$

Seja $D(x, y, T, \alpha) \leq 1$ e $A=\left\{\alpha: \alpha_{L} \leq \alpha \leq \alpha_{M}\right\}$ onde $\alpha_{L} \geq 0$ e $\alpha_{M} \leq 1$. Se a tecnologia apresenta retornos decrescentes à escala a equação $\alpha \in A^{*}=\operatorname{argmin}_{\alpha}\{|D(x, y, T, \alpha)-1|: \alpha \in A\}$ implica na escolha de $\alpha=\alpha_{M}$. Se a tecnologia exibe retornos crescentes à escala, implica em escolher $\alpha=\alpha_{L}$. Isto em decorrência da proposição $2 \mathrm{~d}$ referente a retornos variáveis à escala.

\subsection{As abordagens na análise da eficiência}

Os estudos visando analisar a eficiência a partir de fronteiras de produção podem ser agrupados, de acordo com os métodos utilizados para estimar a função de produção, em duas abordagens: paramétrica e não-paramétrica.

$\mathrm{Na}$ abordagem paramétrica a função de fronteira é considerada uma função paramétrica dos insumos (Cobb-Douglas, CES, translog, etc). Neste enfoque, distinguem-se os modelos determinísticos e as fronteiras estocásticas. Nos modelos determinísticos a eficiência técnica é dada pelo termo de erro e podem ser estimados por programação linear ou técnicas econométricas. Nos modelos estocásticos, pressupõe-se que o termo de erro tem dois componentes: um ruído branco que representa os efeitos aleatórios sobre a produção e, portanto, fora do controle da 
unidade de decisão, e um componente assimétrico que mede a ineficiência técnica pela distância em que se situa em relação ao ótimo (fronteira) e que, assume-se, seja resultante de fatores comportamentais que estão sob o controle da unidade de decisão.

A principal restrição ao emprego dos modelos paramétricos se deve à imposição de uma forma funcional explícita aos dados que podem não corresponder à verdadeira estrutura da tecnologia de produção, resultando em erros de estimativa (Lambert \& Shonkwiler, 1995). Mesmo com a utilização de formas funcionais flexíveis, que permitem melhorar as propriedades de aproximação da verdadeira função, podem ocorrer disparidades entre várias estimativas dependendo da forma funcional especificada. Uma segunda restrição aos modelos estocásticos está relacionada ao número de observações disponíveis para as variáveis, o que inviabilizaria a sua aplicação em casos em que o número de graus de liberdade é reduzido.

A abordagem não-paramétrica, desenvolvida mais recentemente, surgiu da necessidade de não se especificar uma forma funcional particular à função de produção. Utilizando técnicas de programação linear a eficiência é medida como a distância de cada firma em relação a uma fronteira de produção não-paramétrica construída como uma combinação convexa de insumos-produtos observados. Nesta abordagem, distinguem-se os modelos primais e duais. Nos modelos primais utilizam-se dados de quantidade de insumos e produtos para obter a fronteira de produção e são conhecidos na literatura como Data Envelopment Analysis. Os modelos duais requerem informações de preços e quantidades para gerar a fronteira de produção sobre a pressuposição de maximização de lucro ou minimização de custo. 


\section{REVISÃO DE LITERATURA}

Ainda que de desenvolvimento recente, existe uma vasta literatura mundial sobre aplicações da abordagem não paramétrica na análise da eficiência econômica, alguns dos quais são citados a seguir:

Lemberg \& Wongcharupan (1998), utilizando uma abordagem não-paramétrica baseada na minimização de custos, avaliaram a eficiência técnica e econômica de uma amostra de 107 produtores de trigo do Kansas, USA, constatando a ocorrência de ineficiência técnica e alocativa para a maioria das observações. Os índices de eficiência técnica, alocativa e de custo apresentaram uma relação positiva com o nível de produto, tanto sob retornos constantes como variáveis à escala, embora esta relação não tenha sido estatisticamente significante para eficiência técnica. A variável área cultivada mostrou uma relação positiva com os índices de eficiência alocativa; sob retornos constantes à escala, a eficiência técnica cresceu levemente com o aumento da área cultivada e, sob retornos variáveis à escala, apresentou uma relação inversa. 
Gilligan (1998) analisou a relação entre tamanho da fazenda e produtividade para uma amostra de produtores de Honduras, usando medidas de eficiência econômica baseadas em funções de distância. Os resultados evidenciaram uma relação negativa entre eficiência economica e tamanho da fazenda. A decomposição do índice de eficiência economica nos efeitos técnico e de escala, sob retornos decrescentes à escala mostraram que as propriedades maiores são tecnicamente mais eficientes; contudo, a ineficiência de escala domina a relativa eficiência técnica das maiores propriedades.

Sharma et al. (1999) analisaram a eficiência na produção de suínos no Havaí comparando medidas de eficiência obtidas através de modelo paramétrico (eficiência estocástica) e não-paramétrico (data envelopment analysis). Os resultados obtidos pelas duas abordagens revelaram considerável ineficiência na produção. Sob retornos constantes à escala, os índices médios de eficiência técnica e economica estimados foram maiores para o modelo paramétrico do que aqueles obtidos por DEA; sob retornos variáveis estes índices foram muito semelhantes. Os índices de eficiência alocativa foram, geralmente, maiores para o modelo DEA. Os resultados mostram ainda um efeito fortemente positivo do tamanho da exploração com os níveis de eficiência e que as firmas que produzem suínos para o mercado são mais eficientes do que aquelas que produzem para o consumo.

No Brasil, ainda são poucos os trabalhos que exploram esta área, alguns dos quais são citados a seguir:

Toreson \& Lanzer (1995), utilizando dados médios de quantidades de insumos e produtos, avaliaram a eficiência 
técnica de 17 empresas agrícolas típicas de Santa Catarina, empregando um modelo de Data Envelopment Analysis (DEA). Os resultados indicaram que as pequenas empresas produtoras de fumo e as empresas médias produtoras de suínos e grãos foram as que, com maior freqüência, apareceram como referência para as empresas menos eficientes e que as produtoras de grãos se mostraram mais ineficientes. Indicam ainda que a inclusão de atividades como fumo e criações intensivas nas empresas voltadas para a produção de mandioca ou grãos podem melhorar seus níveis de produtividade e eficiência na agregação de valor ao conjunto dos insumos empregados.

Taylor et al. (1986) analisaram a eficiência técnica e econômica de um grupo de produtores através da estimativa de uma função de produção de fronteira determinística.

Taylor \& Shonkwiller (1986), utilizando os dados de Taylor et al. (1986) estimaram uma função de produção estocástica.

Tupy (1996) analisou a eficiência econômica de uma amostra de produtores de frangos de corte utilizando um modelo de fronteira estocástica, obtendo estimativas de funções do tipo CobbDouglas na forma log-linear e com especificações meio-normal e exponencial. Os resultados evidenciaram uma eficiência econômica alta, variando de 93 a 100\%, indicando que ganhos de produtividade no setor advirão predominantemente da introdução de novas tecnologias.

Vicente (1997) utilizou modelos econométricos de fronteira para estimar a eficiência da agricultura paulista e modelos probit e tobit para identificar e analisar os fatores determinantes da eficiência na produção. Os resultados indicaram que as variáveis 
estruturais escolaridade, experiência do produtor, disponibilidade de pesquisa agrícola, trabalho residente e não-residente, escalas do imóvel e das explorações influenciaram a adoção e a intensidade do uso da tecnologia, e a eficiência da produção. As variáveis conjunturais (acesso ao crédito e política de preços mínimos) e ambientais (deficiência hídrica, valor e qualidade da terra) também condicionaram a eficiência da produção.

Araújo (1997), usando dados de cross-section, aplicou um modelo MOTAD (Minimização do Desvio Absoluto Total) para analisar a eficiência econômica sob condições de risco de empresas agrícolas da região sul de Santa Catarina. Pela identificação ao longo da fronteira de eficiência dos pontos de máxima margem bruta e utilidade observou a existência de um potencial de crescimento da margem bruta de $49,9 \%$ e $62,59 \%$ se o produtor adotasse, respectivamente, o plano de máxima utilidade e de máximo retorno, dada a disponibilidade de fatores de produção e o nível de risco que deseja suportar.

Conceição (1998), com dados primários referentes ao ano agrícola $1989 / 90$ de uma amostra de propriedades modernas/comerciais de 4 regiões do Brasil, analisou a eficiência técnica média e de cada fazenda a partir de um modelo de função de produção estocástica. A eficiência técnica média estimada da amostra foi de $73,08 \%$ e, para cada fazenda, variaram no intervalo de $41,47 \%$ a $93,09 \%$ com aproximadamente $52 \%$ dos produtores com eficiência técnica entre $75 \%$ e $90 \%$. Os resultados indicaram ainda que as variáveis experiência do produtor, extensão privada, e fontes alternativas de informação (rádio) foram as mais importantes na explicação da eficiência técnica. 
Gomes \& Alves (2000) utilizaram a técnica conhecida por Data Envelopment Analysis para medir a eficiência técnica e de escala de uma amostra de 241 produtores de leite de Minas Gerais e São Paulo. Os resultados indicaram uma eficiência técnica média da ordem de $85 \%$ e que $51 \%$ da amostra estava operando na escala ótima, $25 \%$ estava acima e $20 \%$ abaixo da escala ótima. 


\section{METODOLOGIA}

Neste trabalho será utilizado um modelo nãoparamétrico, multi-produto, e multi-insumo fundamentado no conceito de funções de distância de Shephard (1970), para a análise da eficiência técnica e econômica.

O modelo apresentado baseia-se nos trabalhos de Chavas \& Cox (1990, 1994 e 1999), Lambert \& Ussif (1997), Lambert (1997), Lemberg \& Wongcharupan (1998), Varian (1984 e $1985)$ e Sharma et al. (1999).

A metodologia apresentada engloba as seguintes etapas de desenvolvimento da pesquisa:

1) verificação da consistência dos dados com o comportamento de minimização de custos;

2) cálculo dos índices de eficiência técnica, eficiencia de escala, eficiência alocativa e eficiência agregada;

3 ) análise das relações entre eficiência e variáveis sócio-econômicas e ambientais. 


\subsection{Teste da hipótese de minimização de custos:}

No conjunto das observações podem ocorrer casos em que algumas firmas apresentam ineficiência técnica ou alocativa e, até mesmo, erros de medição, violando a condição de comportamento otimizador. Neste caso, as análises que envolvem medidas de eficiência procuram, numa primeira etapa, verificar a ocorrência de violações ao comportamento otimizador e testar a possibilidade destas violações serem devidas a erros de medição nas observações. Esta análise, geralmente, envolve a utilização de modelos determinísticos e estocásticos.

A parte determinística da análise consiste em verificar, no conjunto de todas as observações, aquelas que violam o comportamento otimizador. Sob a hipótese de minimização de custos, corresponde a verificar, sobre todos os produtos e insumos observados, violações de WACM ou, em termos equivalentes, testar a seguinte condição:

Se $y_{i} \leq y_{j}$, então $w_{i} x_{i} \leq w_{i} x_{j}, \forall i, i, j \in I, i \neq j$

Para se proceder ao teste é necessário, em primeiro lugar, ordenar as observações por ordem crescente do produto. Seja $n=$ número de observações da amostra e $m=$ número de insumos, definem-se as matrizes $\mathbf{W}$ (preço dos fatores) e $\mathbf{X}$ (quantidade dos fatores), de dimensão nxm. O produto $\mathbf{W}$, define a matriz de custos $\mathbf{C}$, de dimensão $n \times n$ : 


$$
\mathbf{C}=\left[\begin{array}{cccc}
\sum w_{l} x_{l} & \sum w_{l} x_{2} & \ldots & \sum w_{l} x_{n} \\
\sum w_{2} x_{l} & \sum w_{2} x_{2} & \ldots & \sum w_{2} x_{n} \\
\vdots & \vdots & \vdots & \vdots \\
\sum w_{n} x_{l} & \sum w_{n} x_{2} & \ldots & \sum w_{n} x_{n}
\end{array}\right]
$$

Cada linha da matriz $\mathbf{C}$ corresponde a uma observação e os elementos da diagonal principal são os custos observados para cada firma. Tome-se, por exemplo, a primeira linha: o elemento da diagonal principal correspondente $\left(\sum w_{i} x_{i}\right)$ é o custo observado para a firma $i$ e, à sua direita, $\left(\sum w_{i} x_{2}, \ldots, \sum w_{i} x_{n}\right)$ são os custos que a firma $i$ teria se, dados os seus preços, utilizasse qualquer outra combinação de insumos do conjunto das observações. Lembrando que as observações estão crescentemente ordenadas pelo produto, por construção, ocorre violação de WACM quando um elemento à direita do elemento da diagonal principal é menor que o próprio elemento da diagonal.

Para cada firma $i$ da amostra são testadas (n-i) desigualdades perfazendo um total de $n(n-1) / 2$ desigualdades para toda a amostra.

Verificadas as violações de WACM, procura-se testar se as violações encontradas podem estar relacionadas a erros de medição. Neste estudo, utilizou-se um modelo estocástico proposto por Varian (1985).

Admitindo-se a ocorrência de erros de medição dos dados, supõe-se que a demanda observada pelo fator $k$ na observação $i, x_{i k}$, está relacionado com a demanda "verdadeira", $z_{i k}$, da seguinte forma:

$$
x_{i k}=z_{i k}+\varepsilon_{i k}, i=1, \ldots, n, k=1, \ldots, m
$$


onde $\varepsilon_{i k}$ é o termo de erro aleatório com distribuição normal, média zero e variância $\sigma^{2}$. A hipótese a ser considerada é que as observações são c-racionalizáveis, ou seja:

$$
\mathrm{H}_{0}=\operatorname{os} \mathrm{dados}\left(w_{i}, z_{i}, y_{i}\right) \text { satisfazem WACM. }
$$

Se fosse possível observar a demanda "verdadeira" por insumos $\left(z_{i k}\right)$ e a variância da população $\left(\sigma^{2}\right)$ a seguinte estatística poderia ser calculada:

$$
T=\sum_{i=1}^{n} \sum_{k=1}^{m}\left(z_{i k}-x_{i k}\right)^{2} / \sigma^{2}
$$

Esta estatística tem distribuição de $\chi^{2} \operatorname{com} n m$ graus de liberdade. Para um nível de significância $\alpha$, se $T$ for maior que o valor crítico $\chi^{2} \alpha, m n$ rejeita-se a hipótese nula.

No entanto, a estatística $T$ não é observável já que se desconhece a demanda "verdadeira" pelos fatores $\left(z_{i k}\right)$ e a variância da população $\left(\sigma^{2}\right)$. Pode-se, mesmo assim, testar a hipótese de minimização de custos através da solução do seguinte problema de programação quadrática:

$$
\begin{aligned}
& R=\sum_{i=1}^{n} \sum_{k=1}^{m}\left(t_{i k}-x_{i k}\right)^{2} \\
& \text { sujeito a } \\
& \sum_{k=1}^{m} w_{l k} t_{j k} \geq \sum_{k=1}^{m} w_{l k} t_{l k}, \forall j=1,2, \ldots, n, y_{r} \leq y_{J}
\end{aligned}
$$


onde $R$ é igual à soma dos quadrados mínimos dos desvios que satisfazem WACM relativa às quantidades observadas, $w_{i k}$ é o preço do insumo $k$ para a $i$-ésima firma, $x_{i k}$ é a quantidade de insumo $k$ para a $i$-ésima firma e $t_{i k}$ é a solução do problema representando a quantidade ideal do insumo $k$ para a firma $i$.

Considerando que a demanda por fatores seja medida em diferentes unidades, Varian (1985) sugere que a relação entre a demanda "verdadeira" e demanda observada seja especificada de forma que o erro seja uma medida proporcional no lugar de aditiva como anteriormente especificado:

$$
Z_{i k}=x_{i k}\left(1+\varepsilon_{i k}\right)
$$

Deste modo, a função objetivo do modelo de programação quadrática acima especificado toma a seguinte forma:

$$
R=\sum_{i=1}^{n} \sum_{k=1}^{m}\left[\left(t_{i k} / x_{i k}\right)-1\right]^{2}
$$

Se a variância da população $\left(\sigma^{2}\right)$ fosse conhecida, a hipótese nula seria rejeitada quando $R / \sigma^{2}>\chi^{2}{ }_{\alpha, n m}$ ou $\sigma^{2}<R / \chi^{2}{ }_{\alpha, n m}$. Fazendo $\bar{\sigma}=100 \sqrt{R / \sigma_{a, n m}^{2}}$ a hipótese de minimização de custos será rejeitada se o valor de $\bar{\sigma}$ assim obtido ao nível de significância $\alpha$ for maior do que o percentual de erro de medição esperado (ou aceitável) nos dados. Em outras palavras, $\bar{\sigma}$ pode ser entendido como o percentual de erros de medição que deve ser aceito para não rejeitar a hipótese de minimização de custos. 


\subsection{Medidas de eficiência}

Diz-se que uma empresa é tecnicamente eficiente quando a produção ocorre na fronteira tecnológica. Por eficiência alocativa entende-se quando o processo de produção ocorre de tal forma que, dados os preços dos fatores, os custos são minimizados. Por eficiência econômica entende-se o processo de produção que é eficiente do ponto de vista técnico e alocativo, ou seja, a firma deve estar na fronteira de produção e com seus custos minimizados.

Sejam $\left(y^{*}, x^{*}\right) \in T$ a representação de um processo tecnicamente eficiente $\left\{D_{T}\left(y^{*}, x^{*}\right)=1\right\}$ e $(y, x) \in T$ uma observação no espaço $R^{m+n}$. Uma medida da eficiência técnica orientada para insumos (Caves et al, 1982) é dada pela seguinte expressão:

$$
I P=1 / D_{T}(y, x)
$$

$O$ índice $I P$ mede o fator de expansão radial para todos os insumos de tal modo que os insumos expandidos $(I P, x)=x / D_{T}(y, x)$ encontre-se na isoquanta de fronteira $I R_{T}(y)$ gerada pela tecnologia $T$. Para uma dada firma, $I P=1$ se esta for tecnicamente eficiente e $I P<1$ se sua eficiência for menor que a tecnologia de referência $T$.

Uma medida alternativa da eficiência técnica é obtida da expressão (6). Seja $F_{T}\left(y^{*}, x^{*}\right)=1$ um processo tecnicamente eficiente, o índice de eficiência técnica orientada para o produto de uma observação $(y, x) \in T$ proposto por Caves et al (1982b) é dado por:

$$
O P=F_{T}(y, x)
$$


$O$ índice $O P$ mede a fator de deflação radial para todos os produtos tal que os produtos deflacionados $(y / O P)=$ $y / F_{T}(y, x)$ encontrem-se na fronteira correspondente $F C_{T}(x)$ gerada pela tecnologia $T$. Se $I P=I$, a firma é tecnicamente eficiente; valores de $I P$ menores que 1 indicam que firma é menos eficiente em relação à tecnologia de referência $T$.

\subsection{Estimativa dos índices de eficiência}

As funções de distância de insumos e de produtos (equações 5 e 6 ) são obtidas diretamente da solução de problemas de programação linear.

Seja a tecnologia representada pelo seguinte conjunto de requerimento de insumos:

$$
T=\left\{(y, x): y \leq \sum_{j \in I} \lambda_{J} y_{j}, x \geq \sum_{j \in I} \lambda_{j} x_{j}, \sum_{j \in I} \lambda_{j}=1, \forall j\right\},
$$

onde $x$ = vetor dos insumos, $y=$ vetor dos produtos, $\lambda=$ fator de expansão (redução) radial de produtos (insumos).

O conjunto $T$ é fechado, convexo e monotônicamente decrescente.

Dadas as características da tecnologia, o índice de eficiência técnica baseada nos insumos é obtido a partir da solução do seguinte problema de programação linear: 
$\operatorname{Min} \theta_{i}=\left[D_{s}\left(y_{t}, x_{t}\right)\right]^{-1}$

sujeito a:

$$
\begin{aligned}
& y_{i} \leq \sum_{j \in I} \lambda_{j} y_{j} \\
& \theta x_{i} \geq \sum_{j \in I} \lambda_{j} x_{j} \\
& \sum_{j \in I} \lambda_{j}=1 \\
& \lambda_{j} \geq 0, \forall j
\end{aligned}
$$

onde $\theta_{i}$ é o índice de eficiência técnica da firma $i$ e os valores de $\lambda_{j}$ expressam as unidades eficientes que são referência para a unidade em análise, ou seja, expressam os fatores de multiplicação dos insumos e produtos para que a firma em análise tivesse a mesma eficiência das unidades de referência. A condição de retornos variáveis à escala é dada por $\sum_{j \in l} \lambda_{j}=1$. Sob retornos constantes à escala a restrição é dada por $\lambda \in \mathfrak{R}^{+}$e, sob retornos não crescentes à escala $\sum_{\mathrm{j} \in 1} \lambda_{j} \leq 1$.

O processo descrito acima é conhecido na literatura como Data Envelopment Analysis (DEA) e consiste em se obter a máxima redução radial (equiproporcional) possível das quantidades de insumos da unidade em análise ( $i$ ) em relação às demais $n-1$ unidades $(j)$.

Para $\theta$ igual a 1 , a firma encontra-se na fronteira de produção e, portanto, nenhuma redução equiproporcional é possível. Para $\theta$ menor que 1 tem-se que o conjunto de insumos pode ser reduzido na proporção $1-\theta$. 
Considerando que a análise sob retornos variáveis à escala é mais flexível (admite retornos constantes, crescentes e decrescentes à escala), os índices de eficiência estimados sob esta condição são maiores do que aqueles obtidos sob retornos constantes à escala. Esta relação é utilizada para obter uma medida de eficiencia de escala (Sharma et al., 1999) dada pela seguinte expressão:

$$
\psi_{i}=\theta_{i}^{r c e} / \theta_{i}{ }^{r v e}
$$

onde $\psi_{i}$ é o índice de eficiência de escala, $\theta_{i}{ }^{r c e}$ e $\theta_{i}{ }^{r v e}$ são os índices de eficiência técnica sob retornos constantes e variáveis à escala, respectivamente. Uma firma é eficiente em escala se $\psi_{i}=1$, ou seja, a eficiencia técnica calculada sob retornos constantes à escala é igual àquela calculada sob retornos variáveis. Valores de $\psi_{i}<1$ indicam a presença de retornos crescentes ou decrescentes à escala que podem ser determinados a partir da solução do índice de eficiência técnica sob retornos não crescentes à escala $\left(\theta_{i}{ }^{r n c e}\right)$ : se $\theta_{i}{ }^{r n c e}=\theta_{i}{ }^{r c e}$, tem-se retornos crescentes e se $\theta_{i}{ }^{r n c e}>\theta_{i}{ }^{r c e}$, retornos decrescentes à escala.

A expressão acima é uma decomposição do índice de eficiência tecnica sob retornos constantes em dois componentes: índice de eficiência de escala $\left(\psi_{i}\right)$ e índice de eficiência técnica pura $\left(\theta_{i}{ }^{r v e}\right)$.

O índice de eficiência alocativa está relacionado com processo de tomada de decisão da firma no que se refere à escolha de uma combinação de insumos que minimize os custos. 
Seja $C(w, y, T)$ o custo mínimo e $\theta_{i}$ o índice de eficiência técnica, a eficiência alocativa (ou eficiência de preço) é obtida através da seguinte expressão:

$$
\phi_{i}=C(w, y, T) /\left(w^{\prime} \theta_{i} x\right)
$$

Sob retornos constantes à escala o custo mínimo, $C(w, y, T)$, é obtido pela solução do seguinte problema de programação linear:

$$
\begin{aligned}
& \text { Min } w_{i} x=C(w, y, T) \\
& \text { sujeito } a \text { : } \\
& y_{i} \leq \sum_{j \in l} \lambda_{j} y_{j} \\
& x \geq \sum_{j \in l} \lambda_{j} x_{j} \\
& \lambda_{j} \geq 0, \forall j
\end{aligned}
$$

O índice de eficiência econômica (eficiência total) é então obtido da seguinte expressão:

$$
\omega_{i}=\theta_{i}{ }^{r v e} \psi_{i} \phi_{i}{ }^{r c e}
$$

Para uma firma operando em escala ótima $\left(\psi_{i}=1\right)$ o índice de eficiência agregada, ou de eficiência econômica ( $\omega$ i), é obtido pela seguinte expressão:

$$
\omega_{i}=\theta_{i}^{r c e} \phi_{i}^{r c e}
$$

O montante da ineficiência de custos (ou ineficiência econômica) é dado por $w^{\prime} x(l-\omega)=w^{\prime} x-w^{\prime} x^{*}$ onde $w^{\prime} x$ é o custo observado e $w^{\prime} x^{*}$ é o custo mínimo sob retornos constantes à escala. 
A ineficiência de custos pode, então, ser decomposta nos seus componentes técnico, alocativo e de escala da seguinte forma:

$$
w^{\prime} x(1-\omega)=w^{\prime} x\left[\left(1-\theta^{r v e}\right)+\theta^{r c e}\left(1-\phi_{i}^{r c e}\right)+\left(\theta^{r v e}-\theta^{r c e}\right)\right]
$$

onde os termos da soma entre colchetes são, respectivamente, os componentes de ineficiência técnica, alocativa e de escala.

Um exemplo dos problemas de programação a serem solucionados, para o caso de 2 produtos $\left(y_{1}, y_{2}\right)$, dois insumos $\left(x_{1}\right.$, $\left.x_{2}\right)$ e 5 observações tais que $I=(1,2,3,4,5)$ é apresentado a seguir.

O índice de eficiência técnica, sob retornos variáveis à escala, é dado pela solução do seguinte problema:

$$
\begin{aligned}
& 1 / D_{S}\left(y_{j}, \quad x_{j}\right)=\operatorname{Min} \theta_{i} \\
& \text { sujeito a: } \\
& y_{1 i} \leq \lambda_{1} y_{11}+\lambda_{2} y_{12}+\lambda_{3} y_{13}+\lambda_{4} y_{14}+\lambda_{5} y_{15} \\
& y_{2 i} \leq \lambda_{1} y_{21}+\lambda_{22} y_{22}+\lambda_{3} y_{23}+\lambda_{4} y_{24}+\lambda_{5} y_{25} \\
& x_{1 i} \theta_{i} \leq \lambda_{1} x_{11}+\lambda_{2} x_{12}+\lambda_{3} x_{13}+\lambda_{4} x_{14}+\lambda_{5} x_{15} \\
& x_{2 i} \theta_{i} \leq \lambda_{1} x_{21}+\lambda_{2} x_{22}+\lambda_{3} x_{23}+\lambda_{4} x_{24}+\lambda_{5} x_{25} \\
& \lambda_{1}+\lambda_{2}+\lambda_{3}+\lambda_{4}+\lambda_{5}=1 \\
& \lambda_{i} \geq 0
\end{aligned}
$$

Eliminando-se a restrição $\Sigma \lambda_{i}=1$ obtem-se o índice de eficiência técnica sob retornos constantes e, fazendo esta restrição menor ou igual a 1 tem-se o índice de eficiência técnica sob retornos não crescentes à escala. 
O custo mínimo, sob retornos constantes à escala, para cada observação $i \in I$, é dado pela solução do seguinte problema de programação linear:

$$
\begin{aligned}
& \text { Min } w_{i}{ }^{\prime} x=C(w, y, T) \\
& \text { sujeito a: } \\
& y_{1 i} \leq \lambda_{1} y_{11}+\lambda_{2} y_{12}+\lambda_{3} y_{13}+\lambda_{4} y_{14}+\lambda_{5} y_{15} \\
& y_{2 i} \leq \lambda_{1} y_{21}+\lambda_{2} y_{22}+\lambda_{3} y_{23}+\lambda_{4} y_{24}+\lambda_{5} y_{25} \\
& x_{1 i} \leq \lambda_{1} x_{11}+\lambda_{2} x_{12}+\lambda_{3} x_{13}+\lambda_{4} x_{14}+\lambda_{5} x_{15} \\
& x_{2 i} \leq \lambda_{1} x_{21}+\lambda_{2} x_{22}+\lambda_{3} x_{23}+\lambda_{4} x_{24}+\lambda_{5} x_{25} \\
& \lambda_{i} \geq 0
\end{aligned}
$$

Note-se que os problemas de minimização acima mencionados devem ser rodados para cada uma das observações $i \in I$.

Um aspecto a ser observado na análise da eficiência é a forma como se distribuem os índices calculados. Ray \& Bhadra (1993) propõem a construção de classes baseadas na magnitude dos desvios dos índices em relação a 1 . Definindo IE como um índice de eficiência adotou-se, neste trabalho, a seguinte classificação: Eficientes $(\mathrm{IE}=1)$, Ineficiência fraca $(0,9 \leq \mathrm{IE}<1)$, Ineficiência moderada $(0,7 \leq \mathrm{IE}<0,9)$ e Ineficiência forte $(\operatorname{IE}<0,7)$.

\subsection{Determinantes dos níveis de eficiência}

Neste trabalho será utilizado o modelo logito (logit model) para analisar a relação entre índices de eficiência e fatores 
determinantes, já que as variáveis dependentes consideradas (propriedades eficientes ou ineficientes) são dicotômicas.

Sendo a variável dependente definida como E (eficiência) pode-se estabelecer os seguintes estados:

$$
\begin{aligned}
& E=I \text { se a propriedade é eficiente; } \\
& E=0 \text { se a propriedade é ineficiente. }
\end{aligned}
$$

De acordo com GREENE (1997), definindo como $z$ o vetor das variáveis explicativas do nível de eficiencia tem-se que:

$$
\begin{aligned}
& \operatorname{Prob}(E=I)=F\left(\beta^{\prime} \mathbf{z}\right) \\
& \operatorname{Prob}(E=0)=I-F\left(\beta^{\prime} \mathbf{z}\right)
\end{aligned}
$$

onde $\operatorname{Prob}(E=1)$ é a probabilidade da firma ser eficiente, $\operatorname{Prob}(E=0)$ é a probabilidade da firma apresentar ineficiência e $\beta$ é o vetor dos parâmetros que refletem o impacto de mudanças em $\mathbf{z}$ na probabilidade.

\subsection{Dados}

Os dados a serem utilizados no presente trabalho provêm do projeto "Perfil agro-sócio-econômico dos pequenos produtores do Recôncavo Baiano", coordenado pela Empresa Baiana de Desenvolvimento Agrícola - EBDA, financiado pela EMBRAPA e executado pela EBDA em colaboração com o Departamento de Ciências Sociais Aplicadas à Agricultura da Escola de Agronomia 
da Universidade Federal da Bahia. Os dados foram coletados através de questionários aplicados a uma amostra de 420 pequenas propriedades agrícolas de 8 municípios da região Reconcavo do Estado da Bahia durante o período de janeiro a março de 1996.

Do total de propriedades amostradas retirou-se uma sub-amostra de 44 propriedades resultante da adoção dos seguintes critérios de escolha:
a) haver disponibilidade dos dados necessários à análise;
b) caracterizar a pequena agricultura familiar em termos de utilização de mão-de-obra;
c) explorar produtos dominantes na região.

\subsection{Variáveis}

Para a obtenção das medidas de eficiência foram utilizados os preços (em reais) e as quantidades dos seguintes produtos e fatores:

\section{Produtos.}

Amendoim - em sacas de $50 \mathrm{~kg}$

Farinha de mandioca - em sacas de $60 \mathrm{~kg}$

Feijão - em sacas de $60 \mathrm{~kg}$

Fumo - em arroba $(15 \mathrm{~kg})$

Inhame - em kg 
Laranja - em centos

Limão - em centos

Mandioca - em toneladas

\section{Fatores}

Esterco de gado - em toneladas

Formicida - em kg

Trator - em horas

Inseticida - em litro

Mão-de-obra familiar - em homens/dia

Fertilizantes químicos - em saco de $50 \mathrm{~kg}$

Torta de mamona - em saca de $50 \mathrm{~kg}$

As variáveis explicativas dos índices de eficiência são definidas da seguinte forma:

\section{Variáveis dependentes:}

$\mathrm{E}_{\theta}=$ eficiência técnica ( $1=$ eficiente, $0=$ ineficiente);

$\mathrm{E}_{\psi}=$ eficiência de escala ( $1=$ eficiente, $0=$ ineficiente);

$\mathrm{E}_{\phi}=$ eficiência alocativa ( $1=$ eficiente, $0=$ ineficiente);

$\mathrm{E}_{\Theta}=$ eficiência total ( 1 =eficiente, $0=$ ineficiente).

Variáveis independentes:

$Z_{1}=$ área colhida, medida em tarefas ( 1 hectare corresponde a 2,3 tarefas)

$Z_{2}=$ idade média dos membros da família que trabalham no imóvel; 
$Z_{3}=$ Escolaridade, medida pela média da última série cursada pelos membros da família que operam na propriedade;

$Z_{4}=$ Grau de inserção no mercado, medida pela proporção do valor da produção destinada ao mercado;

$Z_{5}=$ Fonte de informação alternativa, medida pela assistência semanal a programas agrícolas de rádio.

A variável $Z_{5}$ foi incluída no modelo como variável de classificação. Observe-se que esta variável, como definida, capta mudanças na constante da função. Conforme GREENE (1997) esta variável capta os efeitos marginais de $Z_{5}$ sobre as probabilidades. Estes efeitos marginais são dados pela diferença entre as funções obtidas para os dois valores assumidos por $Z_{5}$.

As matrizes de dados sobre preços e quantidade de produtos e insumos são apresentadas nos anexos A a D. Os dados sobre as variáveis explicativas dos índices de eficiência são mostrados no anexo G.

No conjunto de dados, os vetores de preços de cada observação não apresentam valores para produtos e fatores não utilizados no processo produtivo. Por força do modelo utilizado, os vetores de preços de produtos e insumos para cada observação da amostra têm que apresentar valores estritamente positivos. Nestes casos, adotou-se como pressuposto que os preços tomados para os bens não produzidos e insumos não utilizados pela firma, é igual ao preço médio regional calculado com base nas informações dos produtores para os quais os preços foram diretamente observados. 


\section{RESULTADOS E DISCUSSÃO}

A tabela 07 sumariza os resultados obtidos do teste determinístico de violação do axioma fraco de minimização de custos (WACM). Para as 44 observações da amostra, o número de violações possíveis é igual a 946 [n(n-1)/2]. Foram encontradas 454 violações ou, aproximadamente, $48 \%$ do total possível. Das 44 observações, $90,9 \%$ apresentaram pelo menos uma violação de WACM. Em média, o tamanho das violações foi da ordem de $36,48 \%$, indicando que o custo de cada firma onde se observa violação de WACM é, em média, 36,48\% maior do que o custo mínimo. Estes resultados indicam que, para a amostra como um todo, a hipótese conjunta de concavidade, monotonicidade e aderência à condição minimização de custos deve ser rejeitada.

Para um nível aceitável de erro de medição de $10 \%$, os resultados do teste estocástico apresentaram um erro padrão $\bar{\sigma}$ igual a 51,95, ao nível de significância de 5\%, superior ao esperado (em torno de 20), indicando que não se pode levar em conta apenas os erros de medição para atribuir violação do comportamento de minimização de custo. Deste modo, rejeita-se a hipótese nula de 
que as observações da amostra satisfazem WACM, sugerindo que as violações são de natureza comportamental.

Tabela 07: Violações de WACM: teste determinístico.

\begin{tabular}{|c|c|c|c|c|}
\hline obs & $\begin{array}{r}\text { Violações } \\
\text { Observadas }\end{array}$ & $\begin{array}{l}\text { Violações } \\
\text { Possíveis }\end{array}$ & $\begin{array}{r}\% \text { de } \\
\text { violações } \\
\end{array}$ & $\begin{array}{r}\text { Tamanho médio das } \\
\text { violações (em \%) }\end{array}$ \\
\hline 1 & 3 & 19 & 15,79 & 36,16 \\
\hline 2 & 11 & 25 & 44,00 & 26,79 \\
\hline 3 & 18 & 33 & 54,55 & 24,36 \\
\hline 4 & 6 & 43 & 13,95 & 29,94 \\
\hline 5 & 1 & 3 & 33,33 & 1,79 \\
\hline 6 & 3 & 5 & 60,00 & 30,62 \\
\hline 7 & 13 & 15 & 86,67 & 47,37 \\
\hline 8 & 6 & 27 & 22,22 & 38,57 \\
\hline 9 & 12 & 28 & 42,86 & 27,08 \\
\hline 10 & 19 & 26 & 73,08 & 34,05 \\
\hline 11 & 5 & 42 & 11,90 & 33,68 \\
\hline 12 & 11 & 39 & 28,21 & 30,73 \\
\hline 13 & 22 & 24 & 91,67 & 43,41 \\
\hline 14 & 10 & 41 & 24,39 & 32,54 \\
\hline 15 & 9 & 10 & 90,00 & 47,48 \\
\hline 16 & 9 & 12 & 75,00 & 37,57 \\
\hline 17 & 14 & 21 & 66,67 & 26,02 \\
\hline 18 & 0 & 2 & 0,00 & - \\
\hline 19 & 11 & 38 & 28,95 & 30,60 \\
\hline 20 & 20 & 32 & 62,50 & 27,98 \\
\hline 21 & 5 & 34 & 14,71 & 39,56 \\
\hline 22 & 3 & 11 & 27,27 & 48,98 \\
\hline 23 & 0 & 1 & 0,00 & - \\
\hline 24 & 14 & 18 & 77,78 & $\begin{array}{r}43.18 \\
\text { (continua) }\end{array}$ \\
\hline
\end{tabular}


Tabela 07: Violações de WACM: teste determinístico (continuação).

\begin{tabular}{|c|c|c|c|c|}
\hline obs & $\begin{array}{l}\text { Violações } \\
\text { Observadas }\end{array}$ & $\begin{array}{l}\text { Violações } \\
\text { Possíveis }\end{array}$ & $\begin{array}{r}\% \text { de } \\
\text { violações }\end{array}$ & $\begin{array}{l}\text { Tamanho médio das } \\
\text { violações (em \%) }\end{array}$ \\
\hline 25 & 2 & 9 & 22,22 & 61,40 \\
\hline 26 & 18 & 36 & 50,00 & 23,12 \\
\hline 27 & 14 & 22 & 63,64 & 27,19 \\
\hline 28 & 3 & 7 & 42,86 & 27,85 \\
\hline 29 & 40 & 40 & 100,00 & 70,91 \\
\hline 30 & 8 & 14 & 57,14 & 30,45 \\
\hline 31 & 16 & 16 & 100,00 & 66,97 \\
\hline 32 & 30 & 37 & 81,08 & 39,80 \\
\hline 33 & 1 & 13 & 7,69 & 48,57 \\
\hline 34 & 3 & 29 & 10,34 & 31,61 \\
\hline 35 & 0 & 0 & 0,00 & - \\
\hline 36 & 24 & 30 & 80,00 & 41,68 \\
\hline 37 & 3 & 6 & 50,00 & 32,00 \\
\hline 38 & 7 & 20 & 35,00 & 35,38 \\
\hline 39 & 6 & 23 & 26,09 & 41,93 \\
\hline 40 & 1 & 8 & 12,50 & 50,40 \\
\hline 41 & 0 & 4 & 0,00 & - \\
\hline 42 & 7 & 17 & 41,18 & 33,38 \\
\hline 43 & 25 & 35 & 71,43 & 34,22 \\
\hline 44 & 21 & 31 & 67,74 & 23,89 \\
\hline
\end{tabular}

Fonte dos dados: pesquisa. Cálculos: autor

\subsection{Eficiência técnica e de escala}

Os índices de eficiência técnica para cada observação da amostra, sob retornos constantes (RCE), variáveis 
(RVE) e não crescentes à escala (RNCE), são apresentados na tabela 08 e são resultantes das soluções dadas para o problema de programação linear de funções de distância baseadas nos insumos.

Tabela 08: Índices de eficiência técnica $\left(\theta_{i}\right)$ sob retornos constantes, variáveis e não crescentes à escala, para as observações da amostra.

\begin{tabular}{lrrr}
\hline OBS & $\theta_{i}^{\text {rce }}$ & $\theta_{\mathrm{i}}^{\text {rve }}$ & $\theta_{i}^{\text {rnce }}$ \\
\hline 1 & 1,00000 & 1,00000 & 1,00000 \\
2 & 1,00000 & 1,00000 & 1,00000 \\
3 & 0,29737 & 0,57885 & 0,29737 \\
4 & 0,22967 & 1,00000 & 0,22967 \\
5 & 1,00000 & 1,00000 & 1,00000 \\
6 & 1,00000 & 1,00000 & 1,00000 \\
7 & 1,00000 & 1,00000 & 1,00000 \\
8 & 0,59544 & 0,75096 & 0,59544 \\
9 & 1,00000 & 1,00000 & 1,00000 \\
10 & 1,00000 & 1,00000 & 1,00000 \\
11 & 0,06522 & 0,92005 & 0,06522 \\
12 & 1,00000 & 1,00000 & 1,00000 \\
13 & 1,00000 & 1,00000 & 1,00000 \\
14 & 1,00000 & 1,00000 & 1,00000 \\
15 & 0,31446 & 1,00000 & 1,00000 \\
16 & 1,00000 & 1,00000 & 1,00000 \\
17 & 1,00000 & 1,00000 & 1,00000 \\
18 & 1,00000 & 1,00000 & 1,00000 \\
19 & 1,00000 & 1,00000 & 1,00000 \\
20 & 1,00000 & 1,00000 & 1,00000 \\
21 & 0,07083 & 0,52555 & 0,07083 \\
& & & $(\mathrm{continua})$ \\
& & &
\end{tabular}


Tabela 08: Índices de eficiência técnica $\left(\theta_{\mathrm{i}}\right)$ sob retornos constantes, variáveis e não crescentes à escala, para as observações da amostra (continuação).

\begin{tabular}{|c|c|c|c|}
\hline$\overline{\mathrm{OBS}}$ & $\overline{\theta_{i}^{\text {rce }}}$ & $\theta_{i}^{\text {rve }}$ & $\theta_{\mathrm{i}}^{\text {rnce }}$ \\
\hline 22 & 1,00000 & 1,00000 & 1,00000 \\
\hline 23 & 1,00000 & 1,00000 & 1,00000 \\
\hline 24 & 1,00000 & 1,00000 & 1,00000 \\
\hline 25 & 1,00000 & 1,00000 & 1,00000 \\
\hline 26 & 1,00000 & 1,00000 & 1,00000 \\
\hline 27 & 1,00000 & 1,00000 & 1,00000 \\
\hline 28 & 1,00000 & 1,00000 & 1,00000 \\
\hline 29 & 1,00000 & 1,00000 & 1,00000 \\
\hline 30 & 1,00000 & 1,00000 & 1,00000 \\
\hline 31 & 1,00000 & 1,00000 & 1,00000 \\
\hline 32 & 1,00000 & 1,00000 & 1,00000 \\
\hline 33 & 1,00000 & 1,00000 & 1,00000 \\
\hline 34 & 1,00000 & 1,00000 & 1,00000 \\
\hline 35 & 1,00000 & 1,00000 & 1,00000 \\
\hline 36 & 0,67626 & 0,68047 & 0,67626 \\
\hline 37 & 1,00000 & 1,00000 & 1,00000 \\
\hline 38 & 1,00000 & 1,00000 & 1,00000 \\
\hline 39 & 0,60450 & 0,60586 & 0,60450 \\
\hline 40 & 1,00000 & 1,00000 & 1,00000 \\
\hline 41 & 1,00000 & 1,00000 & 1,00000 \\
\hline 42 & 0,31912 & 0,57266 & 0,31912 \\
\hline 43 & 1,00000 & 1,00000 & 1,00000 \\
\hline 44 & 1,00000 & 1,00000 & 1,00000 \\
\hline Índices médios & 0,86757 & 0,94624 & - \\
\hline Índices mínimos & 0,06522 & 0,52555 & 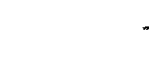 \\
\hline Desvios-padrões & 0,28165 & 0,13501 & - \\
\hline
\end{tabular}

Fonte dos dados: pesquisa. Cálculos:autor 
Os resultados evidenciam que, dada a tecnologia empregada pelos produtores, $79,5 \%$ e $84,1 \%$ das propriedades amostradas são eficientes do ponto de vista técnico, sob RCE e RVE, respectivamente. Em outras palavras, os índices de eficiência técnica indicam que a maioria dos produtores está na fronteira de produção, sugerindo que ganhos de produtividade só seriam possíveis sob uma nova base tecnológica.

Os índices médios de eficiência técnica são da ordem de $86,76 \%$ sob retornos constantes à escala e $94,62 \%$ sob retornos variáveis à escala e, ao nível de significância de 5\%, não diferem estatisticamente entre si.

A relação entre eficiência técnica e o uso da terra ajuda a compreender o número elevado de propriedades na fronteira de produção. A proporção média da área cultivada em relação à área total do imóvel é da ordem de $91,59 \%$ para as observações eficientes $\left(\theta^{\text {rve }}=1\right)$ e de $65,86 \%$ para as observações que são ineficientes $\left(\theta^{\text {rve }}<1\right)$. Estes dados sugerem que, esgotada a possibilidade de aumentar a produção via expansão da área cultivada, os produtores buscam ganhos de produtividade via melhor racionalidade no uso dos insumos.

Admitindo-se retornos constantes à escala, os índices de eficiencia técnica $\left(\theta^{\text {ree }}\right)$ podem conter, como fontes de ineficiência aquelas decorrentes do fato de algumas firmas estarem operando sob retornos crescentes ou decrescentes à escala. Como já descrito na metodologia, a razão entre os índices de eficiência técnica sob retornos constantes e variáveis à escala, é tomada como uma medida de eficiência de escala $\left(\psi_{\mathrm{i}}\right)$. Estes índices de eficiência de escala são apresentados na tabela 09 . 
Tabela 09: Índices de eficiência de escala $\left(\psi_{\mathrm{i}}\right)$.

\begin{tabular}{|c|c|c|}
\hline$\overline{\mathrm{OBS}}$ & $\psi_{\mathrm{i}}$ & Retornos à escala \\
\hline 1 & 1,00000 & Constantes \\
\hline 2 & 1,00000 & Constantes \\
\hline 3 & 0,51373 & Crescentes \\
\hline 4 & 0,22967 & Crescentes \\
\hline 5 & 1,00000 & Constantes \\
\hline 6 & 1,00000 & Constantes \\
\hline 7 & 1,00000 & Constantes \\
\hline 8 & 0,79291 & Crescentes \\
\hline 9 & 1,00000 & Constantes \\
\hline 10 & 1,00000 & Constantes \\
\hline 11 & 0,07089 & Crescentes \\
\hline 12 & 1,00000 & Constantes \\
\hline 13 & 1,00000 & Constantes \\
\hline 14 & 1,00000 & Constantes \\
\hline 15 & 0,31446 & Decrescentes \\
\hline 16 & 1,00000 & Constantes \\
\hline 17 & 1,00000 & Constantes \\
\hline 18 & 1,00000 & Constantes \\
\hline 19 & 1,00000 & Constantes \\
\hline 20 & 1,00000 & Constantes \\
\hline 21 & 0,13477 & Crescentes \\
\hline 22 & 1,0000 & Constantes \\
\hline 23 & 1,00000 & Constantes \\
\hline 24 & 1,00000 & Constantes \\
\hline 25 & 1,00000 & Constantes \\
\hline 26 & 1,00000 & Constantes \\
\hline 27 & 1,00000 & Constantes \\
\hline 28 & 1,00000 & $\begin{array}{r}\text { Constantes } \\
\text { (continua) }\end{array}$ \\
\hline
\end{tabular}


Tabela 09: Índices de eficiência de escala $\left(\psi_{\mathrm{i}}\right)$ (continuação).

\begin{tabular}{lrr}
\hline OBS & $\psi_{\mathrm{i}}$ & Retornos à escala \\
\hline 29 & 1,00000 & Constantes \\
30 & 1,00000 & Constantes \\
31 & 1,00000 & Constantes \\
32 & 1,00000 & Constantes \\
33 & 1,00000 & Constantes \\
34 & 1,00000 & Constantes \\
35 & 1,00000 & Constantes \\
36 & 0,99381 & Crescentes \\
37 & 1,00000 & Constantes \\
38 & 1,00000 & Constantes \\
39 & 0,99776 & Crescentes \\
40 & 1,00000 & Constantes \\
41 & 1,00000 & Constantes \\
42 & 0,55726 & Crescentes \\
43 & 1,00000 & Constantes \\
44 & 1,00000 & Constantes \\
\hline Índices médios & 0,90012 & - \\
Índices mínimos & 0,07089 & - \\
Desvios-padrões & 0,25112 & - \\
\hline Fonte dos das: & & \\
\hline
\end{tabular}

Fonte dos dados: pesquisa. Cálculos: autor

As firmas eficientes em escala apresentam $\psi_{\mathrm{i}}=1$ (retornos constantes) e as ineficientes, $\psi_{i}<1$. Como já observado, para verificar se as firmas escala-ineficientes estão operando sob retornos crescentes ou decrescentes comparam-se os índices de eficiência técnica sob retornos constantes com aqueles obtidos sob a pressuposição de retornos não crescentes à escala $\left(4^{a}\right.$ coluna da tabela 08$)$. 
Do total da amostra 9 firmas $(20,5 \%)$ apresentaram ineficiência de escala sendo que, destas, 8 estão operando sob retornos crescentes e apenas uma sob retornos decrescentes à escala. Estes resultados indicam que as firmas que estão na região de retornos crescentes à escala poderão ganhar eficiência técnica se aumentarem o tamanho da produção e, para tanto, seria necessário aumentar o tamanho do imóvel já que a área disponível não utilizada atual é minima ou nula. No caso da observação operando sob retornos decrescentes, ganhos de eficiência adviriam da redução do tamanho da produção. Os resultados mostram que, em média, a insuficiente escala de operação é a maior fonte de ineficiência técnica.

Os índices de eficiência técnica $(\theta)$ são interpretados como a redução equiproporcional nos insumos que ainda assim permitiria à firma obter o mesmo nível de produto se utilizasse a eficiência das suas unidades de referência.

Nas tabelas 10 e 11 são mostrados, respectivamente, os valores de $\lambda$ sob retornos constantes e variáveis à escala, para cada observação tecnicamente ineficiente da amostra em relação às suas unidades de referência.

Admitindo-se que as firmas ineficientes seguissem o exemplo de suas unidades de referência pode-se calcular as "folgas" de produtos e insumos a partir das inequações de oferta de produtos e demanda de insumos do problema de programação linear da função de eficiência técnica. Para cada insumo, a folga é dada

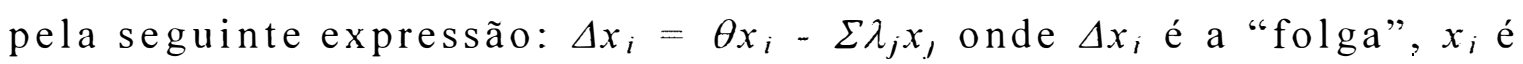
a quantidade do insumo usada pela firma $i$ e $x_{j}$ as quantidades de insumos usadas pelas unidades de referência $j$. 
Tabela 10: Valores de $\lambda^{(*)}$ para as observações tecnicamente ineficientes, sob retornos constantes à escala.

\begin{tabular}{|c|c|c|c|c|c|c|c|c|c|c|c|c|c|}
\hline \multirow{2}{*}{\multicolumn{2}{|c|}{$\begin{array}{c}\text { OBS Eficiência } \\
\text { técnica }\end{array}$}} & \multicolumn{12}{|c|}{ Valores de $\lambda_{i}^{(*)}$} \\
\hline & & $\lambda_{1}$ & $\lambda_{5}$ & $\lambda_{13}$ & $\lambda_{20}$ & $\lambda_{27}$ & $\lambda_{28}$ & $\lambda_{32}$ & $\lambda_{33}$ & $\lambda_{35}$ & $\lambda_{37}$ & $\lambda_{38}$ & $\lambda_{41}$ \\
\hline 03 & 0,29737 & & & 0,090 & & & & & 0,214 & & 0,038 & & 0,023 \\
\hline 04 & 0,22967 & & & 0,029 & & & & & & & & & 0,019 \\
\hline 08 & 0,59544 & & 0,365 & & 0,113 & & & & & & & & \\
\hline 11 & 0,06522 & & & & & & & & & & 0,010 & & 0,019 \\
\hline 15 & 0,31446 & 0,343 & & & & & 0,033 & & & & & 0,067 & 1,000 \\
\hline 21 & 0,07083 & & & & & 0,032 & & & & & & & 0,059 \\
\hline 36 & 0,67626 & & & & & & & 0,617 & 0,203 & & & & 0,098 \\
\hline 39 & 0,60450 & & & & & & & & 0,821 & & 0,160 & & 0,013 \\
\hline 42 & 0,31912 & & 0,060 & & & & & & 0,119 & 0,084 & & & \\
\hline
\end{tabular}

Fonte dos dados: pesquisa. Cálculos: autor.

(*) Os índices indicam as unidades de referência. Para as observações i eficientes, $\lambda_{i}=1$ e $\lambda_{j}=0, i \neq j$.

Tabela 11: Valores de $\lambda^{(*)}$ para as observações tecnicamente ineficientes, sob retornos variáveis à escala.

\begin{tabular}{|c|c|c|c|c|c|c|c|c|c|c|c|c|}
\hline \multirow[t]{2}{*}{ OBS } & \multirow{2}{*}{$\begin{array}{c}\text { Eficiência } \\
\text { técnica }\end{array}$} & \multicolumn{11}{|c|}{ Valores de $\lambda_{i}{ }^{\left({ }^{*}\right)}$} \\
\hline & & $\lambda_{1}$ & $\lambda_{4}$ & $\lambda_{5}$ & $\lambda_{9}$ & $\lambda_{20}$ & $\lambda_{32}$ & $\lambda_{33}$ & $\lambda_{34}$ & $\lambda_{35}$ & $\lambda_{37}$ & $\lambda_{41}$ \\
\hline 3 & 0,57885 & & 0,493 & & & & & 0,433 & & & 0,072 & 0,001 \\
\hline 8 & 0,75096 & & & 0,332 & & 0,158 & & & & & & 0,511 \\
\hline 11 & 0,92005 & 0,346 & & & & 0,093 & & & 0,552 & & & 0,009 \\
\hline 21 & 0,52555 & & & & & & & 0,642 & & & & 0,358 \\
\hline 36 & 0,68047 & & & & 0,119 & & 0,544 & 0,204 & & & & 0,133 \\
\hline 39 & 0,60586 & & & & & & & 0,821 & 0,009 & & 0,156 & 0,013 \\
\hline 42 & 0,57266 & 0,150 & & & & & & 0,230 & & 0,100 & & 0,520 \\
\hline
\end{tabular}

Fonte dos dados: pesquisa. Cálculos: autor.

$\left.{ }^{*}\right)$ Os indices indicam as unidades de referência. Para as observações i eficientes, $\lambda_{i}=1$ e $\lambda_{j}=0, i \neq j$. 
Tome-se, por exemplo, a observação 21, com um indice de eficiência técnica, sob retornos variáveis à escala, igual a 0,52555 . Suas unidades de referência são as observações 33 e 41 com valores de $\lambda$ iguais a 0,642 e 0,358 , respectivamente. Tomando-se as quantidades dos fatores utilizados pelas observações 33 e 41 teríamos que a firma 21 poderia obter o mesmo nível de produto poupando 3,6 toneladas de esterco e 4 sacos de fertilizante químico.

As "folgas" de produtos e fatores para as propriedades tecnicamente ineficientes são sumarizadas nas tabelas 12 e 13.

Tabela 12: Acréscimo no produto das propriedades ineficientes levando em conta suas unidades de referência.

\begin{tabular}{|c|c|c|c|c|c|c|c|c|c|}
\hline & $\mathrm{Obs}$ & $\begin{array}{l}\text { Amendoim } \\
\text { (sc } 50 \mathrm{~kg})\end{array}$ & $\begin{array}{l}\text { Farinha } \\
\text { (sc. } 60\end{array}$ & $\begin{array}{l}\text { Feijão } \\
\text { (sc } 60\end{array}$ & $\begin{array}{r}\text { Fumo } \\
\text { (arroba) }\end{array}$ & $\begin{array}{l}\text { Inhame } \\
(\mathrm{kg})\end{array}$ & $\begin{array}{l}\text { Laranja } \\
\text { (cento) }\end{array}$ & $\begin{array}{c}\text { Limão } \\
\text { (cento) }\end{array}$ & $\begin{array}{l}\text { Mandioca } \\
\text { (tonelada) }\end{array}$ \\
\hline \multirow{9}{*}{ RCE } & 3 & 6,000 & 0 & 0 & 5,157 & 150,000 & 6,311 & 0 & 4,000 \\
\hline & 4 & 0 & 0 & 0 & 0,431 & 0 & 2,010 & 0 & 2,000 \\
\hline & 8 & 0 & 36,000 & 0 & 0 & 0 & 292,061 & 0 & 0 \\
\hline & 11 & 0 & 0 & 0 & 0,978 & 0 & 0 & 0 & 2,000 \\
\hline & 15 & 0,669 & 0 & 0 & 3,300 & 0 & 150,000 & 31,339 & 100,000 \\
\hline & 21 & 0 & 0 & 0 & 0,552 & 0 & 0 & 3,896 & 6,000 \\
\hline & 36 & 10,000 & 0 & 0 & 0 & 142,015 & 0 & 0 & 12,000 \\
\hline & 39 & 23,000 & 0 & 0 & 16,000 & 575,000 & 0 & 0 & 7,000 \\
\hline & 42 & 5,000 & 30,000 & 0 & 0 & 166,946 & 50,000 & 0 & 0,593 \\
\hline \multirow{7}{*}{ RVE } & 3 & 12,128 & 0 & 0 & 7,245 & 303,203 & 0 & 0 & 4,000 \\
\hline & 8 & 0 & 36,000 & 0 & 0 & 0 & 265,478 & 0 & 51,062 \\
\hline & 11 & 0 & 5,593 & 0 & 22,081 & 110,654 & 34,597 & 0 & 2,000 \\
\hline & 21 & 17,985 & 0 & 0 & 0 & 449,635 & 0 & 0 & 38,978 \\
\hline & 36 & 10,000 & 0 & 0,357 & 0 & 142,899 & 0 & 0 & 15,450 \\
\hline & 39 & 23,000 & 0 & 0 & 16,000 & 575,000 & 0 & 0 & 7,000 \\
\hline & 42 & 8,427 & 30,000 & 0 & 0 & 260,678 & 0 & 15,000 & 53,194 \\
\hline
\end{tabular}

Fonte dos dados: pesquisa. Cálculos: autor. 
Para a amostra como um todo, se as propriedades tecnicamente ineficientes buscassem o benchmarking em suas unidades de referência, os acréscimos no produto, sob retornos contantes e variáveis à escala seriam, respectivamente, da ordem de $38,8 \%$ e $62,2 \%$ para amendoim, 9,7\% e $10,5 \%$ para farinha, $0 \%$ e $2 \%$ para feijão, $3,7 \%$ e $6,3 \%$ para fumo, $49,2 \%$ e $87,8 \%$ para inhame, $8,6 \%$ e $5,2 \%$ para laranja, $4,6 \%$ e $2 \%$ para limão e $32 \%$ e $41,1 \%$ para mandioca.

Tabela 13: Redução no uso de fatores das propriedades ineficientes levando em conta as suas unidades de referência, retornos constantes e variáveis à escala.

\begin{tabular}{|c|c|c|c|c|c|c|c|c|}
\hline & $\mathrm{Obs}$ & $\begin{array}{r}\text { Esterco } \\
\text { de gado } \\
\text { (tonelada) }\end{array}$ & $\begin{array}{l}\text { Formicida } \\
\qquad(\mathrm{kg})\end{array}$ & $\begin{array}{l}\text { Aluguel } \\
\text { de trator } \\
\text { (horas) }\end{array}$ & $\begin{array}{c}\text { Inseticida } \\
\text { (litro) }\end{array}$ & $\begin{array}{l}\text { Mão-de-obra } \\
\text { (Homens/dia) }\end{array}$ & $\begin{array}{r}\text { NPK } \\
(\mathrm{sc} 50 \mathrm{~kg})\end{array}$ & $\begin{array}{r}\text { Torta de } \\
\text { mamona } \\
(\mathrm{sc} 50 \mathrm{~kg})\end{array}$ \\
\hline \multirow{9}{*}{$\mathrm{RCE}$} & 3 & 1,443 & 0 & 0,740 & 0 & 0 & 0 & 0 \\
\hline & 4 & 0 & 0 & 0 & 0 & 38,947 & 0 & 0 \\
\hline & 8 & 0 & 0 & 2,382 & 0 & 0 & 0 & 0 \\
\hline & 11 & 0 & 0 & 0,157 & 0 & 10,870 & 0 & 0 \\
\hline & 15 & 2,169 & 0 & 0 & 0,182 & 0 & 2,146 & 0 \\
\hline & 21 & 0,047 & 0 & 0 & 0 & 0 & 0,384 & 0 \\
\hline & 36 & 0 & 9,579 & 0 & 0 & 0 & 0,947 & 0 \\
\hline & 39 & 0,085 & 19,428 & 1,778 & 0 & 0 & 2,411 & 0 \\
\hline & 42 & 2,350 & 1,322 & 2,688 & 0 & 0 & 0,939 & 0 \\
\hline \multirow{7}{*}{ RVE } & 3 & 3,704 & 0 & 1,447 & 0 & 0 & 0 & 0 \\
\hline & 8 & 0 & 0 & 3,004 & 0 & 0 & 0 & 0 \\
\hline & 11 & 0 & 0 & 0 & 0 & 0 & 0 & 0 \\
\hline & 21 & 3,562 & 0 & 0 & 0 & 0 & 3,971 & 0 \\
\hline & 36 & 0 & 8,791 & 0 & 0 & 0 & 0 & 0 \\
\hline & 39 & 0,087 & 24,427 & 1,751 & 0 & 0 & 2,449 & 0 \\
\hline & 42 & 4,252 & 0 & 5,127 & 0 & 0 & 1,904 & 0 \\
\hline
\end{tabular}

Fonte dos dados: Pesquisa. Cálculos: autor 
Quanto aos fatores de produção, as reduções nos níveis de utilização, sob retornos constantes e variáveis à escala, seriam, respectivamente, da ordem de $4,0 \%$ e $7,6 \%$ para esterco de gado, $5,4 \%$ e $5,1 \%$ para formicidas, $13,1 \%$ e $19,2 \%$ para trator e $2,8 \%$ e $3,4 \%$ para fertilizantes químicos. Inseticidas, mão-de-obra familiar e torta de mamona seriam mantidos, aproximadamente, nos mesmos níveis observados. Isto ocorre porque, no plano ótimo, o acréscimo no produto seria maior para as culturas intensivas no uso de mão-de-obra (inhame, amendoim e mandioca) e por ser a torta de mamona um insumo importante para a cultura do fumo.

\subsection{Eficiência alocativa e de custo}

Os índices de eficiência alocativa e de custo, como descrito na metodologia, são obtidos a partir da estimativa de funções de custo mínimo e de funções de distância baseada nos insumos para cada observação da amostra. Estes índices são mostrados na tabela 14 , juntamente com os índices de eficiência técnica e de escala, sob as condições de retornos constantes à escala.

Sob retornos constantes à escala, 11 observações (25\%) são preço-eficientes $(\phi=1)$ ou seja, dados os preços tomados pelos produtores, a combinação de fatores empregadas na produção é aquela que minimiza os custos. Observa-se que $31,4 \%$ das propriedades tecnicamente eficientes são, também, eficientes em relação à alocação fatores e, portanto, com índice de eficiência total igual a 1 . 
Tabela 14: Custo mínimo e índices de eficiência técnica, de escala, alocativa e agregada sob retornos constantes à escala.

\begin{tabular}{lrrrrr}
\hline Obs & Custo mínimo & \multicolumn{4}{c}{ Índices de eficiência } \\
\hline 1 & 1181,50 & técnica pura & escala & alocativa & total \\
2 & 1,00000 & 1,00000 & 1,00000 & 1,00000 \\
3 & 1398,88 & 1,00000 & 1,00000 & 0,64944 & 0,64944 \\
4 & 194,81 & 0,57885 & 0,51373 & 0,28884 & 0,08589 \\
5 & 9,66 & 1,00000 & 0,22967 & 0,02967 & 0,00681 \\
6 & 1894,23 & 1,00000 & 1,00000 & 1,00000 & 1,00000 \\
7 & 2010,33 & 1,00000 & 1,00000 & 1,00000 & 1,00000 \\
8 & 3135,04 & 1,00000 & 1,00000 & 1,00000 & 1,00000 \\
9 & 405,69 & 0,75096 & 0,79291 & 0,41716 & 0,24839 \\
10 & 1600,96 & 1,00000 & 1,00000 & 0,86583 & 0,86583 \\
11 & 1290,45 & 1,00000 & 1,00000 & 0,51804 & 0,51804 \\
12 & 7,36 & 0,92005 & 0,07089 & 0,10488 & 0,00684 \\
13 & 254,51 & 1,00000 & 1,00000 & 0,12054 & 0,12054 \\
14 & 345,02 & 1,00000 & 1,00000 & 0,10463 & 0,10463 \\
15 & 230,64 & 1,00000 & 1,00000 & 0,11120 & 0,11120 \\
16 & 791,05 & 1,00000 & 0,31446 & 0,70632 & 0,22211 \\
17 & 999,32 & 1,00000 & 1,00000 & 0,36659 & 0,36659 \\
18 & 559,53 & 1,00000 & 1,00000 & 0,27334 & 0,27334 \\
19 & 1922,10 & 1,00000 & 1,00000 & 1,00000 & 1,00000 \\
20 & 501,96 & 1,00000 & 1,00000 & 0,28311 & 0,28311 \\
21 & 682,82 & 1,00000 & 1,00000 & 0,31365 & 0,31365 \\
22 & 23,38 & 0,52555 & 0,13477 & 0,26224 & 0,01857 \\
23 & 920,35 & 1,00000 & 1,00000 & 0,51296 & 0,51296 \\
24 & 2779,85 & 1,00000 & 1,00000 & 0,99396 & 0,99396 \\
25 & 1056,29 & 1,00000 & 1,00000 & 0,30877 & 0,30877 \\
& 1755,00 & 1,00000 & 1,00000 & 1,00000 & 1,00000 \\
& & & & & $(\mathrm{con}$ tinua)
\end{tabular}


Tabela 14: Custo mínimo e índices de eficiência técnica, de escala, alocativa e agregada sob retornos constantes à escala (continuação).

\begin{tabular}{lrrrrr}
\hline \multirow{2}{*}{ Obs } & Custo mínimo & \multicolumn{4}{c}{ Índices de eficiência } \\
\hline 26 & 1370,00 & 1,00000 & 1,00000 & 1,00000 & 1,00000 \\
27 & 870,40 & 1,00000 & 1,00000 & 0,57449 & 0,57449 \\
28 & 1617,39 & 1,00000 & 1,00000 & 0,76112 & 0,76112 \\
29 & 1942,73 & 1,00000 & 1,00000 & 0,22741 & 0,22741 \\
30 & 601,77 & 1,00000 & 1,00000 & 0,27478 & 0,27478 \\
31 & 2774,67 & 1,00000 & 1,00000 & 0,49622 & 0,49622 \\
32 & 173,34 & 1,00000 & 1,00000 & 0,06352 & 0,06352 \\
33 & 840,00 & 1,00000 & 1,00000 & 1,00000 & 1,00000 \\
34 & 574,74 & 1,00000 & 1,00000 & 0,60359 & 0,60359 \\
35 & 3773,73 & 1,00000 & 1,00000 & 1,00000 & 1,00000 \\
36 & 342,70 & 0,68047 & 0,99381 & 0,15177 & 0,10263 \\
37 & 1675,44 & 1,00000 & 1,00000 & 0,74135 & 0,74135 \\
38 & 1156,55 & 1,00000 & 1,00000 & 0,73426 & 0,73426 \\
39 & 794,33 & 0,60586 & 0,99776 & 0,80653 & 0,48755 \\
40 & 568,38 & 1,00000 & 1,00000 & 0,76601 & 0,76601 \\
41 & 420,00 & 1,00000 & 1,00000 & 1,00000 & 1,00000 \\
42 & 560,66 & 0,57266 & 0,55726 & 0,81949 & 0,26152 \\
43 & 225,45 & 1,00000 & 1,00000 & 0,10092 & 0,10092 \\
44 & 2288,00 & 1,00000 & 1,00000 & 1,00000 & 1,00000 \\
\hline Média & 1102,75 & 0,94624 & 0,90012 & 0,47626 & 0,52741 \\
\hline 26 & & & & &
\end{tabular}

Fonte dos dados: pesquisa. Cálculos: autor

O índice médio de eficiência alocativa é da ordem de $57,6 \%$. Os índices de eficiência alocativa para as propriedades ineficientes variam de $2,97 \%$ a $99,4 \%$. A tabela 15 sumariza os 
resultados encontrados para a amostra utilizando a classificação proposta por Ray \& Bhadra (1993) quanto à minimização de custos.

Tabela 15: Grau de eficiencia alocativa das propriedades da amostra segundo o critério de Ray \& Bhadra (1993).

\begin{tabular}{lrr}
\hline Grau de eficiência & $\mathrm{N}^{0}$ observações & $\%$ \\
\hline Eficientes $(\phi=1)$ & 11 & 25,0 \\
Ineficiência fraca $(0,9 \leq \phi<1)$ & 1 & 2,3 \\
Ineficiência moderada $(0,7 \leq \phi<0,9)$ & 8 & 18,2 \\
Ineficiência forte $(\phi<0,7)$ & 24 & 54,5 \\
\hline
\end{tabular}

Na tabela 16 o critério de Ray \& Bhadra (1993) foi adaptado para classificar as propriedades considerando-se os índices de eficiência técnica e alocativa obtidos.

Tabela 16: Classificação das propriedades amostradas de acordo com os índices de eficiência técnica e alocativa.

\begin{tabular}{cccr}
\hline Eficiência técnica & Eficiência alocativa & Observações & $\%$ \\
\hline$\theta=1$ & $\phi=1$ & 11 & 25,0 \\
$\theta=1$ & $0,9 \leq \phi<1$ & 1 & 2,3 \\
$\theta=1$ & $0,7 \leq \phi<0,9$ & 5 & 11,4 \\
$\theta=1$ & $\phi<0,7$ & 18 & 40,9 \\
$0,9 \leq \theta<1$ & $\phi<0,7$ & 0 & 0 \\
$0,7 \leq \theta<0,9$ & $\phi<0,7$ & 0 & 0 \\
$\theta<0,7$ & $0,7 \leq \phi<0,9$ & 3 & 6,8 \\
$\theta<0,7$ & $\phi<0,7$ & 6 & 13,6 \\
\hline
\end{tabular}


Os resultados acima mostram que, para o caso em estudo, as pequenas propriedades familiares são, em sua maioria, eficientes do ponto de vista técnico e ineficientes do ponto de vista alocativo. Dentre as observações tecnicamente eficientes, $68,5 \%$ são preço-ineficientes, indicando que ganhos de eficiência total (eficiência de custos) poderão ser obtidos se as decisões quanto à alocação dos recursos levarem em conta a relação de preço dos fatores.

De modo semelhante à eficiência técnica, as propriedades custo-ineficientes podem obter ganhos de eficiência econômica seguindo o exemplo de suas unidades de referência dadas pelo problema de minimização de custo (tabela 17). Observase que as propriedades 41,6 e 18 são as mais influentes para o benchmarking das propriedades ineficientes. Para o total da amostra, se as firmas ineficientes seguissem o exemplo de suas unidades de referência, os incrementos nos produtos seriam da ordem de 26,2\% para amendoim, 7,7\% para fumo, $118,8 \%$ para inhame, 12,6\% para laranja e 15,4\% para mandioca. A produção de farinha de mandioca, feijão e limão permaneceriam nos mesmos níveis observados. A redução no uso de fatores seria da ordem de $72,2 \%$ para esterco de gado, 24,5\% para formicidas, 20,49\% para trator, 51,74\% para mão de obra familiar e $69,78 \%$ para fertilizantes químicos (NPK); os níveis de utilização de inseticidas e torta de mamona aumentariam em $55,7 \%$ e $124,25 \%$, respectivamente. Estes resultados indicam que, dadas as relações de preços observadas por cada firma, os produtores ineficientes minimizariam seus custos substituindo esterco de gado e fertilizantes químicos por torta de mamona. O aumento no uso de inseticidas pode estar associado à redução do uso da mão-de-obra, 
considerando que quanto maior a intensidade do trabalho, maior a vigilância sanitária nas culturas e a erradicação de focos de pragas.

As variações no uso dos fatores e na produção para cada observação da amostra são apresentadas nos anexos E e F.

Tabela 17: Unidades de referência e valores de $\lambda^{*}$ resultantes da minimização de custos sob retornos constantes à escala.

\begin{tabular}{|c|c|c|c|c|c|c|c|c|c|c|c|}
\hline \multirow{2}{*}{ OBS } & \multicolumn{11}{|c|}{ Unidades de referência } \\
\hline & $\lambda_{1}$ & $\lambda_{5}$ & $\lambda_{6}$ & $\lambda_{7}$ & $\lambda_{18}$ & $\lambda_{25}$ & $\lambda_{26}$ & $\lambda_{33}$ & $\lambda_{35}$ & $\lambda_{41}$ & $\lambda_{44}$ \\
\hline 1 & 1,000 & & & & & & & & & & \\
\hline 2 & 0,607 & & & & & 0,262 & & 0,286 & & & \\
\hline 3 & & & & & & & & 0,214 & & 0,029 & \\
\hline 4 & & & & & & & & & & 0,020 & \\
\hline 5 & & 1,000 & & & & & & & & & \\
\hline 6 & & & 1,000 & & & & & & & & \\
\hline 7 & & & & 1,000 & & & & & & & \\
\hline 8 & & & & & & & & & 0,120 & & \\
\hline 9 & & & 0,300 & & & & & 0,143 & & & 0,500 \\
\hline 10 & 1,000 & & & & & & & & 0,090 & & \\
\hline 11 & & & & & & & & & & 0,020 & \\
\hline 12 & & & & & & & & 0,286 & & 0,006 & \\
\hline 13 & & & 0,070 & & 0,115 & & & & & 0,026 & \\
\hline 14 & 0,021 & & & & & 0,017 & 0,077 & & & & \\
\hline 15 & & & 0,150 & & 0,025 & & & & & 0,991 & \\
\hline 16 & & & 0,500 & & & & & & & 0,020 & \\
\hline 17 & & & 0,150 & & 0,154 & & & & & & \\
\hline 18 & & & & & 1,000 & & & & & & \\
\hline 19 & & & & & & 0,182 & 0,114 & & & & atinua) \\
\hline
\end{tabular}


Tabela 17: Unidades de referência e valores de $\lambda^{*}$ resultantes da minimização de custos sob retornos constantes à escala (continuação).

\begin{tabular}{|c|c|c|c|c|c|c|c|c|c|c|c|}
\hline \multirow{2}{*}{ OBS } & \multicolumn{11}{|c|}{ Unidades de referência } \\
\hline & $\lambda_{1}$ & $\lambda_{5}$ & $\lambda_{6}$ & $\lambda_{7}$ & $\lambda_{18}$ & $\lambda_{25}$ & $\lambda_{26}$ & $\lambda_{33}$ & $\lambda_{35}$ & $\lambda_{41}$ & $\lambda_{44}$ \\
\hline 20 & & & & & & & & & 0,200 & & \\
\hline 21 & & & & & & & & & & 0,060 & \\
\hline 22 & & & & & 0,500 & & & & & & \\
\hline 23 & & 0,305 & & & 0,615 & & & & 0,319 & & \\
\hline 24 & & & 0,500 & & & & & & & 0,030 & \\
\hline 25 & & & & & & 1,000 & & & & & \\
\hline 26 & & & & & & & 1,000 & & & & \\
\hline 27 & 0,041 & & & & & 0,773 & & & & & \\
\hline 28 & & & & & 0,769 & & & & & & \\
\hline 29 & & & & & & & & & & & 0,833 \\
\hline 30 & & & & & 0,268 & & & & & 0,050 & \\
\hline 31 & & & & & & & & & 0,100 & & 1,333 \\
\hline 32 & & & & & & & & 0,250 & & 0,007 & \\
\hline 33 & & & & & & & & & 1,000 & & \\
\hline 34 & & & & & 0,308 & & & & & 0,020 & \\
\hline 35 & & & & & & & & & 1,000 & & \\
\hline 36 & & & & & & & & 0,357 & & 0,102 & \\
\hline 37 & & & & & 0,769 & & & & & 0,100 & \\
\hline 38 & & & 0,600 & & & & & 0,357 & & & \\
\hline 39 & & & & & 0,123 & & & 0,821 & & 0,029 & \\
\hline 40 & & & & & 0,115 & & & & & 1,000 & \\
\hline 41 & & & & & & & & & & 1,000 & \\
\hline 42 & & 0,006 & & & & & & 0,119 & 0,084 & & \\
\hline 43 & & & 0,150 & & & & & & & & \\
\hline 44 & & & & & & & & & & & 1,000 \\
\hline
\end{tabular}


Como descrita na metodologia a ineficiência de custos (ineficiência econômica ou total) pode ser decomposta nos efeitos técnico, de escala e alocativo. Esta decomposição é mostrada na tabela 18 .

Tabela 18: Decomposição da ineficiência econômica nos efeitos técnico, de escala e alocativo (em reais).

\begin{tabular}{lrrrr}
\hline OBS & Ineficiência & \multicolumn{3}{c}{ Fontes de ineficiência (em reais) } \\
\hline 1 & Econômica & Técnica & De escala & Alocativa \\
2 & 0,00 & 0,00 & 0,00 & 0,00 \\
3 & 755,10 & 0,00 & 0,00 & 755,10 \\
4 & 2073,23 & 955,19 & 638,41 & 479,64 \\
5 & 1408,64 & 0,00 & 1092,56 & 316,08 \\
6 & 0,00 & 0,00 & 0,00 & 0,00 \\
7 & 0,00 & 0,00 & 0,00 & 0,00 \\
8 & 0,00 & 0,00 & 0,00 & 0,00 \\
9 & 1227,56 & 406,74 & 254,00 & 566,81 \\
10 & 248,08 & 0,00 & 0,00 & 248,08 \\
11 & 1200,55 & 0,00 & 0,00 & 1200,55 \\
12 & 1068,65 & 86,03 & 919,81 & 62,82 \\
13 & 1856,99 & 0,00 & 0,00 & 1856,99 \\
14 & 2952,49 & 0,00 & 0,00 & 2952,49 \\
15 & 1843,37 & 0,00 & 0,00 & 1843,37 \\
16 & 2770,51 & 0,00 & 2441,59 & 328,92 \\
17 & 1726,68 & 0,00 & 0,00 & 1726,68 \\
18 & 1487,47 & 0,00 & 0,00 & 1487,47 \\
19 & 0,00 & 0,00 & 0,00 & 0,00 \\
20 & 1271,04 & 0,00 & 0,00 & 1271,04 \\
21 & 1494,18 & 0,00 & 0,00 & 1494,18 \\
22 & 1235,12 & 597,10 & 572,27 & 65,76 \\
23 & 873,83 & 0,00 & 0,00 & 873,83 \\
24 & 16,90 & 0,00 & 0,00 & 16,90 \\
& 2364,71 & 0,00 & 0,00 & 2364,71 \\
& & & & $($ continua)
\end{tabular}


Tabela 18: Decomposição da ineficiência econômica nos efeitos técnico, de escala e alocativo (em reais) (continuação).

\begin{tabular}{lrrrr}
\hline \multirow{2}{*}{ OBS } & \multicolumn{1}{c}{$\begin{array}{l}\text { Ineficiência } \\
\text { Econômica }\end{array}$} & \multicolumn{3}{c}{ Fontes de ineficiência } \\
\cline { 2 - 5 } 25 & 0,00 & 0,00 & 0,00 & Alocativa \\
26 & 0,00 & 0,00 & 0,00 & 0,00 \\
27 & 644,68 & 0,00 & 0,00 & 644,68 \\
28 & 507,62 & 0,00 & 0,00 & 507,62 \\
29 & 6600,29 & 0,00 & 0,00 & 6600,29 \\
30 & 1588,23 & 0,00 & 0,00 & 1588,23 \\
31 & 2816,99 & 0,00 & 0,00 & 2816,99 \\
32 & 2555,66 & 0,00 & 0,00 & 2555,66 \\
33 & 0,00 & 0,00 & 0,00 & 0,00 \\
34 & 377,46 & 0,00 & 0,00 & 377,46 \\
35 & 0,00 & 0,00 & 0,00 & 0,00 \\
36 & 2996,30 & 1066,91 & 14,06 & 1915,34 \\
37 & 584,56 & 0,00 & 0,00 & 584,56 \\
38 & 418,57 & 0,00 & 0,00 & 418,57 \\
39 & 834,90 & 642,15 & 2,22 & 190,54 \\
40 & 173,62 & 0,00 & 0,00 & 173,62 \\
41 & 0,00 & 0,00 & 0,00 & 0,00 \\
42 & 1583,24 & 916,17 & 543,56 & 123,50 \\
43 & 2008,55 & 0,00 & 0,00 & 2008,55 \\
44 & 0,00 & 0,00 & 0,00 & 0,00 \\
\hline Total & 51565,75 & 4670,28 & 6478,47 & 40416,99 \\
Media & 1171,95 & 106,14 & 147,24 & 918,57 \\
$\%$ de ineficiência & 100,00 & 9,06 & 12,56 & 78,38 \\
\hline Fon & 5 & & &
\end{tabular}

Fonte dos dados: pesquisa. Cálculos: autor

Os resultados indicam que $78,4 \%$ da ineficiência total da amostra são devidas à ineficiência na alocação dos recursos produtivos. Estes resultados são, como esperado, coerentes com o teste de violação do axioma fraco de minimização de custos. 
As receitas e custos observados e otimizados pela solução do problema de minimização de custos, e suas respectivas variações, são mostrados na tabela 19.

Tabela 19: Receitas e custos observados e otimizados pela minimização de custos sob retornos constantes à escala.

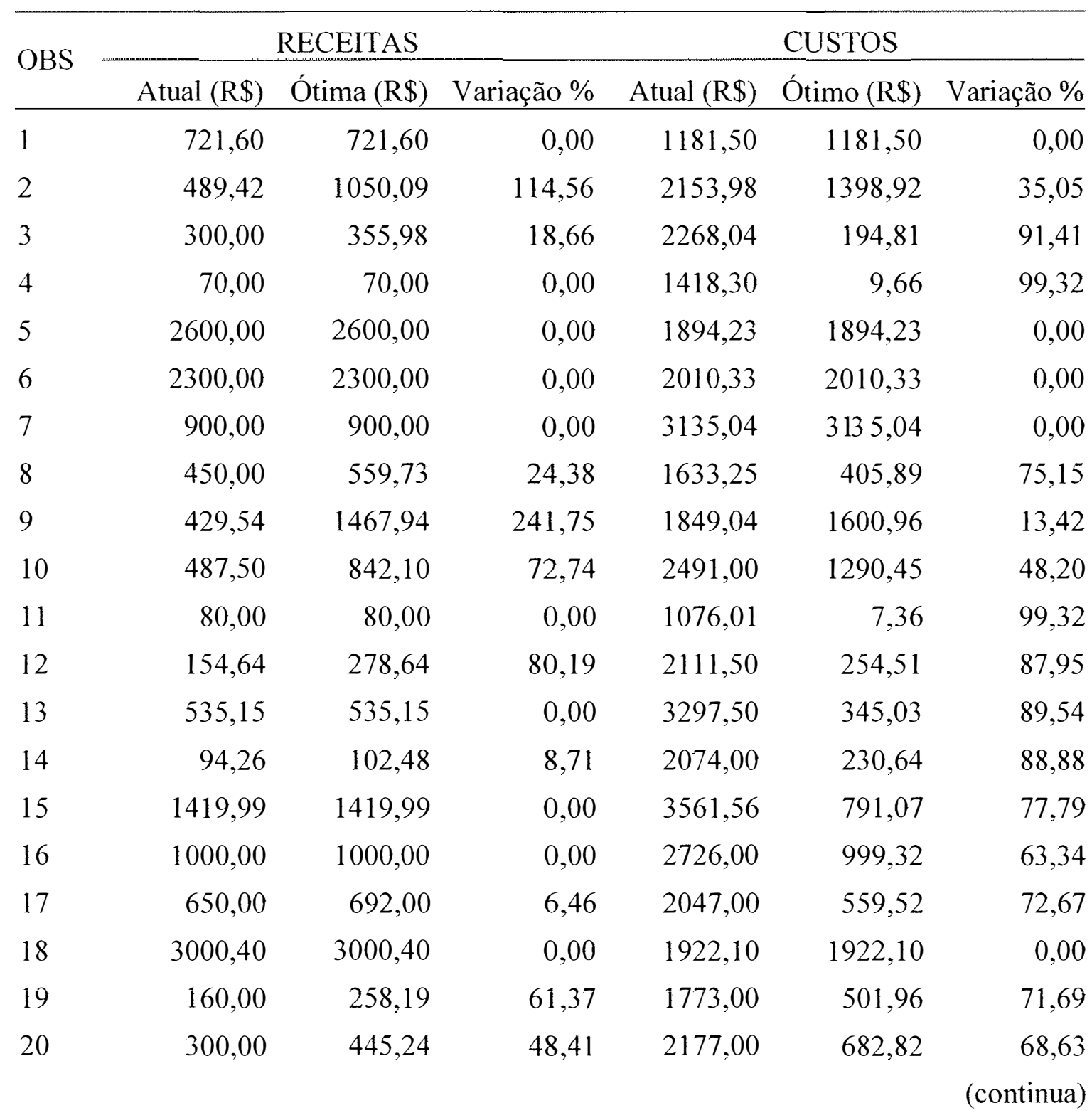


Tabela 19: Receitas e custos observados e otimizados pela minimização de custos sob retornos constantes à escala (continuação).

\begin{tabular}{|c|c|c|c|c|c|c|}
\hline \multirow{2}{*}{ OBS } & \multicolumn{3}{|c|}{ RECEITAS } & \multicolumn{3}{|c|}{ CUSTOS } \\
\hline & Atual & Ótima & Variação \% & Atual & Ótimo & Variação \% \\
\hline 21 & 266,64 & 266,64 & 0,00 & 1258,50 & 23,38 & 98,14 \\
\hline 22 & 1099,80 & 1099,80 & 0,00 & 1794,18 & 920,35 & 48,70 \\
\hline 23 & 3905,00 & 4125,35 & 5,64 & 2796,75 & 2685,95 & 3,96 \\
\hline 24 & 750,02 & 750,02 & 0,00 & 3421,00 & 1056,29 & 69,12 \\
\hline 25 & 1497,04 & 1497,04 & 0,00 & 1755,00 & 1755,00 & 0,00 \\
\hline 26 & 200,00 & 200,00 & 0,00 & 1370,00 & 1370,00 & 0,00 \\
\hline 27 & 610,00 & 909,73 & 49,14 & 1515,08 & 870,40 & 42,55 \\
\hline 28 & 2000,00 & 2000,00 & 0,00 & 2125,00 & 1617,39 & 23,89 \\
\hline 29 & 99,16 & 803,82 & 710,67 & 8543,01 & 1942,73 & 77,26 \\
\hline 30 & 950,00 & 950,00 & 0,00 & 2190,00 & 601,78 & 72,52 \\
\hline 31 & 784,52 & 2086,75 & 165,99 & 5591,66 & 2774,67 & 50,38 \\
\hline 32 & 162,36 & 270,86 & 66,83 & 2729,00 & 173,34 & 93,65 \\
\hline 33 & 958,45 & 958,45 & 0,00 & 840,00 & 840,00 & 0,00 \\
\hline 34 & 418,66 & 418,66 & 0,00 & 952,20 & 574,74 & 39,64 \\
\hline 35 & 3975,40 & 3975,40 & 0,00 & 3773,73 & 3773,73 & 0,00 \\
\hline 36 & 386,32 & 541,32 & 40,12 & 3339,00 & 342,69 & 89,74 \\
\hline 37 & 2000,00 & 2000,00 & 0,00 & 2260,00 & 1675,44 & 25,87 \\
\hline 38 & 650,00 & 1059,00 & 62,92 & 1575,12 & 1156,55 & 26,57 \\
\hline 39 & 569,96 & 926,46 & 62,55 & 1629,24 & 794,18 & 51,25 \\
\hline 40 & 1555,00 & 1555,00 & 0,00 & 742,00 & 568,39 & 23,40 \\
\hline 41 & 2551,00 & 2551,00 & 0,00 & 420,00 & 420,00 & 0,00 \\
\hline 42 & 750,00 & 825,25 & 10,03 & 2143,90 & 560,67 & 73,85 \\
\hline 43 & 199,50 & 227,91 & 14,24 & 2234,00 & 225,45 & 89,91 \\
\hline 44 & 315,96 & 315,96 & 0,00 & 2288,00 & 2288,00 & 0,00 \\
\hline
\end{tabular}

Fonte dos dados: pesquisa. Cálculos: autor 
A redução média dos custos das propriedades ineficientes, caso seguissem o exemplo de suas unidades de referência, seria da ordem de $63,11 \%$, variando entre, aproximadamente, $3,96 \%$ e $99,32 \%$.

O incremento médio na receita, dada pelo plano de minimização de custos, seria da ordem de $56,09 \%$, variando entre $0 \%$ e $710,7 \%$.

As contribuições de cada fator na redução dos custos e de cada produto no aumento das receitas para o total da amostra são apresentadas na tabela 20. Os resultados mostram que o fator mão-de-obra familiar é o principal componente para se obter redução de custos. Do lado da produção, ganhos de eficiência implicam maior participação dos produtos raiz de mandioca, inhame, fumo e laranja na composição da receita.

Tabela 20: Participação percentual dos fatores e dos produtos para a redução dos custos e aumento das receitas, respectivamente.

\begin{tabular}{|c|c|c|c|}
\hline \multicolumn{2}{|c|}{$\begin{array}{c}\text { Contribuição de cada fator para } \\
\text { a redução dos custos }\end{array}$} & \multicolumn{2}{|c|}{$\begin{array}{l}\text { Contribuição de cada produto } \\
\text { para o aumento das receitas }\end{array}$} \\
\hline Fatores & $(\%)$ & Produtos & $(\%)$ \\
\hline Esterco de gado & 3,13 & Amendoim & 3,74 \\
\hline Formicida & 0,71 & Farinha de mandioca & 0,00 \\
\hline Aluguel de trator & 0,41 & Feijão & 0,00 \\
\hline Inseticidas & $-0,15$ & Fumo em folha & 15,72 \\
\hline Mão-de-obra & 93,55 & Inhame & 24,74 \\
\hline NPK & 3,02 & Laranja & 15,37 \\
\hline \multirow[t]{2}{*}{ Torta de mamona } & $-0,67$ & Limão & 0,00 \\
\hline & & Raiz de mandioca & 40,43 \\
\hline
\end{tabular}

Fonte dos dados: pesquisa. Cálculos: autor 
Na tabela 21 são apresentados os lucros observados e otimizados pela minimização de custos para cada propriedade da amostra.

Tabela 21: Lucro observado e otimizado pela minimização de custos sob retornos constantes à escala.

\begin{tabular}{|c|c|c|c|c|}
\hline \multirow{2}{*}{ OBS } & \multicolumn{4}{|c|}{ LUCRO } \\
\hline & Observado $(\mathrm{R} \$)$ & Ótimo $(\mathrm{R} \$)$ & Acréscimo $(\mathrm{R} \$)$ & Variação (\%) \\
\hline 1 & $-459,90$ & $-459,90$ & 0,00 & 0,00 \\
\hline 2 & $-1664,56$ & $-348,83$ & 1315,73 & 79,04 \\
\hline 3 & $-1968,04$ & 161,17 & 2129,21 & 108,19 \\
\hline 4 & $-1348,30$ & 60,34 & 1408,64 & 104,47 \\
\hline 5 & 705,77 & 705,77 & 0,00 & 0,00 \\
\hline 6 & 289,67 & 289,67 & 0,00 & 0,00 \\
\hline 7 & $-2235,04$ & $-2235,04$ & 0,00 & 0,00 \\
\hline 8 & $-1183,25$ & 153,84 & 1337,09 & 113,00 \\
\hline 9 & $-1419,51$ & $-133,02$ & 1286,48 & 90,63 \\
\hline 10 & $-2003,50$ & $-448,35$ & 1555,15 & 77,62 \\
\hline 11 & $-996,01$ & 72,64 & 1068,65 & 107,29 \\
\hline 12 & $-1956,86$ & 24,13 & 1980,99 & 101,23 \\
\hline 13 & $-2762,35$ & 190,12 & 2952,47 & 106,88 \\
\hline 14 & $-1979,74$ & $-128,16$ & 1851,58 & 93,53 \\
\hline 15 & $-2141,57$ & 628,92 & 2770,49 & 129,37 \\
\hline 16 & $-1726,00$ & 0,68 & 1726,68 & 100,04 \\
\hline 17 & $-1397,00$ & 132,49 & 1529,49 & 109,48 \\
\hline 18 & 1078,30 & 1078,30 & 0,00 & 0,00 \\
\hline 19 & $-1613,00$ & $-243,77$ & 1369,23 & 84,89 \\
\hline 20 & $-1877,00$ & $-237,58$ & 1639,42 & 87,34 \\
\hline 21 & $-991,86$ & 243,26 & 1235,12 & 124,53 \\
\hline 22 & $-694,38$ & 179,45 & 873,83 & 125,84 \\
\hline 23 & 1108,25 & 1439,40 & 331,15 & 29,88 \\
\hline 24 & $-2670,98$ & $-306,27$ & 2364,71 & 88,53 \\
\hline 25 & $-257,96$ & $-257,96$ & 0,00 & 0,00 \\
\hline 26 & $-1170,00$ & $-1170,00$ & 0,00 & 0,00 \\
\hline 27 & $-905,08$ & 39,33 & 944,41 & 104,35 \\
\hline 28 & $-125,00$ & 382,61 & 507,61 & $\begin{array}{r}406,09 \\
(\text { continua) }\end{array}$ \\
\hline
\end{tabular}


Tabela 21: Lucro observado e otimizado pela minimização de custos sob retornos constantes à escala (continuação).

\begin{tabular}{lrrrr}
\hline \multirow{2}{*}{ OBS } & \multicolumn{4}{c}{ LUCRO } \\
\cline { 2 - 5 } & Observado (R\$) & Ótimo (R\$) & Acréscimo (R\$) & Variação (\%) \\
\hline 29 & $-8443,86$ & $-1138,90$ & 7304,95 & 86,51 \\
30 & $-1240,00$ & 348,22 & 1588,22 & 128,08 \\
31 & $-4807,14$ & $-687,91$ & 4119,23 & 85,69 \\
32 & $-2566,64$ & 97,52 & 2664,16 & 103,80 \\
33 & 118,45 & 118,45 & 0,00 & 0,00 \\
34 & $-533,54$ & $-156,08$ & 377,46 & 70,75 \\
35 & 201,67 & 201,67 & 0,00 & 0,00 \\
36 & $-2952,68$ & 198,63 & 3151,31 & 106,73 \\
37 & $-260,00$ & 324,56 & 584,56 & 224,83 \\
38 & $-925,12$ & $-97,55$ & 827,58 & 89,46 \\
39 & $-1059,28$ & 132,28 & 1191,55 & 112,49 \\
40 & 813,00 & 986,61 & 173,61 & 21,35 \\
41 & 2131,00 & 2131,00 & 0,00 & 0,00 \\
42 & $-1393,90$ & 264,58 & 1658,48 & 118,98 \\
43 & $-2034,50$ & 2,46 & 2036,96 & 100,12 \\
44 & $-1972,04$ & $-1972,04$ & 0,00 & 0,00 \\
\hline Fontedos dados: pesquisa. Cálculos: autor & &
\end{tabular}

Os dados observados sugerem que a maximização do lucro não é um objetivo perseguido pela pequena produção agrícola do tipo familiar. Em apenas $18,2 \%$ das propriedades amostradas o lucro observado (imputando nos custos o salário da mão-de-obra familiar) é positivo. Na mesma tabela pode-se ainda verificar que mesmo algumas propriedades eficientes do ponto de vista da minimização de custos apresentam lucro negativo (observações 1, 7, 25,26 e 44). Isto indica que, para a maioria dos produtores, a renda familiar resultante da exploração agrícola (lucro mais remuneração da mão-de-obra familiar) é menor do que a que teria se, alternativamente, e pressupondo constância dos salários, alocasse a mão-de-obra familiar no mercado de trabalho. 
Sob a hipótese de minimização de custos, se todas as observações de amostra operassem no plano ótimo (eficiência de custos igual a 1), 63,64\% apresentariam lucro positivo e, em média, haveria um aumento da renda familiar da ordem de 164,48\%, variando de $-13,75 \%$ a $1880,95 \%$. A tabela 22 apresenta os dados referentes à renda familiar observada e otimizada.

Tabela 22: Renda familiar observada e otimizada pela minimização de custos sob retornos constantes à escala.

\begin{tabular}{lrrrr}
\hline Obs & Observada $(\mathrm{R} \$)$ & Ótima $(\mathrm{R} \$)$ & Acréscimo $(\mathrm{R} \$)$ & Variação (\%) \\
\hline 1 & 696,60 & 696,60 & 0,00 & 0,00 \\
2 & 335,44 & 988,37 & 652,93 & 194,65 \\
3 & 31,96 & 344,32 & 312,36 & 977,33 \\
4 & 39,50 & 68,56 & 29,06 & 73,57 \\
5 & 2299,52 & 2299,52 & 0,00 & 0,00 \\
6 & 1670,92 & 1670,92 & 0,00 & 0,00 \\
7 & 858,96 & 858,96 & 0,00 & 0,00 \\
8 & 198,00 & 527,84 & 329,84 & 166,59 \\
9 & 348,50 & 1326,25 & 977,75 & 280,56 \\
10 & 427,50 & 790,95 & 363,45 & 85,02 \\
11 & 3,99 & 79,04 & 75,05 & 1880,95 \\
12 & 99,14 & 261,45 & 162,31 & 163,72 \\
13 & 425,15 & 477,02 & 51,87 & 12,20 \\
14 & 20,26 & 76,52 & 56,26 & 277,67 \\
15 & 898,43 & 1316,03 & 417,60 & 46,48 \\
16 & 914,00 & 788,36 & $-125,64$ & $-13,75$ \\
17 & 335,00 & 590,05 & 255,05 & 76,13 \\
18 & 2680,40 & 2680,40 & 0,00 & 0,00 \\
19 & 119,00 & 208,91 & 89,91 & 75,55 \\
20 & 288,00 & 403,26 & 115,26 & 40,02 \\
& & & & $($ co ntinua)
\end{tabular}


Tabela 22: Renda familiar observada e otimizada pela minimização de custos (continuação).

\begin{tabular}{|c|c|c|c|c|}
\hline Obs & Observada (R\$) & Ótima $(\mathrm{R} \$)$ & Acréscimo $(\mathrm{R} \$)$ & Variação (\%) \\
\hline 21 & 90,64 & 264,05 & 173,41 & 191,32 \\
\hline 22 & 803,80 & 980,50 & 176,70 & 21,98 \\
\hline 23 & 3598,00 & 3941,26 & 343,26 & 9,54 \\
\hline 24 & 579,02 & 518,23 & $-60,79$ & $-10,50$ \\
\hline 25 & 1367,04 & 1367,04 & 0,00 & 0,00 \\
\hline 26 & 30,00 & 30,00 & 0,00 & 0,00 \\
\hline 27 & 294,92 & 820,35 & 525,43 & 178,16 \\
\hline 28 & 1875,00 & 1805,69 & $-69,31$ & $-3,70$ \\
\hline 29 & 56,15 & 719,43 & 663,29 & 1181,39 \\
\hline 30 & 760,00 & 866,30 & 106,30 & 13,99 \\
\hline 31 & 400,06 & 1986,75 & 1586,69 & 396,61 \\
\hline 32 & 153,36 & 259,92 & 106,56 & 69,48 \\
\hline 33 & 886,45 & 886,45 & 0,00 & 0,00 \\
\hline 34 & 289,16 & 343,80 & 54,64 & 18,90 \\
\hline 35 & 3753,67 & 3753,67 & 0,00 & 0,00 \\
\hline 36 & 311,32 & 512,14 & 200,82 & 64,51 \\
\hline 37 & 1740,00 & 1787,63 & 47,63 & 2,74 \\
\hline 38 & 314,88 & 911,03 & 596,15 & 189,33 \\
\hline 39 & 240,73 & 849,40 & 608,68 & 252,85 \\
\hline 40 & 1413,00 & 1477,38 & 64,38 & 4,56 \\
\hline 41 & 2515,00 & 2515,00 & 0,00 & 0,00 \\
\hline 42 & 231,10 & 783,15 & 552,05 & 238,88 \\
\hline 43 & 109,50 & 197,46 & 87,96 & 80,33 \\
\hline 44 & 257,96 & 257,96 & 0,00 & 0,00 \\
\hline Media & 790,02 & 1006,54 & 216,52 & 27,41 \\
\hline Mínima & 3,99 & 30,00 & $-125,64$ & $-13,75$ \\
\hline Máxima & 3753,67 & 3941,26 & 1586,69 & 1881,39 \\
\hline Desvio padrão & 944,92 & 915,48 & 323,69 & 353,53 \\
\hline
\end{tabular}

Fonte dos dados: pesquisa. Cálculos: autor 
Os resultados acima evidenciam que, embora os ganhos de eficiência decorram principalmente da redução do uso da mãode-obra, ocorre, de um modo geral, aumento da renda familiar, independentemente da ocupação, em outras atividades, da força de trabalho dispensada. Isto é resultante do aumento das receitas decorrentes da recombinação dos produtos e das mudanças no uso de todos os fatores de produção por unidade do produto.

\subsection{Fatores determinantes da eficiência da pequena produção}

Nas tabela 23 a 25 são mostradas as estimativas dos parâmetros das funções explicativas da eficiência da produção. As estimativas das variâncias e covariâncias assintóticas das estimativas dos parâmetros do modelo referente à eficiência técnica foram corrigidas já que o teste de $\aleph^{2}$ para ajustamento foi significativo para esta regressão. Para as demais regressões, os testes de $\aleph^{2}$ foram não significantes e, portanto, as estimativas das variâncias e covariâncias assintóticas das estimativas dos parâmetros não foram corrigidas.

Os resultados apresentados na tabela 23 indicam uma relação inversa entre área colhida e eficiência técnica, significante ao nível de $20 \%$, indicando que a probabilidade de uma firma ser tecnicamente eficiente é maior entre as propriedades menores. As variáveis $Z_{3}$ (escolaridade média da mão-de-obra familiar) e $Z_{5}$ (fonte alternativa de informação: rádio) estão positivamente relacionadas com a eficiência técnica, como esperado, embora os parâmetros estimados sejam não significantes. A variável $Z_{2}$ (idade 
média da mão-de-obra familiar), cujo coeficiente estimado é significante ao nível de 5\%, mostra uma relação inversa com a eficiência técnica, o que pode ser entendido pelo fato de que as pessoas mais idosas apresentam um menor vigor para o trabalho na agricultura, principalmente quando se considera que os sistemas de produção utilizados pelos produtores considerados neste estudo são intensivos na utilização de trabalho. A variável $Z_{4}$ (inserção no mercado de produtos) apresenta uma forte relação positiva com a eficiência técnica, indicando que quanto maior a parcela da produção direcionada para o mercado, maior a busca de eficiência técnica no processo produtivo.

Tabela 23: Estimativa dos parâmetros do modelo logito para eficiência técnica.

\begin{tabular}{|c|c|c|c|}
\hline Variáveis independentes & Coeficientes & Erro padrão & Significância \\
\hline Área colhida & $-0,0803$ & 0,0661 & 0,1866 \\
\hline Escolaridade & 0,0011 & 0,3491 & 0,9975 \\
\hline Id ade & $-0,1075$ & 0,0500 & 0,0314 \\
\hline Inserção no mercado & 4,2755 & 1,8615 & 0,0216 \\
\hline Informação: rádio & 0,0617 & 1,1754 & 0,9582 \\
\hline Constante & 3,7288 & 2,8128 & 0,1850 \\
\hline$\chi^{2}$ & 114,516 & & \\
\hline
\end{tabular}

Fonte dos dados: pesquisa. Cálculos: autor

A figura 04 apresenta os valores médios de área colhida (em tarefas), escolaridade média da mão-de-obra familiar (em anos de escola concluídos), idade média da mão-de-obra 
familiar (em anos) e inserção no mercado de produtos (em percentual do valor da produção destinado ao mercado).

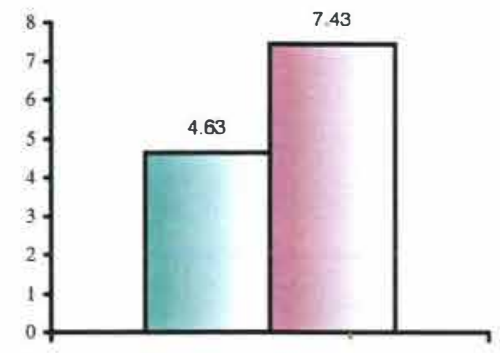

4a: Área colhida

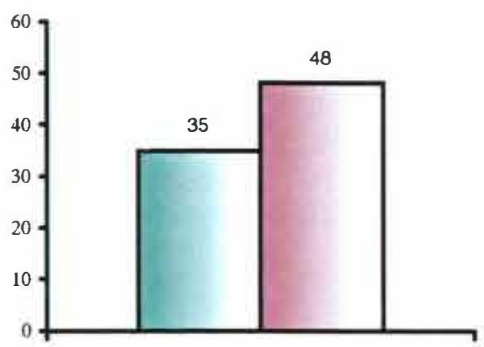

4c: Idade média

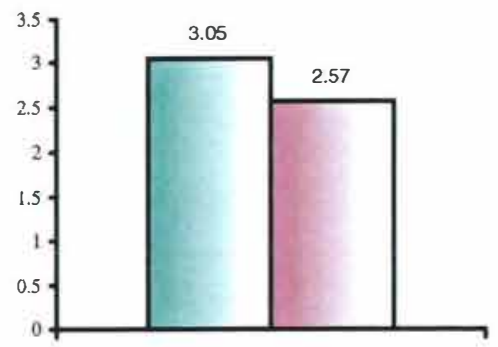

4b: Escolaridade média

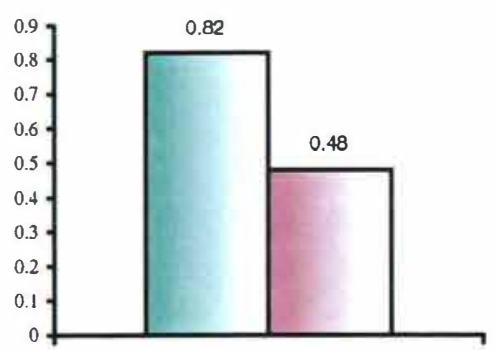

4d: Inserçao no mercado

Ineficientes

Figura 4: Fatores associados à eficiência técnica (valores médios)

As estimativas dos parâmetros do modelo logito para eficiência de escala são apresentadas na tabela 24. Os coeficientes das variáveis $Z_{3}$ (escolaridade média da mão-de-obra familiar) e $Z_{4}$ (inserção no mercado), significantes aos níveis de $10 \%$ e $5 \%$, respectivamente, indicam a influência destas variáveis na determinação da eficiência de escala. O coeficiente da variável área 
colhida, embora não significante, indica que a ineficiência de escala está associada às propriedades maiores.

Tabela 24: Estimativa dos parâmetros do modelo logito para eficiência de escala.

\begin{tabular}{lrrr}
\hline Variáveis independentes & Coeficientes & Erro padrão & Significância \\
\hline Área colhida & $-0, \bullet 407$ & 0,0561 & 0,4677 \\
Escolaridade & 0,1726 & 0,2901 & 0,5518 \\
Idade & -0.0636 & 0,0353 & 0,0716 \\
Inserção no mercado & 3,1862 & 1,4571 & 0,0288 \\
Informação: rádio & 0,7204 & 1,0599 & 0,4967 \\
Constante & 1,1790 & 2,1821 & 0,5890 \\
\hline$\aleph^{2}$ & 46,389 & & \\
\hline
\end{tabular}

Os valores médios das variáveis associadas à eficiência de escala são sumarizados na figura 5 . 


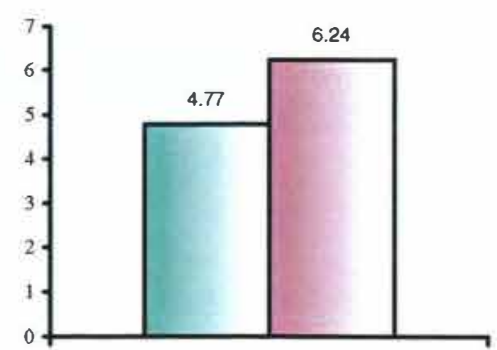

5a: Área colhida

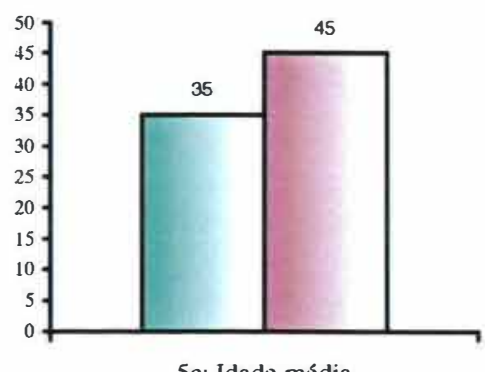

5c: Idade média

Eficientes

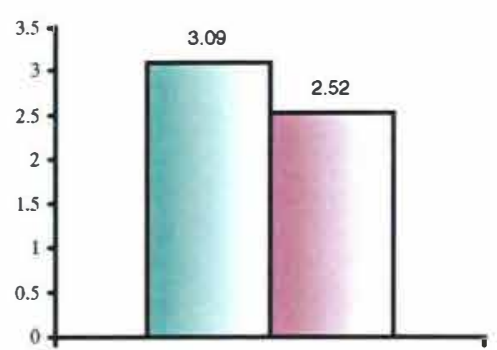

5b: Escolaridade média

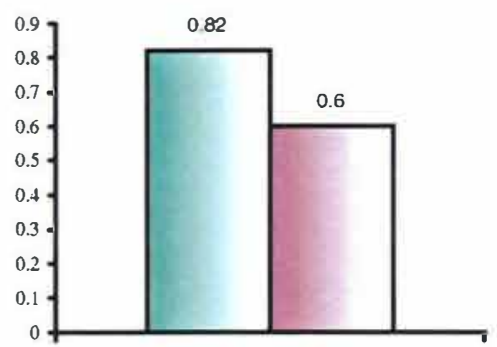

5d: Inserção no mercado

Ineficientes

Figura 5: Fatores associados à eficiência de escala (valores médios)

Conforme os resultados apresentados na tabela 25 , as variáveis idade média da mão-de-obra familiar e fonte alternativa de informação (rádio), são as que estão mais fortemente associadas à eficiência alocativa. Os parâmetros estimados para estas variáveis apresentam significância ao nível de $5 \%$. Estes resultados indicam que o rádio pode constituir-se num instrumento de tomada de decisão dos produtores através da divulgação de informações referentes à demanda de produtos e a oferta de fatores de produção. 
Tabela 25: Estimativa dos parâmetros do modelo logito para eficiência alocativa.

\begin{tabular}{lrrr}
\hline Variáveis independentes & Coeficientes & Erro padrão & Significância \\
\hline Área colhida & 0,0700 & 0,0592 & 0,2377 \\
Escolaridade & $-0,0193$ & 0,2331 & 0,9341 \\
Idade & $-0,1387$ & 0,0674 & 0,0395 \\
Inserção no mercado & 1,9164 & 1,6981 & 0,2591 \\
Informação: rádio & 2,2481 & 0,9378 & 0,0165 \\
Constante & 0,6904 & 2,5623 & 0,7876 \\
\hline \multirow{2}{2}{} & 35,064 & \\
\hline
\end{tabular}

Os valores médios para as variáveis explicativas da eficiência alocativa são sumarizados na figura 6 . 


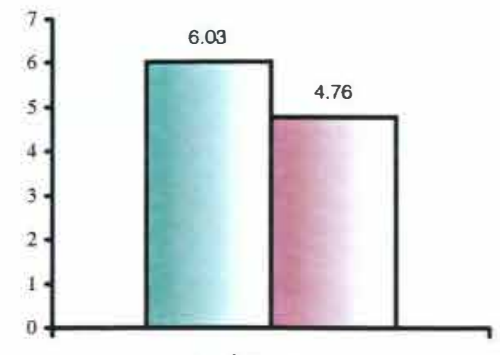

6a: Área colhida

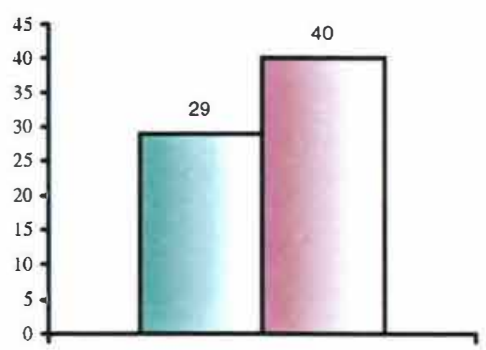

6c: Idade média

Eficientes

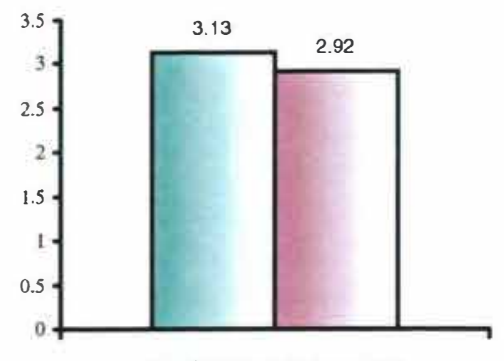

6b: Escolaridade média

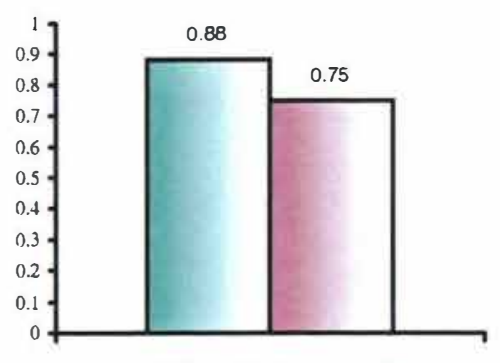

6d: Inserção no mercado

Ineficientes

Figura 6: Fatores associados à eficiência alocativa (valores médios) 


\section{CONCLUSÕES}

Este trabalho aplica um modelo não-paramétrico de análise da eficiência econômica para uma amostra de 44 pequenos produtores agrícolas da região Recôncavo do estado da Bahia. O contexto adotado foi o de comportamento de minimização de custos e as medidas de eficiencia técnica, de escala e alocativa foram obtidas com base nas funções de distância de Shephard (1970).

Com base nos resultados obtidos, pode-se afirmar que a pequena propriedade familiar agrícola da região em estudo é tecnicamente eficiente, ou seja, os produtores estão, ou se aproximam, do nível ótimo de produção, dada a tecnologia empregada. Deste modo, ganhos de produtividade marginal dos fatores de produção só seriam possíveis através de mudança tecnológica.

A dispersão dos índices de eficiência alocativa, com forte concentração nos níveis abaixo de $70 \%$, indica que a maioria dos produtores não está conseguindo ajustar a combinação de insumos que levaria ao custo mínimo. 
Os resultados indicam a possibilidade de se aumentar a lucratividade através da racionalização dos custos de produção. Operando com eficiência econômica plena, a redução dos custos da amostra de produtores seria da ordem de 63\%. A redução do uso da mão-de-obra seria o principal componente a contribuir para a minimização dos custos. Contudo, a agricultura familiar apresenta algumas características que a diferencia das empresas capitalistas no que se refere à lógica da racionalidade econômica. Considerando que a organização da produção se dá por relações de parentesco, estes produtores tendem a maximizar a utilização da mão-de-obra familiar, como sugerem os resultados deste estudo, limitando ou até mesmo excluindo a possibilidade de racionalização dos custos que implique dispensar o excedente de trabalho. Pode-se argumentar que esta limitação poderia ser desconsiderada já que a produção poderia se expandir pelo aumento da área cultivada minimizando o excedente da mão-de-obra. No entanto, no presente caso, esta possibilidade praticamente não existe para os pequenos produtores da região Recôncavo da Bahia já que a área agricultável não utilizada das propriedades é quase nula.

Os resultados apresentados mostram que os índices de eficiência técnica e de escala estão inversamente relacionados com o tamanho da exploração e a idade média da mão-de-obra familiar, e positivamente relacionados com o grau de participação no mercado de produtos. Idade média da mão-de-obra familiar e fonte de informação (radio) são as principais variáveis associadas à eficiência alocativa.

Dos resultados obtidos pode-se inferir que politicas de geração de empregos em outros setores da economia regional poderiam ser eficazes para a redução do excedente de mão-de-obra 
na agricultura familiar. Tal política, complementada com programas de qualificação profissional e de desenvolvimento de tecnologias agrícolas mais adequadas à estrutura da pequena produção familiar possibilitaria a obtenção de ganhos de eficiência e, consequentemente, melhoria do nível de renda e de bem-estar social deste segmento de agricultores.

As principais limitações do estudo estão associadas aos dados disponíveis para análise. Por tratar-se de informações sobre uma única safra agrícola não foram incluidas no modelo algumas variáveis que devem estar relacionadas com os índices de eficiência como, por exemplo, variações climáticas e mudanças nas relações de preço de produtos e fatores. Por insuficiência de informação, deixaram de ser consideradas, ainda, variáveis que identificassem a experiencia do produtor, a qualidade da terra, fontes de financiamento e acesso a instituições de assistência técnica e de pesquisa.

Além destes aspectos, trabalhos futuros devem considerar a presença de insumos fixos e de incerteza que podem alterar os índices de eficiência. 


\section{REFERÊNCIAS BIBLIOGRÁFICAS}

ALVES, E.R.A. Teoria da produção: métodos não paramétricos. Piracicaba, ESALQ/USP, 1995, 72p. (Série Didática, 97).

ALVES, E. \& PASTORE, A. C. A política agrícola do Brasil e a hipótese de inovação induzida. In: Empresa Brasileira de Pesquisa Agropecuária, Brasília. Coletânea de trabalhos sobre a EMBRAPA. Brasília, 1980.

ALVES, E.R.A; PASTORE, J. Uma nova abordagem para a pesquisa agrícola no Brasil. Revista de Economia Rural. v.15, n.1, p.235-256, 1977.

ARAÚJO, L. A. Fronteira de eficiência econômica sob condições de risco: uma análise da convergência econômica entre empresas do sulde Santa Catarina. Piracicaba, 1997.150p. Tese (Mestrado) Escola Superior de Agricultura Luiz de Queiroz, Universidade de São Paulo. 
BANKER, R.D.; MAINDIRATTA, A. Nonparametric analysis of technical and alocative efficiencies in Data Envelop Analysis. Econometrica, v.56, n.6, p.1315-1332, 1988.

BARROS, G. S. C. A transição na política agrícola brasileira. In: CONGRESSO BRASILEIRO DE ECONOMIA E SOCIOLOGIA RURAL, 36., Poços de Caldas, 1998. Anais, Brasília: SOBER, 1998. p.1-19.

CAVES, D. W.; Christensen, L. R.; DIEWERT, W. E. The economic theory of index numbers and the measurement of input, output, and productivity. Econometrica, v. 50, p.1393$1414,1982$.

CHAVAS, J. P.; COX T. L.. A nonparametric analysis of productivity: the case of U. S. and Japanese manufacturing. American Economic Review, v. 80, n.3, p.450-464, 1990.

CHAVAS, J. P.; COX, T. L. A primal-dual approach to nonparametric productivity analysis: the case of $U$. S. agriculture. Madison: University of Wisconsin, 1994, $25 \mathrm{p}$. (Staff Paper Series Dept. Agricultural Economics, 372).

CHAVAS, J. P.; COX, T. L. A generalized distance function and the analysis of production efficience. Madison: University of Wisconsin, 1999, 34p. (Staff Paper Series Agricultural \& Applied Economics, 422).

CONCEIÇÃO, J. C. P. R. Fronteira de produção estocástica e eficiência técnica na agricultura. Piracicaba, 1998. 108 p. Tese (Doutorado) - Escola Superior de Agricultura Luiz de Queiroz, Universidade de São Paulo. 
DEBREU, G. The coefficient of resource utilization. Econometrica, v. 19, n.3, p.273-292, 1951.

DIAS, G. L. S. Pobreza rural no Brasil: caracterização do problema e recomendações de política. Brasília: Comissão de Financiamento da Produção - CFP, 1979, 115p. (Coleção Análise e Pesquisa, 16).

DILLON, J. \& HARDAKER, J. B., Farm management research for small farmer development. Rome: FAO, 1980, 20p. (FAO Agricultural Services Bulletin, $\left.n^{\circ} 41\right)$.

FARRELL, M. J. The mesurement of productive efficiency. Journal of Royal Statistical Society, v. 19, n.2, p.253-281, 1957.

FÄRE， R.; GROSSKOPF， S.; LOVELL， C. A. K. Production Frontiers. Cambridge: Cambridge University Press, 1994.

GILligAN, D. O. Farm size, productivity, and economic efficience: accounting for differences in efficiency of farms by size in Honduras. University of Maryland, 1998 15p. http://www.agecon.lib.umn.edu/(21/09/1999).

GOMES, A. P.; ALVES, E. Eficiência de escala na produção de leite: uma abordagem não-paramétrica.(CD-ROM). In: CONGRESSO BRASILEIRO DE ECONOMIA E SOCIOLOGIA RURAL, Rio de Janeiro, 2000. Anais, Rio de Janeiro: SOBER, 2000 .

GREENE, W. H. Econometric analysis. 3.ed. New Jersey: Printice Hall, 1997, 1075 p. 
HOFFMANN, R. \& VIEIRA, S. Análise de regressão: uma introdução à econometria. São Paulo: HUCITEC-EDUSP, 1977, $335 \mathrm{p}$.

HOMEM DE MELO, F. B. A política econômica e o setor agrícola no período pós-guerra. Revista Brasileira de Economia, v. 33, $n^{\circ} 1$, p.23-63, 1979 .

INSTITUTO BRASILEIRO DE GEOGRAFIA E ESTATÍSTICA. Censo Agropecuário 1995-1996 - Bahia. Rio de Janeiro, 1998. (compact disc)

KOOPMANS, T. C. An analysis of production as un efficient combination of activities. In: KOOPMANS, T. C. ed. Activity analysis of production and allocation. New York, Cowles Commission for Research in Economics, 1951.

LAMBERT, D. K.; USSIF, A. A distance function approach to multifactor productivity measurement in U. S. agriculture. Reno: University of Nevada, 1997, 17p. http://www. agecon.lib.umn.edu/ (25/10/1998).

LAMBERT, D. K.; SHONKWILER, J. S. Factor bias stochastic technical change. American Journal of Agricultural Economics, v. 37, p.578-90, 1995.

LAMBERT, D. K., A programming approach to estimate production functions using bounds on the true production set. Reno: University of Nevada, 1997, 30p. (Discussion Paper A PES97-01) 
LEMBERG, B.; WONGCHARUPAN, M. Nonparametric analysis of cost minimization and efficiency. Texas A\&M University, 1998, 14 p. http://www.agecon.lib.umn.edu/(fev/2000).

PASTORE, A. C. Exportações agrícolas e desenvolvimento econômico. In: VEIGA, A. (coord). Ensaios sobre política brasileira. São Paulo: Secretaria da Agricultura, 1979, p.207231.

RAMOS, E. L. Relações entre o crescimento industrial e o desenvolvimento agrícola da Região Fumageira de Mata Fina: industrialização da mandioca. 1972. 115 p. Tese (Professor Assistente) - Escola de Agronomia, Universidade Federal da Bahia.

RAY, S. C.; BHADRA, D. Nonparametric tests of cost minimizing behavior: a study of Indian farms. American Journal of Agricultural Economics, v. 75, n. 4, p. 990-999, 1993.

SCHULTZ, T. W. Transforming tradicional Agriculture. New Haven, Yale University Press, 1964.

SHARMA, K. R.; LEUNG, P.; ZALESKI, H. M. Technical, allocative and economic efficiencies in swine production in Hawaii: a comparation of parametric and nonparametric approaches. Agricultural Economics, v. 20, n. 1, p.23-35, 1999.

SHEPHARD, R. W. Theory of cost and production functions. New Jersey: Princeton University Press, 1970. 
SHERLUND, S. M., C. B. Barrett e A. A. Adesina. Smallholder technical efficiency with stochastic exogenous production conditions. Cornell: Cornell University, 1998, 30 p.(Working Paper Dept. of Res. and Mgrl. Economics, 98-15).

TAYLOR, T. G.; DRUMMOND, H. E.; GOMES, A. T. Agricultural credit programs and production efficiency: an analysis of tradicional farming in south eastern Minas Gerais, Brazil. American Journal of Agricultural Economics, v. 68, n. 1, p.110-119, 1986 .

TAYLOR, T. G.; SHONKWILLER, J. S. Alternative stochastic specifications of the frontier production function in the analysis of agricultural credit programs and technical efficiency. Journal of Development Economics, v.21, n.1, p.149-160, 1986.

TORESON, L; LANZER, E. A. Avaliação da eficiência relativa das propriedades agrícolas típicas de Santa Catarina. In: CONGRESSO BRASILEIRO DE ECONOMIA E SOCIOLOGIA RURAL, Curitiba, 1995. Anais. Brasília: SOBER, 1995, p.559565 .

TUPY, O. Fronteiras estocásticas, dualidade neoclássica e eficiência econômica na produção de frangos de corte. Piracicaba, 1996. 91p. Tese(Doutorado) - Escola Superior de Agricultura Luiz de Queiroz, Universidade de São Paulo.

VARIAN, H. R. The nonparametric approach to production analysis. Econometrica, v. 54, p.579-597, 1984. 
VARIAN, H. R. Non-parametric analysis of optimizing behavior with measurement error. Journal of econometrics, v. $30, n .1 / 2$, p. $445-458,1985$.

VICENTE, J. R. Determinantes da adoção de tecnologia e da eficiência na produção agrícola paulista. São Paulo, 1997. 223 p.Tese (Doutorado) - Faculdade de Economia, Administração e Contabilidade, Universidade de São Paulo.

ZAGATtO, L. C. A. G. Estrutura produtiva de pequenos agricultores e implicações para a geração e adoção de tecnologia. Viçosa, 1991. 112p. Tese (Doutorado) Universidade Federal deViçosa. 
8. ANEXOS 
Anexo A: Quantidades dos produtos por observação da amostra.

\begin{tabular}{|c|c|c|c|c|c|c|c|c|}
\hline Observação & Amendoim & Farinha & Feijão & Fumo & Inhame & Laranja & Limão & Mandioca \\
\hline 1 &, 00 &, 00 &, 00 &, 00 &, 00 & 320,00 & 100,00 &, 00 \\
\hline 2 &, 00 & ,00 &, 00 &, 00 & 200,00 &, 00 & 100,00 & 3,00 \\
\hline 3 &, 00 &, 00 &, 00 &, 00 & 150,00 &, 00 &, 00 & 4,00 \\
\hline 4 &, 00 &, 00 &, 00 &, 00 &, 00 &, 00 &, 00 & 2,00 \\
\hline 5 &, 00 & 80,00 &, 00 &, 00 &, 00 & 800,00 &, 00 &, 00 \\
\hline 6 & ,00 &, 00 &, 00 &, 00 &, 00 & 1000,00 &, 00 & 6,00 \\
\hline 7 &, 00 &, 00 &, 00 &, 00 &, 00 & 700,00 &, 00 & 5,00 \\
\hline 8 &, 00 & 36,00 &, 00 &, 00 &, 00 &, 00 &, 00 &, 00 \\
\hline 9 & 4,00 &, 00 & 3,00 &, 00 &, 00 & 300,00 & 00 &, 50 \\
\hline 10 &, 00 & 27,00 &, 00 &, 00 &, 00 & 50,00 & 100,00 &, 00 \\
\hline 11 &, 00 &, 00 &, 00 &, 00 &, 00 &, 00 &, 00 & 2,00 \\
\hline 12 & 8,00 & ,00 &, 00 &, 00 &, 00 &, 00 &, 00 & 2,00 \\
\hline 13 &, 00 &, 00 &, 00 & 15,00 & 00 & 70,00 & ,00 & 3,00 \\
\hline 14 &, 00 &, 00 &, 00 &, 00 &, 00 & 10,00 & 20,00 &, 10 \\
\hline 15 & .00 &, 00 &, 00 & 3,30 &, 00 & 150,00 &, 00 & 100,00 \\
\hline 16 &, 00 & 00 &, 00 &, 00 &, 00 & 500,00 &, 00 & 5,00 \\
\hline 17 &, 00 &, 00 &, 00 & 20,00 &, 00 & 150,00 &, 00 &, 00 \\
\hline 18 &, 00 &, 00 & 00 & 130,00 &, 00 &, 00 &, 00 &, 00 \\
\hline 19 &, 00 & .00 &, 00 & 4,00 &, 00 &, 00 & 50,00 &, 00 \\
\hline 20 &, 00 & 60,00 &, 00 &, 00 &, 00 &, 00 &, 00 &, 00 \\
\hline 21 &, 00 &, 00 &, 00 &, 00 &, 00 &, 00 &, 00 & 6,00 \\
\hline 22 &, 00 &, 00 & 00 & 65,00 & .00 &, 00 &, 00 &, 00 \\
\hline 23 &, 00 & 120,00 & 00 & 80,00 &, 00 & 250,00 &, 00 &, 00 \\
\hline 24 &, 00 &, 00 &, 00 &, 00 &, 00 & 500,00 &, 00 & 6,00 \\
\hline 25 & ,00 &, 00 & 00 & 22,00 &, 00 & 200,00 & 150,00 & 6,00 \\
\hline 26 &, 00 &, 00 &, 00 &, 00 & .00 &, 00 & 200,00 &, 00 \\
\hline 27 & ,00 & , 00 & , 00 & 17,00 &, 00 &, 00 & 120,00 & 3,00 \\
\hline 28 &, 00 &, 00 &, 00 & 100,00 &, 00 &, 00 &, 00 &, 00 \\
\hline 29 &, 00 & 00 & 5,00 &, 00 &, 00 &, 00 &, 00 & 1,50 \\
\hline 30 & ,00 & ,00 &, 00 & 35,00 &, 00 &, 00 &, 00 & 5,00 \\
\hline 31 &, 00 & 30,00 & 8,00 & 30,00 &, 00 &, 00 &, 00 &, 00 \\
\hline 32 & 7,00 &, 00 &, 00 &, 00 &, 00 &, 00 &, 00 & 2,00 \\
\hline 33 & 28,00 &, 00 & 00 &, 00 & 700,00 &, 00 &, 00 & 5,00 \\
\hline 34 &, 00 &, 00 & 00 & 40,00 &, 00 &, 00 &, 00 & 2,00 \\
\hline 35 & 20,00 & 300,00 &, 00 &, 00 & 1000,00 & 20,00 &, 00 &, 00 \\
\hline 36 & 10,00 &, 00 &, 00 &, 00 &, 00 &, 00 &, 00 & 12,00 \\
\hline 37 &, 00 &, 00 & 00 & 100,00 &, 00 &, 00 &, 00 & 10,00 \\
\hline 38 & 10,00 &, 00 &, 00 &, 00 &, 00 & 600,00 &, 00 &, 00 \\
\hline 39 & 23,00 &, 00 & 00 & 16,00 &, 00 &, 00 &, 00 & 7,00 \\
\hline 40 &, 00 &, 00 &, 00 & 15,00 &, 00 &, 00 &, 00 & 100,00 \\
\hline 41 &, 00 &, 00 &, 00 &, 00 &, 00 &, 00 &, 00 & 100,00 \\
\hline 42 & 5,00 & 30,00 &, 00 &, 00 & 50,00 & 50,00 &, 00 &, 00 \\
\hline 43 &, 00 &, 00 &, 00 &, 00 &, 00 & 150,00 &, 00 &, 00 \\
\hline 44 &, 00 &, 00 & 6,00 & 30,00 &, 00 &, 00 &, 00 & 20,00 \\
\hline
\end{tabular}

Fonte: Dados da pesquisa 
Anexo B: Quantidade dos fatores utilizados na produção, por observação da amostra.

\begin{tabular}{|c|c|c|c|c|c|c|c|}
\hline Observação & $\begin{array}{r}\text { Esterco de } \\
\text { gado }\end{array}$ & Formicida & $\begin{array}{r}\text { Horas de } \\
\text { trator }\end{array}$ & Inseticida & $\begin{array}{r}\text { Mão de } \\
\text { obra } \\
\end{array}$ & NPK & $\begin{array}{l}\text { Torta de } \\
\text { mamona }\end{array}$ \\
\hline 1 &, 00 & 10,00 &, 00 &, 00 & 225,00 &, 00 &, 00 \\
\hline 2 & 2,50 & 6,00 & 3,00 &, 00 & 400,00 & 2,00 &, 00 \\
\hline 3 & 8,00 & 4,00 & 3,00 & ,00 & 400,00 & 4,00 & ,00 \\
\hline 4 & 1,00 & 2,00 &, 00 &, 00 & 270,00 &, 00 & , 00 \\
\hline 5 &, 00 & 96,00 &, 00 & , 00 & 375,00 & ,00 & , 00 \\
\hline 6 & 8,00 & 48,00 & 5,00 & , 00 & 325,00 & ,00 & , 00 \\
\hline 7 & ,00 & 12,00 &, 00 & , 00 & 728,00 & ,00 & , 00 \\
\hline 8 & , 00 & 60,00 & 4,00 & ,00 & 325,00 &, 00 & , 00 \\
\hline 9 &, 00 & 4,00 &, 00 &, 00 & 416,00 & 8,00 & , 00 \\
\hline 10 & 00 &, 00 &, 00 & 1,00 & 572,00 & 5,00 & , 00 \\
\hline 11 &, 00 & 7,00 & 3,00 &, 00 & 250,00 & 3,00 & , 00 \\
\hline 12 & 1,00 & 2,00 & 2,00 &, 00 & 400,00 & ,00 & , 00 \\
\hline 13 & 8,00 &, 00 &, 00 &, 00 & 750,00 & ,00 & , 00 \\
\hline 14 &, 00 & 2,00 &, 00 &, 00 & 400,00 & 8,00 & , 00 \\
\hline 15 & 12,00 & 100,00 & ,00 & 1,00 & 608,00 & 10,00 & , 00 \\
\hline 16 &, 00 &, 00 &, 00 & 2,00 & 550,00 & 3,00 &, 00 \\
\hline 17 & 8,00 & , 00 &, 00 &, 00 & 400,00 & 10,00 & 10,00 \\
\hline 18 &, 00 &, 00 & 4,00 & 4,00 & 370,00 &, 00 & 20,00 \\
\hline 19 &, 00 & 5,00 &, 00 &, 00 & 400,00 & ,00 & 5,00 \\
\hline 20 &, 00 & 6,00 & ,00 &, 00 & 500,00 &, 00 &, 00 \\
\hline 21 & 8,00 & 20,00 &, 00 &, 00 & 250,00 & 10,00 &, 00 \\
\hline 22 & 2,00 &, 00 &, 00 &, 00 & 346,00 & 10,00 &, 00 \\
\hline 23 &, 00 & 11,00 & 2,00 &, 00 & 575,00 & 30,00 & 00 \\
\hline 24 & 24,00 & 3,00 &, 00 &, 00 & 650,00 &, 00 &, 00 \\
\hline 25 &, 00 & 4,00 &, 00 & 2,00 & 325,00 & 8,00 & 00 \\
\hline 26 & 8,00 &, 00 &, 00 &, 00 & 400,00 & 15,00 &, 00 \\
\hline 27 & 16,00 &, 00 &, 00 &, 00 & 400,00 & 10,00 &, 00 \\
\hline 28 &, 00 &, 00 &, 00 & 4,00 & 400,00 & 10,00 &, 00 \\
\hline 29 & 3,00 & 1,00 &, 00 &, 00 & 1700,00 &, 00 & 2,00 \\
\hline 30 &, 00 &, 00 &, 00 & 2,00 & 400,00 & 15,00 &, 00 \\
\hline 31 & 8,00 & 22,00 &, 00 &, 00 & 1301,80 & 5,00 &, 00 \\
\hline 32 &, 00 & 6,00 &, 00 &, 00 & 680,00 &, 00 & ,00 \\
\hline 33 & 1,00 & 3,00 &, 00 &, 00 & 160,00 & 2,00 &, 00 \\
\hline 34 &, 00 & 4,00 & 5,00 &, 00 & 190,00 & 5,00 & ,00 \\
\hline 35 & 1,00 & 25,00 & 6,00 &, 00 & 740,00 & 5,00 &, 00 \\
\hline 36 &, 30 & 24,00 &, 00 &, 00 & 680,00 & 2,00 &, 00 \\
\hline 37 &, 00 &, 00 & 4,00 &, 00 & 400,00 & 20,00 & 00 \\
\hline 38 & 24,00 & 60,00 &, 00 &, 00 & 310,00 & 10,00 & , 00 \\
\hline 39 & 1,50 & 45,00 & 4,00 &, 00 & 325,00 & 12,00 &, 00 \\
\hline 40 &, 00 & 6,00 & 4,00 & 1,00 & 150,00 & 5,00 & , 00 \\
\hline 41 &, 00 & 24,00 &, 00 &, 00 & 80,00 &, 00 & , 00 \\
\hline 42 & 8,00 & 30,00 & 10,00 & ,00 & 325,00 & 5,00 & , 00 \\
\hline 43 &, 00 &, 00 &, 00 &, 00 & 536,00 & 10,00 & , 00 \\
\hline 44 &, 00 & 2,00 &, 00 & 1,00 & 446,00 & 6,00 &, 00 \\
\hline
\end{tabular}

Fonte: Dados da pesquisa 
Anexo C: Preços dos produtos por observação da amostra.

\begin{tabular}{|c|c|c|c|c|c|c|c|c|}
\hline Obs & Amendoim & Farinha & Feijão & Fumo & Inhame & Laranja & Limão & Mandioca \\
\hline 1 & 9,33 & 12,50 & 14,29 & 15,00 & ,62 & 1,88 & 1,20 & 42,27 \\
\hline 2 & 9,33 & 12,50 & 14,29 & 15,00 & 1,00 & 1,62 & 1,00 & 63,14 \\
\hline 3 & 9,33 & 12,50 & 14,29 & 15,00 & 1,00 & 1,62 & 1,37 & 37,50 \\
\hline 4 & 9,33 & 12,50 & 14,29 & 15,00 & ,62 & 1,62 & 1,37 & 35,00 \\
\hline 5 & 15,00 & 12,50 & 14,29 & 22,38 & ,62 & 2,00 & 1,37 & 42,62 \\
\hline 6 & 15,00 & 12,50 & 14,29 & 22,38 & ,62 & 2,00 & 1,37 & 50,00 \\
\hline 7 & 15,00 & 12,50 & 14,29 & 22,38 &, 62 & 1,00 & 1,37 & 40,00 \\
\hline 8 & 15,00 & 12,50 & 14,29 & 22,38 & ,62 & 2,22 & 1,37 & 42,62 \\
\hline 9 & 15,00 & 12,50 & 14,29 & 22,38 & ,62 & 1,00 & 1,37 & 53,33 \\
\hline 10 & 15,00 & 12,50 & 14,29 & 22,38 &, 62 & 1,00 & 1,00 & 42,62 \\
\hline 11 & 15,00 & 12,50 & 14,29 & 22,38 & ,62 & 2,22 & 1,37 & 40,00 \\
\hline 12 & 9,33 & 12,50 & 14,29 & 15,00 & ,62 & 1,62 & 1,37 & 40,00 \\
\hline 13 & 15,00 & 12,50 & 14,29 & 22,47 & ,62 & 1,33 & 1,37 & 35,00 \\
\hline 14 & 15,00 & 12,50 & 14,29 & 22,38 & 62 & 5,00 & 2,00 & 42,62 \\
\hline 15 & 7,73 & 13,92 & 14,29 & 36,36 & ,62 & 2,00 & 1,37 & 10,00 \\
\hline 16 & 7,73 & 13,92 & 14,29 & 22,38 &, 62 & 1,50 & 1,37 & 50,00 \\
\hline 17 & 7,73 & 15,00 & 14,29 & 25,00 & 62 & 1,00 & 1,37 & 46,67 \\
\hline 18 & 7,73 & 15,00 & 14,29 & 23,08 &, 62 & 1,30 & 1,37 & 46,67 \\
\hline 19 & 7,73 & 15,00 & 14,29 & 15,00 &, 62 & 1,30 & 2,00 & 46,67 \\
\hline 20 & 3,56 & 5,00 & 14,29 & 16,38 & .62 & 1,75 & 1,37 & 39,81 \\
\hline 21 & 3,56 & 7,51 & 14,29 & 16,38 &, 62 & 1,75 & 1,37 & 44,44 \\
\hline 22 & 3,56 & 7,51 & 14,29 & 16,92 &, 62 & 1,75 & 1,37 & 39,81 \\
\hline 23 & 3,56 & 12,00 & 14,29 & 23,00 & .62 & 2,50 & 1,37 & 39,81 \\
\hline 24 & 3,56 & 7,51 & 14,29 & 16,38 & .62 & 1,00 & 1,37 & 41,67 \\
\hline 25 & 7,73 & 15,00 & 14,29 & 25,32 & 62 & 2,00 & 2,00 & 40,00 \\
\hline 26 & 7,73 & 15,00 & 14,29 & 19,19 &, 62 & 1,30 & 1,00 & 46,67 \\
\hline 27 & 7,73 & 15,00 & 14,29 & 20,00 &, 62 & 1,30 & 1,00 & 50,00 \\
\hline 28 & 3,56 & 5,00 & 11,80 & 20,00 &, 62 & 1,50 & 1,37 & 31,57 \\
\hline 29 & 3,56 & 5,00 & 13,33 & 15,04 & 62 & 1,50 & 1,37 & 21,67 \\
\hline 30 & 3,56 & 5,00 & 11,80 & 20,00 & 62 & 1,50 & 1,37 & 50,00 \\
\hline 31 & 3,56 & 5,54 & 14,29 & 16,80 &, 62 & 1,75 & 1,37 & 39,81 \\
\hline 32 & 7,06 & 12,50 & 14,29 & 8,75 & 62 & 1,25 & 1,37 & 56,47 \\
\hline 33 & 12,00 & 13,92 & 14,29 & 22,38 &, 54 & 1,44 & 1,37 & 48,89 \\
\hline 34 & 3,56 & 7,51 & 14,29 & 8,80 & 62 & 1,75 & 1,37 & 33,33 \\
\hline 35 & 8,89 & 11,33 & 14,29 & 22,38 &, 38 & ,93 & 1,37 & 28,28 \\
\hline 36 & 7,78 & 13,92 & 14,29 & 22,38 & 62 & 1,44 & 1,37 & 25,71 \\
\hline 37 & 3,56 & 5,00 & 11,80 & 15,00 &, 62 & 1,50 & 1,37 & 50,00 \\
\hline 38 & 5,00 & 12,50 & 14,29 & 8,75 & 62 & 1,00 & 1,37 & 47,16 \\
\hline 39 & 6,52 & 12,50 & 14,29 & 8,75 & 62 & 1,25 & 1,37 & 40,00 \\
\hline 40 & 7,73 & 13,92 & 14,29 & 8,40 & 62 & 1,44 & 1,37 & 14,29 \\
\hline 41 & 7,73 & 13,92 & 14,29 & 22,38 &, 62 & 1,44 & 1,37 & $25,5 \mathrm{I}$ \\
\hline 42 & 5,00 & 20,00 & 14,29 & 22,38 &, 50 & 2,00 & 1,37 & 28,28 \\
\hline 43 & 3,56 & 5,00 & 11,80 & 15,04 & 62 & 1,33 & 1,37 & 31,57 \\
\hline 44 & 3,56 & 5,00 & 10,26 & 5,40 &, 62 & 1,50 & 1,37 & 4,62 \\
\hline
\end{tabular}

Fonte: Dados da pesquisa 
Anexo D: Preços dos fatores utilizados na produção, por observação da amostra.

\begin{tabular}{|c|c|c|c|c|c|c|c|}
\hline Observação & $\begin{array}{r}\text { Esterco de } \\
\text { gado } \\
\end{array}$ & Formicida & $\begin{array}{r}\text { Horas de } \\
\text { trator }\end{array}$ & Inseticida & $\begin{array}{r}\text { Mão de } \\
\text { obra }\end{array}$ & NPK & $\begin{array}{l}\text { Torta de } \\
\text { mamona }\end{array}$ \\
\hline 1 & 24,50 & 2,50 & 13,50 & 15,00 & 5,14 & 11,74 & 7,63 \\
\hline 2 & 30,00 & 2,33 & 15,00 & 15,00 & 5,00 & 10,00 & 7,63 \\
\hline 3 & 21,88 & 2,00 & 15,00 & 15,00 & 5,00 & 10,00 & 7,63 \\
\hline 4 & 24,50 & 3,00 & 13,50 & 15,00 & 5,14 & 11,74 & 7,63 \\
\hline 5 & 22,19 & 3,13 & 13,80 & 20,00 & 4,25 & 8,71 & 7,63 \\
\hline 6 & 50,00 & 3,21 & 15,00 & 20,00 & 4,25 & 8,71 & 7,63 \\
\hline 7 & 22,19 & 3,42 & 13,80 & 20,00 & 4,25 & 8,71 & 7,63 \\
\hline 8 & 22,19 & 3,20 & 15,00 & 20,00 & 4,25 & 8,71 & 7,63 \\
\hline 9 & 22,19 & 1,50 & 13,80 & 20,00 & 4,25 & 9,38 & 7,63 \\
\hline 10 & 22,19 & 3,11 & 13,80 & 20,00 & 4,25 & 8,00 & 7,63 \\
\hline 11 & 22,19 & 2,00 & 12,00 & 20,00 & 4,00 & 8,67 & 7,63 \\
\hline 12 & 24,50 & 3,50 & 12,00 & 15,00 & 5,14 & 11,74 & 7,63 \\
\hline 13 & 13,75 & 3,11 & 13,80 & 20,00 & 4,25 & 8,71 & 7,63 \\
\hline 14 & 22,19 & 7,00 & 13,80 & 20,00 & 5,00 & 7,50 & 7,63 \\
\hline 15 & 18,13 & 2,00 & 16,33 & 24,00 & 5,00 & 8,00 & 7,63 \\
\hline 16 & 29,73 & 2,12 & 16,33 & 25,00 & 4,80 & 12,00 & 7,63 \\
\hline 17 & 16,25 & 2,85 & 15,00 & 17,38 & 4,33 & 8,50 & 10,00 \\
\hline 18 & 12,97 & 2,85 & 15,00 & 25,00 & 4,33 & 9,13 & 8,00 \\
\hline 19 & 12,97 & 3,20 & 15,00 & 17,38 & 4,33 & 9,13 & 5,00 \\
\hline 20 & 33,92 & 2,00 & 13,50 & 8,00 & 4,33 & 9,00 & 7,63 \\
\hline 21 & 7,50 & 1,80 & 13,50 & 8,00 & 4,33 & 8,00 & 7,63 \\
\hline 22 & 88,00 & 3,21 & 13,50 & 8,00 & 4,33 & 12,00 & 7,63 \\
\hline 23 & 33,92 & 2,00 & 15,00 & 8,00 & 4,33 & 8,50 & 7,63 \\
\hline 24 & 6,25 & 7,00 & 13,50 & 8,00 & 5,00 & 9,00 & 7,63 \\
\hline 25 & 12,97 & 2,50 & 15,00 & 20,00 & 5,00 & 10,00 & 7,63 \\
\hline 26 & 6,25 & 2,85 & 15,00 & 17,38 & 3,00 & 8,00 & 7,63 \\
\hline 27 & 14,38 & 2,85 & 15,00 & 17,38 & 3,00 & 8,50 & 7,63 \\
\hline 28 & 12,71 & 4,10 & 15,00 & 10,00 & 5,00 & 8,50 & 7,63 \\
\hline 29 & 6,67 & 8,00 & 15,00 & 12,67 & 5,00 & 12,10 & 7,50 \\
\hline 30 & 12,71 & 4,10 & 15,00 & 20,00 & 5,00 & 10,00 & 7,63 \\
\hline 31 & 33,92 & 3,55 & 13,50 & 8,00 & 4,00 & 7,00 & 7,63 \\
\hline 32 & 22,19 & 1,50 & 15,00 & 20,00 & 4,00 & 8,00 & 7,63 \\
\hline 33 & 50,00 & 2,00 & 16,33 & 20,67 & 4,80 & 8,00 & 7,63 \\
\hline 34 & 33,92 & 3,00 & 13,50 & 8,00 & 4,33 & 10,00 & 7,63 \\
\hline 35 & 29,73 & 2,48 & 15,00 & 20,67 & 4,80 & 8,00 & 7,63 \\
\hline 36 & 50,00 & 2,00 & 16,33 & 20,67 & 4,80 & 6,00 & 7,63 \\
\hline 37 & 12,71 & 4,10 & 15,00 & 12,67 & 5,00 & 10,00 & 7,63 \\
\hline 38 & 4,38 & 2,50 & 15,00 & 20,00 & 4,00 & 8,00 & 7,63 \\
\hline 39 & 22,19 & 3,11 & 15,00 & 20,00 & 4,00 & 8,00 & 7,63 \\
\hline 40 & 29,73 & 2,00 & 13,00 & 13,00 & 4,00 & 13,00 & 7,63 \\
\hline 41 & 29,73 & 1,50 & 16,33 & 20,67 & 4,80 & 8,89 & 7,63 \\
\hline 42 & 25,00 & 2,63 & 20,00 & 20,67 & 5,00 & 8,00 & 7,63 \\
\hline 43 & 10,00 & 1,00 & 15,00 & 12,67 & 4,00 & 9,00 & 7,63 \\
\hline 44 & 12,71 & 1,00 & 15,00 & 8,00 & 5,00 & 8,00 & 7,63 \\
\hline
\end{tabular}

Fonte: Dados da pesquisa 
Anexo E: Redução no uso dos fatores para cada observação da amostra resultante da minimização de custos sob retornos constantes à escala.

\begin{tabular}{|c|c|c|c|c|c|c|c|}
\hline Obs & $\begin{array}{r}\text { Esterco de } \\
\text { gado } \\
\text { (toneladas) } \\
\end{array}$ & $\begin{array}{r}\text { Formicidas } \\
(\mathrm{kg})\end{array}$ & Horas-trator & $\begin{array}{r}\text { Inseticidas } \\
(\mathrm{kg})\end{array}$ & $\begin{array}{l}\text { Mão-de- } \\
\text { obra (saco } \\
\text { (homem/dia) }\end{array}$ & $\begin{array}{r}\mathrm{NPK} \\
50 \mathrm{~kg}) \\
\end{array}$ & $\begin{array}{r}\text { Torta de } \\
\text { mamona } \\
(\text { saco } 50 \mathrm{~kg}) \\
\end{array}$ \\
\hline 1 & 0,000 & 0,000 & 0,000 & 0,000 & 0,000 & 0,000 & 0,000 \\
\hline 2 & 2,214 & $-1,976$ & 3,000 & $-0,524$ & 132,560 & $-0,667$ & 0,000 \\
\hline 3 & 7,786 & 2,654 & 3,000 & 0,000 & 363,371 & 3,571 & 0,000 \\
\hline 4 & 1,000 & 1,520 & 0,000 & 0,000 & 268,400 & 0,000 & 0,000 \\
\hline 5 & 0,000 & 0,000 & 0,000 & 0,000 & 0,000 & 0,000 & 0,000 \\
\hline 6 & 0,000 & 0,000 & 0,000 & 0,000 & 0,000 & 0,000 & 0,000 \\
\hline 7 & 0,000 & 0,000 & 0,000 & 0,000 & 0,000 & 0,000 & 0,000 \\
\hline 8 & $-0,120$ & 57,000 & 4,000 & $-0,720$ & 237,000 & $-0,600$ & 0,000 \\
\hline 9 & $-2,543$ & $-11,829$ & $-1,500$ & $-0,500$ & 72,643 & 4,714 & 0,000 \\
\hline 10 & $-0,090$ & $-12,250$ & $-0,540$ & 1,000 & 280,400 & 4,550 & 0,000 \\
\hline 11 & 0,000 & 6,520 & 3,000 & 0,000 & 248,400 & 3,000 & 0,000 \\
\hline 12 & 0,714 & 1,006 & 2,000 & 0,000 & 353,829 & $-0,571$ & 0,000 \\
\hline 13 & 7,440 & $-3,979$ & $-0,812$ & $-0,462$ & 682,494 & 0,000 & $-2,308$ \\
\hline 14 & $-0,617$ & 1,725 & 0,000 & $-0,033$ & 359,063 & 6,710 & 0,000 \\
\hline 15 & 10,800 & 69,016 & $-0,852$ & 0,898 & 470,578 & 10,000 & $-0,508$ \\
\hline 16 & $-4,000$ & $-24,480$ & $-2,500$ & 2,000 & 385,900 & 3,000 & 0,000 \\
\hline 17 & 6,800 & $-7,200$ & $-1,365$ & $-0,615$ & 294,327 & 10,000 & 6,923 \\
\hline 18 & 0,000 & 0,000 & 0,000 & 0,000 & 0,000 & 0,000 & 0,000 \\
\hline 19 & $-0,909$ & 4,273 & 0,000 & $-0,364$ & 295,455 & $-3,159$ & 5,000 \\
\hline 20 & $-0,200$ & 1,000 & $-1,200$ & 0,000 & 352,000 & $-1,000$ & 0,000 \\
\hline 21 & 8,000 & 18,560 & 0,000 & 0,000 & 245,200 & 10,000 & 0,000 \\
\hline 22 & 2,000 & 0,000 & $-2,000$ & $-2,000$ & 161,000 & 10,000 & $-10,000$ \\
\hline 23 & $-0,319$ & $-26,205$ & $-2,374$ & $-2,462$ & $-2,794$ & 28,406 & 0,000 \\
\hline 24 & 20,000 & $-21,720$ & $-2,500$ & 0,000 & 485,100 & 0,000 & 0,000 \\
\hline 25 & 0,000 & 0,000 & 0,000 & 0,000 & 0,000 & 0,000 & 0,000 \\
\hline 26 & 0,000 & 0,000 & 0,000 & 0,000 & 0,000 & 0,000 & 0,000 \\
\hline 27 & 16,000 & $-3,500$ & 0,000 & $-1,545$ & 139,659 & 3,818 & 0,000 \\
\hline
\end{tabular}


Anexo E: Redução no uso dos fatores para cada observação da amostra resultante da minimização de custos sob retornos constantes à escala (continuação).

\begin{tabular}{|c|c|c|c|c|c|c|c|}
\hline Obs & $\begin{array}{r}\text { Esterco de } \\
\text { gado (em } \\
\text { toneladas) }\end{array}$ & $\begin{array}{r}\text { Formicidas } \\
(\mathrm{kg})\end{array}$ & Horas-trator & $\begin{array}{r}\text { Inseticidas } \\
(\mathrm{kg})\end{array}$ & $\begin{array}{r}\text { Mão-de- } \\
\text { obra } \\
\text { (homem/dia) } \\
\end{array}$ & $\begin{array}{r}\text { NPK (saco } \\
\text { de } 50 \mathrm{~kg} \text { ) }\end{array}$ & $\begin{array}{r}\text { Torta de } \\
\text { mamona } \\
\text { (saco } 50 \mathrm{~kg} \text { ) }\end{array}$ \\
\hline 28 & 0,000 & 0,000 & $-3,077$ & 0,923 & 115,385 & 10,000 & $-15,385$ \\
\hline 29 & 3,000 & $-0,667$ & 0,000 & $-0,833$ & 1328,333 & $-5,000$ & 2,000 \\
\hline 30 & 0,000 & $-1,200$ & $-1,077$ & 0,923 & 296,385 & 15,000 & $-5,385$ \\
\hline 31 & 7,900 & 16,833 & $-0,600$ & $-1,333$ & 633,133 & $-3,500$ & 0,000 \\
\hline 32 & $-0,250$ & 5,070 & 0,000 & 0,000 & 639,400 & $-0,500$ & 0,000 \\
\hline 33 & 0,000 & 0,000 & 0,000 & 0,000 & 0,000 & 0,000 & 0,000 \\
\hline 34 & 0,000 & 3,520 & 3,769 & $-1,231$ & 74,554 & 5,000 & $-6,154$ \\
\hline 35 & 0,000 & 0,000 & 0,000 & 0,000 & 0,000 & 0,000 & 0,000 \\
\hline 36 & $-0,057$ & 20,477 & 0,000 & 0,000 & 614,686 & 1,286 & 0,000 \\
\hline 37 & 0,000 & $-2,400$ & 0,923 & $-3,077$ & 107,385 & 20,000 & $-15,385$ \\
\hline 38 & 18,843 & 30,129 & $-3,000$ & 0,000 & 57,857 & 9,286 & 0,000 \\
\hline 39 & 0,679 & 41,841 & $3 ; 508$ & $-0,492$ & 145,719 & 10,357 & $-2,462$ \\
\hline 40 & 0,000 & $-18,000$ & 3,538 & 0,538 & 27,308 & 5,000 & $-2,308$ \\
\hline 41 & 0,000 & 0,000 & 0,000 & 0,000 & 0,000 & 0,000 & 0,000 \\
\hline 42 & 7,797 & 21,748 & 9,497 & 0,000 & 221,285 & 4,343 & 0,000 \\
\hline 43 & $-1,200$ & $-7,200$ & $-0,750$ & 0,000 & 487,250 & 10,000 & 0,000 \\
\hline$\underline{44}$ & 0,000 & 0,000 & 0,000 & 0,000 & 0,000 & 0,000 & 0,000 \\
\hline Total & 110,668 & 160,286 & 12,088 & $-9,909$ & 10573,27 & 173,044 & $-45,972$ \\
\hline \% variação & $72,19 \%$ & $24,51 \%$ & $20,49 \%$ & $-55,05 \%$ & $51,74 \%$ & $69,78 \%$ & $-124,25 \%$ \\
\hline
\end{tabular}


Anexo F: Incremento nos produtos de cada observação da amostra resultantes da minimização de custos sob retornos constantes à escala.

\begin{tabular}{|c|c|c|c|c|c|}
\hline Obs & $\begin{array}{r}\text { Amendoim } \\
(\text { saco } 50 \mathrm{~kg})\end{array}$ & $\begin{array}{r}\text { Fumo } \\
\text { (arroba) }\end{array}$ & Inhame $(\mathrm{kg})$ & Laranja (cento) & $\begin{array}{l}\text { Mandioca } \\
\text { (tonelada) }\end{array}$ \\
\hline 1 & 0,00 & 0,00 & 0,00 & 0,00 & 0,00 \\
\hline 2 & 8,00 & 5,76 & 0,00 & 246,67 & 0,00 \\
\hline 3 & 6,00 & 0,00 & 0,00 & 0,00 & 0,00 \\
\hline 4 & 0,00 & 0,00 & 0,00 & 0,00 & 0,00 \\
\hline 5 & 0,00 & 0,00 & 0,00 & 0,00 & 0,00 \\
\hline 6 & 0,00 & 0,00 & 0,00 & 0,00 & 0,00 \\
\hline 7 & 0,00 & 0,00 & 0,00 & 0,00 & 0,00 \\
\hline 8 & 2,00 & 0,00 & 120,00 & 2,40 & 0,00 \\
\hline 9 & 0,00 & 15,00 & 100,00 & 0,00 & 12,01 \\
\hline 10 & 1,80 & 0,00 & 90,00 & 271,80 & 0,00 \\
\hline 11 & 0,00 & 0,00 & 0,00 & 0,00 & 0,00 \\
\hline 12 & 0,00 & 0,00 & 200,00 & 0,00 & 0,00 \\
\hline 13 & 0,00 & 0,00 & 0,00 & 0,00 & 0,00 \\
\hline 14 & 0,00 & 0,37 & 0,00 & 0,00 & 0,00 \\
\hline 15 & 0,00 & 0,00 & 0,00 & 0,00 & 0,00 \\
\hline 16 & 0,00 & 0,00 & 0,00 & 0,00 & 0,00 \\
\hline 17 & 0,00 & 0,00 & 0,00 & 0,00 & 0,90 \\
\hline 18 & 0,00 & 0,00 & 0,00 & 0,00 & 0,00 \\
\hline 19 & 0,00 & 0,00 & 0,00 & 36,36 & 1,09 \\
\hline 20 & 4,00 & 0,00 & 200,00 & 4,00 & 0,00 \\
\hline 21 & 0,00 & 0,00 & 0,00 & 0,00 & 0,00 \\
\hline 22 & 0,00 & 0,00 & 0,00 & 0,00 & 0,00 \\
\hline 23 & 6,38 & 0,00 & 318,79 & 0,00 & 0,00 \\
\hline 24 & 0,00 & 0,00 & 0,00 & 0,00 & 0,00 \\
\hline 25 & 0,00 & 0,00 & 0,00 & 0,00 & 0,00 \\
\hline 26 & 0,00 & 0,00 & 0,00 & 0,00 & 0,00 \\
\hline 27 & 0,00 & 0,00 & 0,00 & 167,64 & 1,64 \\
\hline 28 & 0,00 & 0,00 & 0,00 & 0,00 & 0,00 \\
\hline
\end{tabular}


Anexo F: Incremento nos produtos de cada observação da amostra resultantes da minimização de custos sob retornos constantes à escala (continuação).

\begin{tabular}{lrrrrr}
\hline Obs & $\begin{array}{r}\text { Amendoim } \\
(\text { saco } 50 \mathrm{~kg})\end{array}$ & $\begin{array}{r}\text { Fumo } \\
\text { (arroba) }\end{array}$ & Inhame (kg) & $\begin{array}{r}\text { Laranja (cento) } \\
\text { (tonelada) }\end{array}$ \\
\hline 29 & 0,00 & 25,00 & 0,00 & 0,00 & 15,17 \\
30 & 0,00 & 0,00 & 0,00 & 0,00 & 0,00 \\
31 & 2,00 & 10,00 & 100,00 & 2,00 & 26,67 \\
32 & 0,00 & 0,00 & 175,00 & 0,00 & 0,00 \\
33 & 0,00 & 0,00 & 0,00 & 0,00 & 0,00 \\
34 & 0,00 & 0,00 & 0,00 & 0,00 & 0,00 \\
35 & 0,00 & 0,00 & 0,00 & 0,00 & 0,00 \\
36 & 0,00 & 0,00 & 250,00 & 0,00 & 0,00 \\
37 & 0,00 & 0,00 & 0,00 & 0,00 & 0,00 \\
38 & 0,00 & 0,00 & 250,00 & 0,00 & 5,39 \\
39 & 0,00 & 0,00 & 575,00 & 0,00 & 0,00 \\
40 & 0,00 & 0,00 & 0,00 & 0,00 & 0,00 \\
41 & 0,00 & 0,00 & 0,00 & 0,00 & 0,00 \\
42 & 0,00 & 0,00 & 116,95 & 0,00 & 0,59 \\
43 & 0,00 & 0,00 & 0,00 & 0,00 & 0,90 \\
44 & 0,00 & $\mathbf{0 , 0 0}$ & 0,00 & 0,00 & 0,00 \\
\hline Total & 30,18 & 56,13 & 2495,74 & 730,87 & 64,35 \\
\hline variação & $26,24 \%$ & $7,77 \%$ & $118,84 \%$ & $12,56 \%$ & $15,39 \%$ \\
\hline
\end{tabular}


Anexo G: Fatores determinantes dos níveis de eficiência

\begin{tabular}{|c|c|c|c|c|c|}
\hline Obs & $\begin{array}{r}\text { Área colhida } \\
\text { (em tarefas) } \\
\end{array}$ & $\begin{array}{l}\text { Escolaridade } \\
\text { média (anos) }\end{array}$ & $\begin{array}{r}\text { Idade média da } \\
\text { mdo (anos) } \\
\end{array}$ & $\begin{array}{r}\text { Inserção no } \\
\text { mercado }\end{array}$ & $\begin{array}{r}\text { Informações } \\
\text { agricolas de rádio }\end{array}$ \\
\hline 1 & 3,0 & 3,0 & 26 & 1,00 & 0 \\
\hline 2 & 4,0 & 2,5 & 32 & 0,51 & 0 \\
\hline 3 & 2,5 & 1,0 & 67 & 0,38 & 1 \\
\hline 4 & 0,7 & 2,7 & 30 & 0,70 & 0 \\
\hline 5 & 3,0 & 4,0 & 32 & 0,69 & 1 \\
\hline 6 & 18,0 & 3,0 & 46 & 1,00 & 0 \\
\hline 7 & 7,5 & 4,3 & 46 & 1,00 & 1 \\
\hline 8 & 2,0 & 6,0 & 42 & 0,01 & 0 \\
\hline 9 & 6,0 & 3,0 & 45 & 0,83 & 0 \\
\hline 10 & 2,0 & 4,7 & 32 & 0,31 & 0 \\
\hline 11 & 3,0 & 3,5 & 29 & 1,00 & 0 \\
\hline 12 & 1,7 & 4,3 & 27 & 0,75 & 1 \\
\hline 13 & 2,5 & 5,3 & 42 & 0,91 & 1 \\
\hline 14 & 1,6 & 3,0 & 62 & 0,95 & 1 \\
\hline 15 & 3,5 & 2,0 & 39 & 0,82 & 0 \\
\hline 16 & 23,0 & 3,7 & 39 & 1,00 & 1 \\
\hline 17 & 2,0 & 8,0 & 27 & 1,00 & 0 \\
\hline 18 & 5,0 & 2,5 & 21 & 1,00 & 1 \\
\hline 19 & 2,0 & 2,7 & 32 & 1,00 & 0 \\
\hline 20 & 1,5 & 5,0 & 26 & 0,01 & 0 \\
\hline 21 & 1,5 & 0,0 & 70 & 0,80 & 0 \\
\hline 22 & 1,5 & 2,2 & 28 & 1,00 & 0 \\
\hline 23 & 14,0 & 0,8 & 40 & 0,98 & 0 \\
\hline 24 & 3,0 & 4,5 & 33 & 0,87 & 0 \\
\hline 25 & 3,0 & 7,0 & 24 & 1,00 & 1 \\
\hline 26 & 1,0 & 2,0 & 22 & 1,00 & 1 \\
\hline 27 & 4,5 & 1,5 & 34 & 1,00 & 1 \\
\hline 28 & 6,0 & 0,0 & 67 & 1,00 & 0 \\
\hline 29 & 0,5 & 1,7 & 37 & 0,67 & 0 \\
\hline 30 & 6,0 & 3,3 & 27 & 1,00 & 0 \\
\hline 31 & 3,5 & 2,1 & 50 & 0,76 & 0 \\
\hline
\end{tabular}


Anexo G: Fatores determinantes dos níveis de eficiência

\begin{tabular}{lrrrrr}
\hline Obs & $\begin{array}{r}\text { Área colhida } \\
\text { (em tarefas) }\end{array}$ & $\begin{array}{r}\text { Escolaridade } \\
\text { média (anos) }\end{array}$ & $\begin{array}{r}\text { Idade média da } \\
\text { mdo (anos) }\end{array}$ & $\begin{array}{r}\text { Inserção no } \\
\text { mercado }\end{array}$ & $\begin{array}{r}\text { Informações } \\
\text { agrícolas de rádio }\end{array}$ \\
\hline 32 & 2,5 & 1,5 & 49 & 0,78 & 0 \\
33 & 1,0 & 22 & 0,97 & 0 \\
34 & 2,0 & 0,5 & 27 & 0,92 & 0 \\
35 & 2,0 & 5,0 & 24 & 0,84 & 0 \\
36 & 21,0 & 1,5 & 41 & 0,62 & 0 \\
37 & 36,0 & 0,0 & 32 & 1,00 & 0 \\
38 & 3,0 & 5,0 & 26 & 0,08 & 0 \\
39 & 4,0 & 4,5 & 57 & 0,95 & 0 \\
40 & 4,0 & 3,0 & 56 & 0,82 & 0 \\
41 & 2,0 & 0,0 & 25 & 0,95 & 1 \\
42 & 2,0 & 1,5 & 31 & 0,17 & 1 \\
43 & 3,0 & 5,4 & 32 & 1,00 & 0 \\
44 & 2,0 & 2,6 & 31 & 0,22 & 1 \\
\hline
\end{tabular}

